\title{
All-Inclusive Architecture \\ Budget Airlines and the Global Sprawl of Paradise
}

\author{
By
}

Kristen Smith

A thesis submitted to the Faculty of Graduate and Postdoctoral Affairs in partial fulfillment of the requirements for the degree of

Master of Architecture

Carleton University

Ottawa, Ontario

(C) 2019

Kristen Smith 


\section{Abstract}

The conceivable boundaries of 'home' expand with the scale and accessibility of adjacent transportation networks. Subsequently, the threshold between 'home' and 'away' is understood through varying scales of movement. Air travel is assumed to always carry tourists 'away,' by virtue of its speed, spectacle, and indifference to geography.

This thesis engages Canada's budget airline industry and its role in cultivating intense consumer experiences at all-inclusive resorts throughout the greater Caribbean. Paradoxically, these experiences depend on vivid representations of tropical paradise that are both distant and exotic, yet familiar.

Facilitated by expedient air travel and controlled airport transfers, passengers are brought into closer contact with domestic myths of paradise more than any genuine interaction with an unfamiliar place. This thesis in turn positions touristic enclaves as displaced, yet wellconnected extensions of North America's sub-urban network. By reflecting on all-inclusive resorts not as idealized destinations, but as a continuation of standardized development, reductive imaginaries of paradise will be examined against common tropes of suburban banality. 


\section{Acknowledgments}

To my parents — thank you for travelling with me as a kid. Our family holidays formed the foundation of this thesis, and I'm grateful for all the wonderful memories.

To my partner, Albert — thank you for being my sounding board. The depth of your patience and support continues to amaze me.

To my advisor, Ozayr — your critical insights, positive demeanor and unwavering enthusiasm made this year incredibly rewarding. Thank you for seeing such wide potential in my subject matter. 


\section{Table of Contents}

Abstract

ii

Acknowledgments

iii

Table of Contents

iv

List of Figures

Budget Airlines and All-Inclusive Resorts

Flying South

Paradise as a Global Suburb

three

Architecture of Anticipation

Air Canada Vacations Imagery

Air Canada Vacations Text

four

Architecture of Isolation

Locating Suburbia in Paradise

Club Med Cancun, 2009 and 2019

Paradise as a Village

Escape and Enclosure

Trope \#1: The Porch 


\section{List of Figures}

Fig. 01: 2018 E-Brochures from Canadian airlines. 2

Fig. 02: Flight network of the Americas and the Caribbean. 6

Fig. 03: Flight network re-mapped according to airport interconnectivity. 8

Fig. 04: Paradise as a global suburb. 10

Fig. 05: "Beaches ${ }^{\odot ”}$ Resort in Providenciales, Turks and Caicos. 11

Fig. 06: "Sandals ${ }^{\oplus}$ "Resort in Grenada. 12

Fig. 07: Selection of resorts accessible through Air Canada. [panel 1 of 3] 16

Fig. 08: Selection of resorts accessible through Air Canada. [panel 2 of 3] 17

Fig. 09: Selection of resorts accessible through Air Canada. [panel 3 of 3] 18

Fig. 10: Review of supporting literature. [panel 1 of 5] 19

Fig. 11: Review of supporting literature. [panel 2 of 5] 20

Fig. 12: Review of supporting literature. [panel 3 of 5] 21

Fig. 13: Review of supporting literature. [panel 4 of 5] 22

Fig. 14: Review of supporting literature. [panel 5 of 5] 23

Fig. 15: Caribbean map illustrating degree of airport interconnectivity. 25

Fig. 16: Caribbean map illustrating access to all-inclusive resort rooms. 26

Fig. 17: Caribbean map illustrating airports and coastal sand deposits. 27

Fig. 18: Thematic map of tourism's contribution to GDP. 28

Fig. 19: Graph of tourism's contribution to GDP. 28

Fig. 20: Thematic map of all-inclusive rooms per country citizen. 29

Fig. 21: Graph of all-inclusive rooms per country citizen. 29

Fig. 22: Key plan noting three regions of interest. 30

Fig. 23: Satellite image of Cancun (Mexico). 31

Fig. 24: Satellite image of Varadero (Cuba). 31

Fig. 25: Satellite image of Providenciales (Turks and Caicos). 31

Fig. 26: Key plan of Cancun (Mexico). 34

Fig. 27: Key plan of Varadero (Cuba). 34

Fig. 28: Key plan of Providenciales (Turks and Caicos). 34

Fig. 29: Ease of airport to resort access across three regions of interest. 35

Fig. 30: Regional slices translated to 1:30 000 terrain models. 36

Fig. 31: 1:30 000 terrain models with acetate overlay. $\quad 37$

Fig. 32: Cancun terrain model details. 39

Fig. 33: Cancun terrain model details. 39

Fig. 34: Cancun terrain model details. 40

Fig. 35: Cancun terrain model details. $\quad 40$

Fig. 36: Varadero terrain model details. 42

Fig. 37: Varadero terrain model details. 42 
Fig. 38: Varadero terrain model details.

Fig. 39: Varadero terrain model details.

Fig. 40: Providenciales terrain model details. $\quad 45$

Fig. 41: Providenciales terrain model details. $\quad 45$

Fig. 42: Providenciales terrain model details. $\quad 46$

Fig. 43: Providenciales terrain model details. $\quad 46$

Fig. 44: Colloquium II material. $\quad 47$

Fig. 45: Colloquium II material. $\quad 47$

Fig. 46: Radial configuration of 'suburbic' paradise in Cancun. 48

Fig. 47: Radial configuration of 'suburbic' paradise in Varadero. 49

Fig. 48: Radial configuration of 'suburbic' paradise in Providenciales. 50

Fig. 49: Aerial view of Club Med Cancun. 56

Fig. 50: Site map showing resort organization and parcellation. 59

Fig. 51: Fence separating zones of exclusive resort access. 60

Fig. 52: Ropes demarcating a semi-private lounging region. 61

Fig. 53: Unoccupied space between resorts littered with trash. 61

Fig. 54: Resort wall and surveillance equipment. 62

Fig. 55: Branded 'Cancun' lettering.

Fig. 56: Buried post and sports equipment demarcating extended property lines. 63

Fig. 57: Site map showing inhabitation.

Fig. 58: 01.11.2019 GoPro photo series. [panel 1 of 3] 66

Fig. 59: 01.11.2019 GoPro photo series. [panel 2 of 3] 67

Fig. 60: 01.11.2019 GoPro photo series. [panel 3 of 3] 68

Fig. 61: 1:50 surburban trope models.

Fig. 62: 'The Porch' model details.

Fig. 63: 'The Porch' model details.

Fig. 64: 'The Porch' model details.

Fig. 65: 'The Porch' model details.

Fig. 66: 'The Pool' model details.

Fig. 67: 'The Pool' model details. $\quad 78$

Fig. 68: 'The Pool' model details. $\quad 79$

Fig. 69: 'The Pool' model details.

Fig. 70: 'The Garden Path' model details.

Fig. 71: 'The Garden Path' model details.

Fig. 72: 'The Garden Path' model details. 83

Fig. 73: 'The Garden Path' model details. 83

Fig. 74: Trope collage over textured surface mapping. 85

Fig. 75: Final matrix of nine key thesis panels. $\quad 89$

Fig. 76: Configuration of work at thesis defence. 90 
1 "'Sun' E-Brochure."

Air Canada Vacations, 2.

2018 / 2019. Accessed

November 2018.

2 Ritzer, George,

and Allan Liska.

"'McDisneyization'

and 'Post-Tourism':

Complementary

Perspectives on

Contemporary Tourism."

In Touring Cultures:

Transformations of Travel

and Theory, 100. London,

UK: Routledge, 1997.
"As you flip through these pages, decide which spot is yours - really, truly yours. Then take the time to decide what resort will be your home base for every adventure you want to have in your perfect place. Think of every accommodation as a safe, soothing fortress of fun. If it's zip-lining through the jungle or staying as horizontal and hydrated as your beach lounger will allow between naps and massages, don't sweat it. No one decides your dream days but you." ${ }^{I}$

"Our vacations are more and more like the rest of our lives." ${ }^{2}$ 


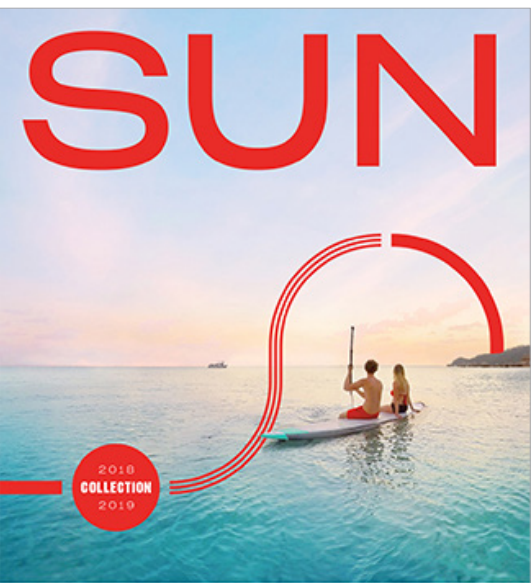

(2) AIR CANADA VACATIONS $\begin{gathered}\text { Making your } \\ \text { droams traver }\end{gathered}$
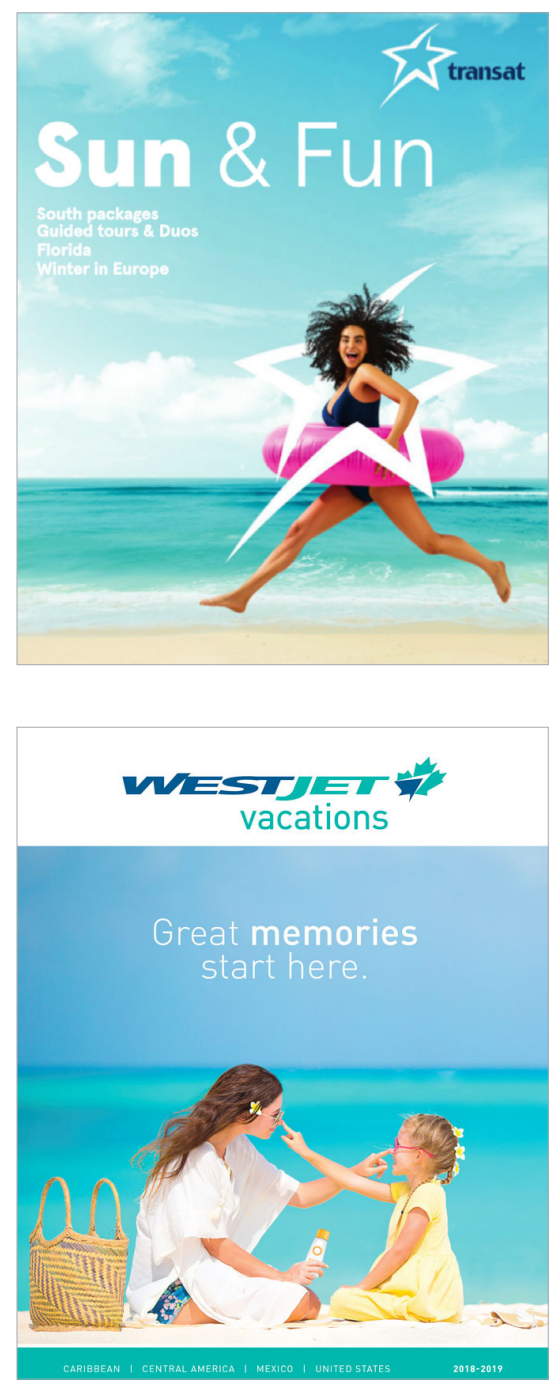
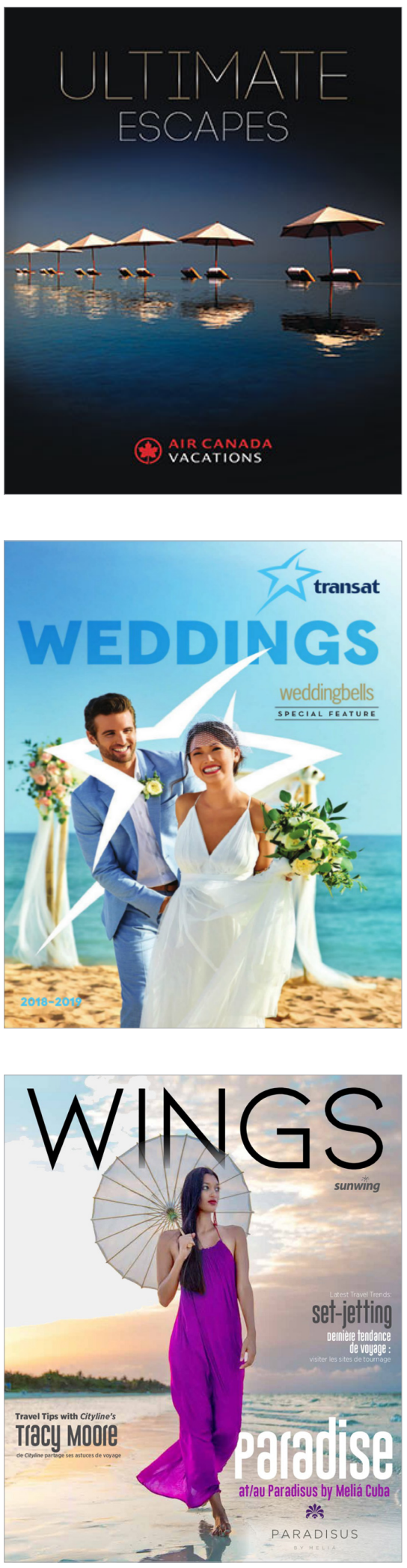
Introduction

3 Round-trip airfare, airport transfers and accommodation

combined into a single travel price. See Coles,

Tim. "What makes a

resort complex?" In

Tourism in the Caribbean:

Trends, Development,

Prospects, 235 - 256.

London, UK: Routledge,

2004.

4 Duval, David

Timothy. "Trends and

Circumstances in

Caribbean Tourism." In

Tourism in the Caribbean:

Trends, Development,

Prospects, 10. London

UK: Routledge, 2004.

5 Venturi, Robert, Denise Scott Brown, and Steven

Izenour. "A Significance for A\&P Parking Lots,

Or Learning From Las Vegas." In Learning

from Las Vegas: The

Forgotten Symbolism

of Architectural Form

3. Cambridge, MA: MIT

Press, 1991.

6 Bianchi, Raoul. "The

Critical Turn in Tourism

Studies." Tourism

Geographies 11, no. 4

(2009): 484
Architects are often quick to declare they do not travel to all-inclusive resorts. Their comments describe a rejection on the basis of formal and social principle. All-inclusive resorts are synonymous with insularity, vernacular pastiche, neo-colonial service standards, and indiscriminate indulgence. Quite understandably, all-inclusive 'package's vacations hold no place in contemporary architectural discourse.

Despite this low regard, package vacations are significantly and deeply enjoyed by millions of tourists each year, ${ }^{4}$ spurring significant capital investment and an immense volume of dedicated construction. This commercial and economic reality provides a compelling foundation for reflecting on their development.

Robert Venturi, Denise Scott Brown and Steven Izenour in Learning from Las Vegas, wrote that "architects are out of the habit of looking nonjudgmentally at their environment...," further observing that "...withholding judgment may be used as a tool to make later judgment more sensitive" (3). ${ }^{5}$ This thesis utilizes data-mining and analytical mapping strategies as key research methods to systematically study architecture at the periphery of geographic and academic consideration. Using airline statistics and promotional language as primary references, all-inclusive resorts are presented as a global iteration of suburban development. A series of three discussions follow, introducing resorts [and suburbia] as spaces of (I) anticipation, (2) isolation and (3) assurance. Together, these sections critique the imagination, production and consumption ${ }^{6}$ of 2Ist century paradise, probing its contentious expression through expectations of commodity, distance and comfort.

This research is conducted across continental, regional, site and person-specific scales, employing suburban motifs as a new frame of reference for interpreting existing all-inclusive sites. Culminating in a series of spatial case studies highlighting points of exclusion, friction and ambiguity, this work identifies latent design devices influencing one's curated perception of tropical paradise. Opening a discussion between architects and architectural consumers, this thesis ultimately speculates on the nature of displaced comfort today. 
7 Urry, John. "Why Tourism is Important." In The Tourist Gaze: Leisure and Travel in Contemporary Societies, 2. London, UK: Sage

Publications, 1990.

8 Corner, James. "The Agency of Mapping: Speculation, Critique and Intervention." In Mappings, 213-252. London, UK: Reaktion Books, 1999.
In The Tourist Gaze, one of the seminal texts on contemporary tourism studies, John Urry states that "tourism is a leisure activity which presupposes its opposite, namely regulated and organized work" (2). ${ }^{7}$ Tourists subsequently stay in places which seem new and foreign, and follow routines that feel distinctly out of the ordinary. As a system of departures and arrivals, international travel is frequently considered in binary terms.

Instead of polarizing touristic practices, this section emphasizes the fluid nature of travel, particularly in relation to the budget airline industry. Through rendering continental flight traffic across a modified global field, ${ }^{8}$ mapping is used as an active process to explore travel's continuity across time, space and infrastructure. 
9 "Sandals Resorts: Fly Free \& Save?." Mouse Print. August 4, 2008. Accessed November 2018.

10 Air Canada Vacations, Sun, 5.

11 Chawla, Gaurav, and Marcelina Ndungu. "The Ethics of an All-inclusive Plan: An Investigation of Social Sustainability in the Case of All-inclusive Resorts, Jamaica."

Research in Hospitality Management 4, no. 1-2 (2014): 21

12 Alcoholic and nonalcoholic beverages.

13 Air Canada Vacations, Sun, 5 .

14 Turner, Simon, and Carolyn Troiano. "The Attraction of All-Inclusive Resorts." Cornell Hotel and Restaurant Administration Quarterly 28, no. 3 (November 1987): 25-26.

15 Cruises are a second form of mass tourism in the Caribbean, though they are not discussed in this thesis.

16 Turner, Attraction, 27.

17 Duval, Trends, 10.

18 Coles, What, 236

19 Before widespread internet use, packages were most often booked through travel agents. Packages may now be booked online through individual airlines (Air Transat, Sunwing, West Jet, etc.) or through travel sites that offer price comparisons (i.e. Expedia, Travelocity, Orbitz, Kayak, etc.)
"Fly Free E Save up to 30\%

on your Luxury Included (c) vacation at Sandals." 9

"Discover the ultimate family-friendly vacation with an exclusive flight experience."

The success of 'package' tourism in the Caribbean reflects converging budget airline and all-inclusive resort industries.

Package vacations form a marketing paradigm ${ }^{\text {II }}$ whereby the cost of round-trip airfare, airport transfers, hotel accommodation, food, beverages, ${ }^{12}$ and daily recreational activities ${ }^{13}$ are combined into a single financial transaction. This collaboration between transportation and accommodation providers offers key incentives to travellers. Since the total trip cost is paid upfront, few fees are incurred while abroad, leading to more accurate budgeting and a carefree, immersive leisure experience. Reduced trip planning and decision-making burdens further contribute to the higher perceived value of travel packages over equivalent travel segments that are booked individually. ${ }^{14}$

The first all-inclusive resort was established in Majorca, Spain, by Paris-based Club Mediterranée during the i950s. The style of travel rapidly gained popularity from the 1960 s to 1980 s and remains a dominant mode of mass tourism in the Caribbean. ${ }^{15}$ Packages are heavily marketed towards couples and families seeking to balance two work schedules and cyclical annual vacation allowances. Seniors also comprise a significant portion of the market base. ${ }^{16,17}$ Travel typically occurs during the northern winter months over regular periods of seven, ten or fourteen days. ${ }^{18}$ Today, most travel packages are booked online through chartered airline operators. ${ }^{19}$

Exploring the infrastructural reliance between budget airlines and all-inclusive resorts, Figure 02 maps the distribution of resorts accessible through Air Canada Vacations in 2018. Concentrations of resorts are scaled and correlated to their servicing airport, reflecting the density of resort development within the greater commercial flight network. Pearson International Airport (Toronto) is indicated in red, while destination airports are highlighted using a gradient of green. 


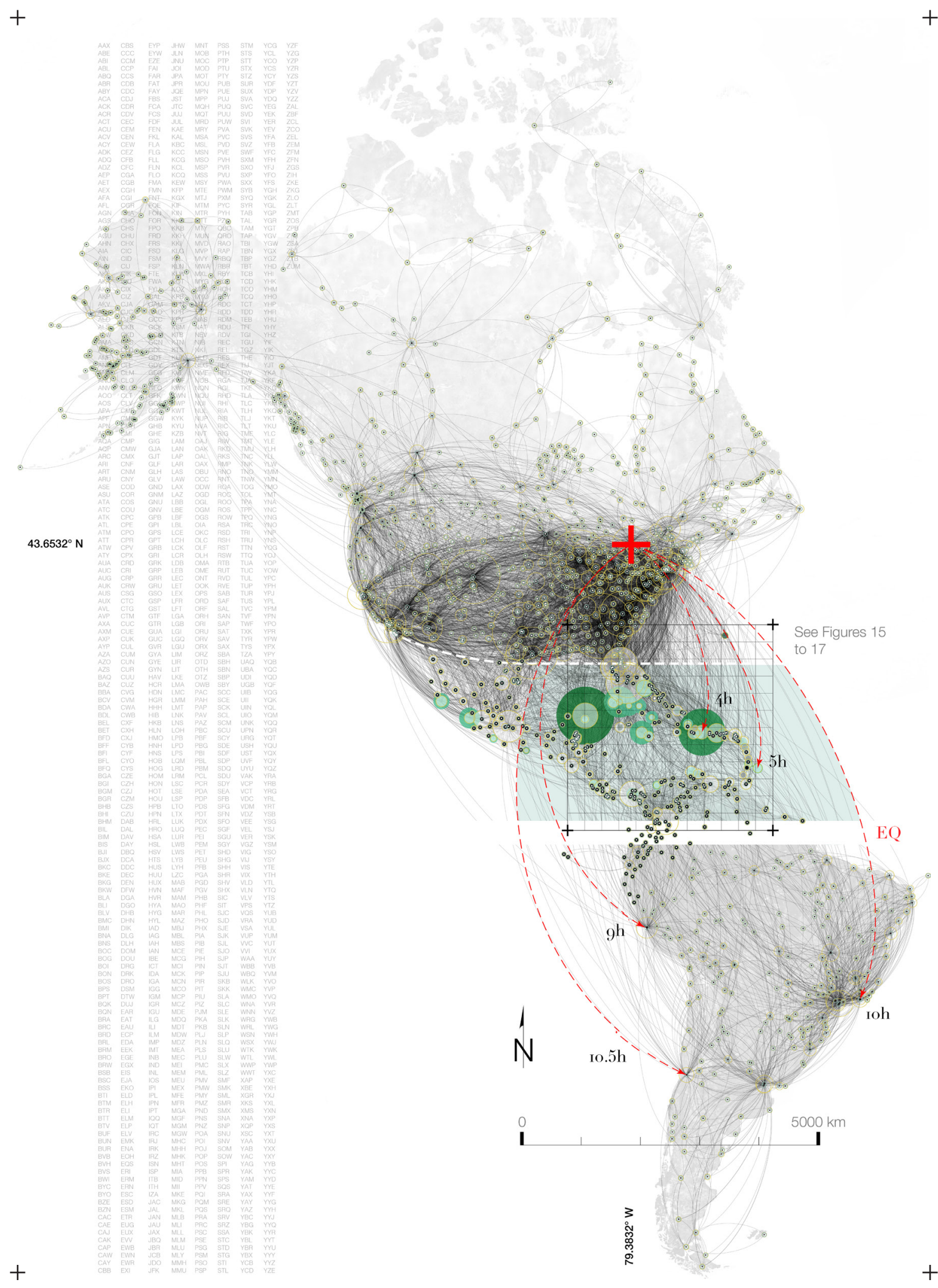

Figure 02: Flight network of the Americas and the Caribbean. 
20 Duval, Trends, 10

21 Thompson, Derek. "How Airline Ticket Prices Fell $50 \%$ in 30 Years (and Why Nobody Noticed)."

The Atlantic. February 28 2013. Accessed July 30, 2018.

22 Simpson, Tim

"Mapping Tourist

Utopias." In Tourist

Utopias: Offshore Islands, Enclave Spaces, and Mobile Imaginaries, 31.

Amsterdam, Netherlands: Amsterdam University

Press, 2017. Also see

E-Brochures in Figure 1.

23 Sheller, Mimi.

"Demobilizing and

Remobilizing Caribbean

Paradise." In Tourism

Mobilities: Places to

Play, Places in Play, 13.

London, UK: Routledge,

2004.

24 Boghosian, Alison.

"Retro Ad of the Week:

Club Med, 1984." M//G.

Accessed November

2018.

25 Air Canada Vacations, Sun, 16.

26 Salazar, Noel, and Nelson Graburn. "Toward an Anthropology of

Tourism Imaginaries."

In Tourism Imaginaries:

Anthropological

Approaches, 1 - 28.

New York, NY: Berghahn

Books, 2016.

27 In the context of this thesis, cultural

'imaginaries' are taken to mean "a complex system

of presumptions," as

defined by Salazar (3).

The term 'imaginaries'

will be used to open

discussions about shared

mental perception.

See Strauss, Claudia.

"The Imaginary."

Anthropological Theory 6,

no. 3 (2006): 322-44.

28 Duval, Trends, 10.

29 Ibid., 3.
The introduction of commercial jet aircraft precipitated the establishment of early all-inclusive resorts. ${ }^{20}$ It may subsequently be inferred that all-inclusive tourism grew in tandem with the accessibility of airfare ${ }^{21}$ and the expanding breadth of scheduled airline routes. Following this infrastructural growth, romantic sentiments of 'flying south' could become positioned as attainable holiday goals for middleclass Canadians.

As illustrated in Figure 02, Canadian all-inclusive partnerships favour destinations within the range of short-haul, direct flights from the eastern seaboard. Airlines in turn market all-inclusive packages as a 'dream,' a 'fantasy,' or an 'escape' 22 - presumably from the climate and contemporary urban lifestyles of 'Northern' nations. Thus, the Caribbean defined by mass tourism is an imagined place, one whose expression informs today's quintessential mythologies of tropical paradise. ${ }^{23}$

"Club Med -

\section{the antidote for civilization." 24}

\section{"Escape the world}

and capture the moment." ${ }^{25}$

These imaginaries of paradise, ${ }^{26,27}$ are in turn manifested through the key tourism commodities of "sun, sand and sea" (3). ${ }^{28}$ Removed from precise awareness of global position, package tourists seek a blissful, placeless setting that is well connected to major North American airports, yet peripheral enough to global economic flows ${ }^{29}$ to still inspire images of deserted beaches and lost Edens. Destinations are rarely marketed on the basis of their unique geographical context, suggesting that the critical variables in opposition are not 'north' / 'south,' but rather 'centre' / 'periphery'. This latter relationship is rendered in Figure 03.

In this illustration, North American and Caribbean airports are mapped according to degree of interconnectivity, not geographic position. Major urban airports congregate in the centre of the graph, while minor remote airports float to the graph's outer extents. Note that the annotation scheme is carried forward from Figure 02. 


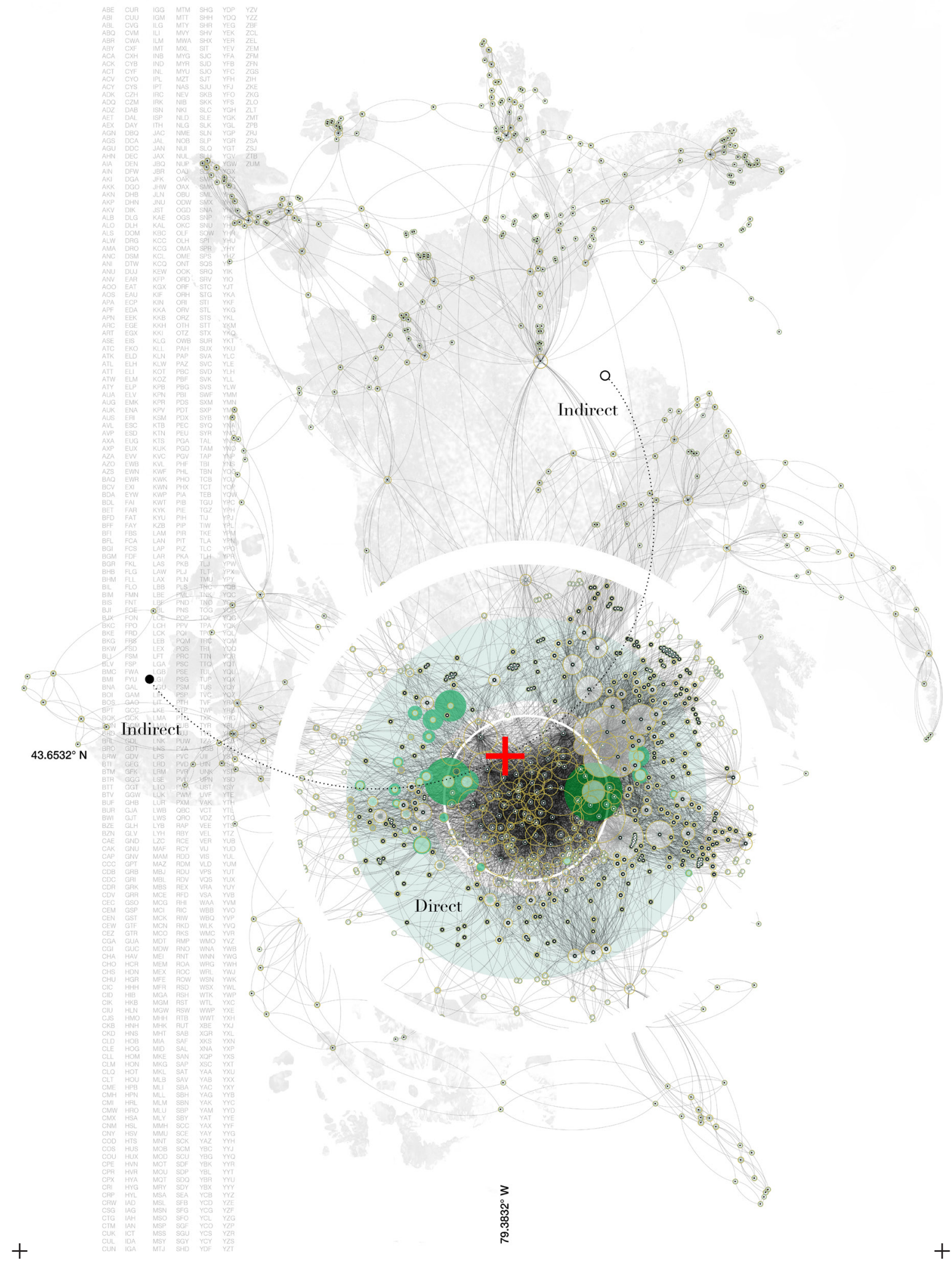

Figure 03: Flight network re-mapped according to airport interconnectivity. 
Referencing the fluidity of airline infrastructure, Figure 03 intentionally adopts a non-spatial approach to network mapping. This method of data visualization provides a new frame of reference for interpreting touristic practices not rooted in specificity of place.

Extrapolated further, Tim Simpson proposes that touristic enclaves are "extra-terrestrial" (30), ${ }^{30}$ a notion supported by the passive, contextually detached experience of flight. The temporal lapse of travel, hermetic enclosure of cabins, and choreography of airport connections premeditate a contrast between endpoints. These spatial experiences reinforce the message that tourists have 'escaped' to an approximated destination that is wholly different from their origin. While the experience of air travel is polarizing, it is suggested that enclavic networks exist on a graduated continuum not explicitly tied to distance.

By viewing the commercial flight network as a scale-less whole, hierarchical relationships between transit nodes may be uncovered. Curiously, all-inclusive 'gateway' airports tightly encircle the dense, central airport cluster. Re-interpreted at a regional scale, this pattern resembles an 'urban' / 'suburban' / 'rural' organization. From this hybrid perspective, 'gateway' airports evoke a continental suburban sprawl.

\section{"Endless Privileges, ${ }^{\circ}$}

Unlimited-Luxury, ${ }^{\odot}$ and Unlimited-Fun. ${ }^{\oplus 31}$

"373 rooms [-]

30 Simpson, Mapping,

Caribbean deluxe: Garden View Terraces..." 32

31 Air Canada Vacations, Sun, 16.

32 Ibid., 51.

33 See discussion of hypermarkets. Baudrillard, Jean. Simulacra and Simulation. Ann Arbor, Ml: University of Michigan Press, 1981

Just as suburbia cannot be isolated from highways and car ownership, ${ }^{33}$ it is argued that all-inclusive resorts are most effectively understood in relation to the global budget airline economy. This thesis in turn presents the realm of tropical paradise as a displaced suburb, challenging whether all tourists leave 'home' when they fly abroad. Illustrating this theoretical position, Figure $\mathrm{O} 4$ abstracts paradise as an extension of southern Ontario. 


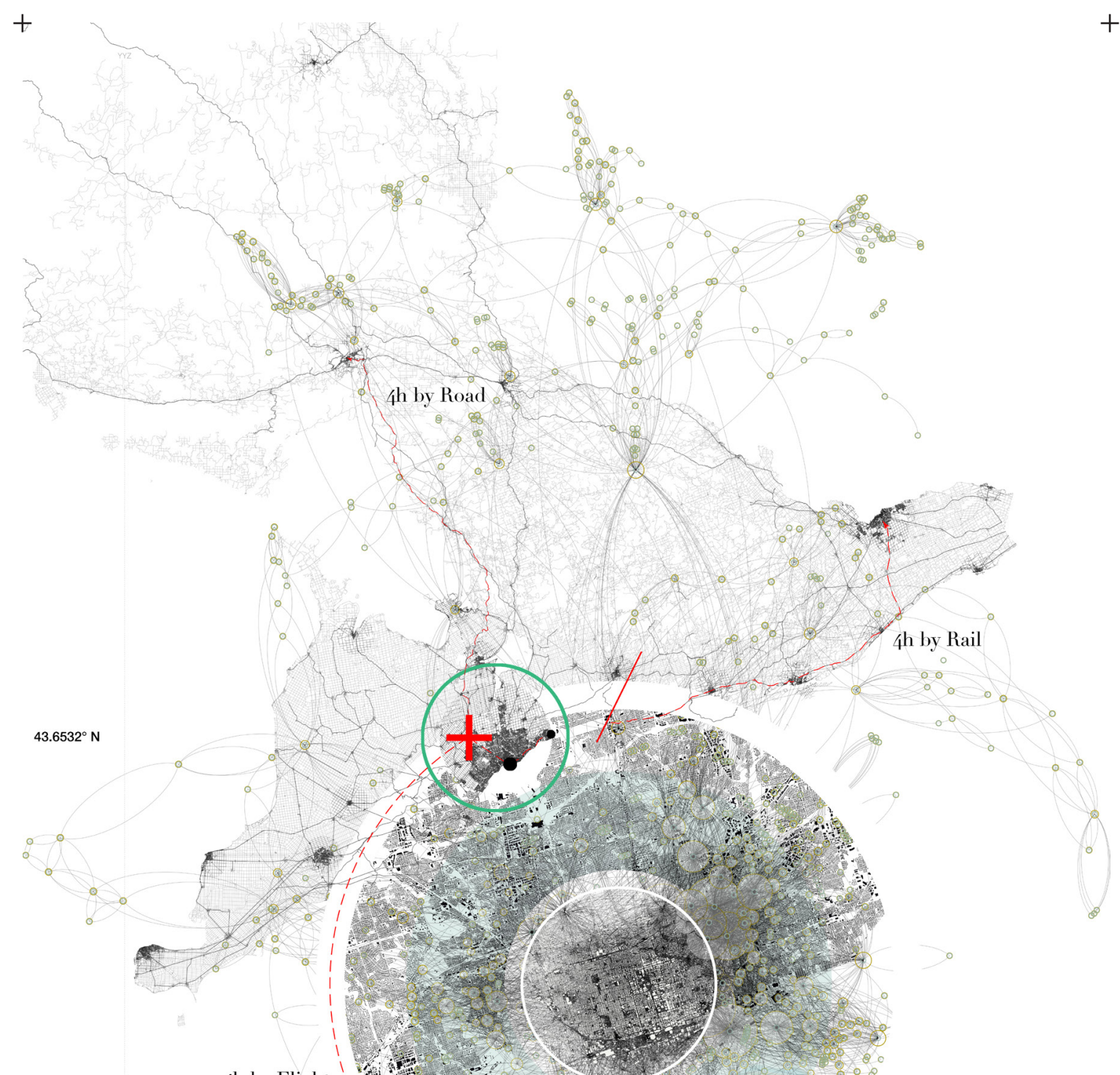

$21.7763^{\circ} \mathrm{N}$

4h by Flight
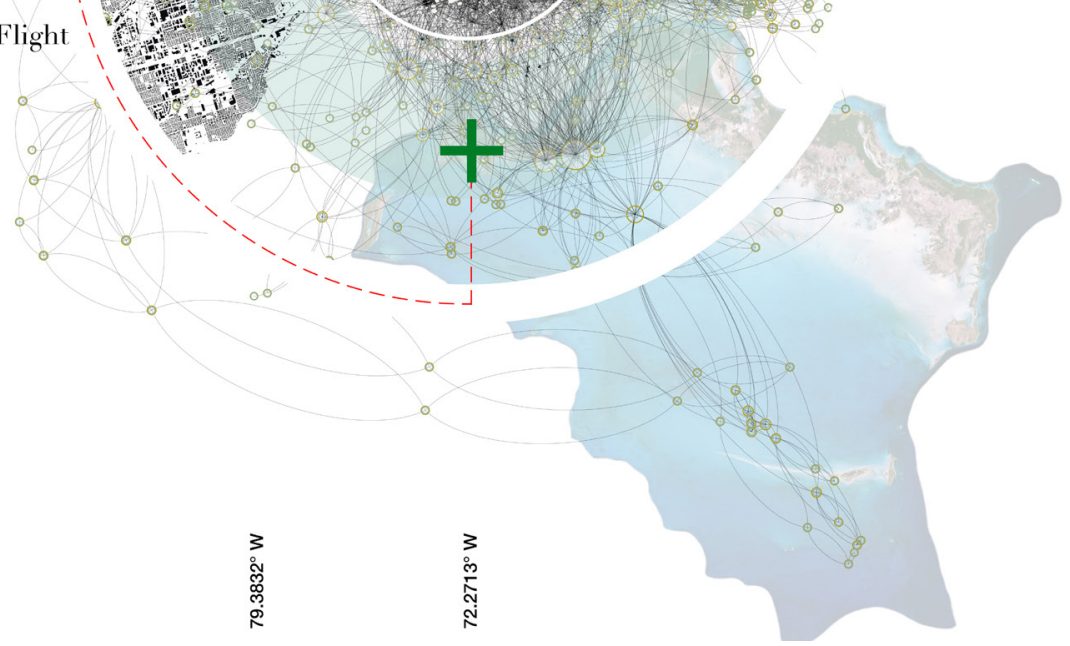

$+$

Figure 04: Paradise as a global suburb. 
34 Forsyth, Ann.

"Defining Suburbia."

Journal of Planning

Literature 27, no. 3

(2012): 270-81.

35 Archer, John.

"Conclusion." In

Architecture and

Suburbia: From English

Villa to American Dream

House, 1690-2000,

331. Minneapolis, MN:

University of Minnesota

Press, 2008

36 Ibid., 368

37 Ritzer,

McDisneyization, 96-109.

38 Archer, Architecture,

$\mathrm{xV}$.

Figure 05: "Beaches ${ }^{\circledR "}$ Resort in Providenciales, Turks and Caicos.
Bridging suburbia into a critique of all-inclusive development is challenging, as there is no common consensus on its definition. ${ }^{34}$ While 'suburbia' remains a general term, its associated urban development is customarily identified according to several traits. Suburbia lies somewhere between the 'city' and 'country,' featuring efficient commuting links to major commercial hubs. Its boundaries extend beyond singular subdivisions to encompass larger regions with schools, shopping malls, light industry, and most notably, airports. Suburbia is closely associated with ideas of 'newness,' and an array of properties such as banality, predictability, cheapness, exclusivity and uncontrolled sprawling growth. While these traits may not be universally true, they are deeply embedded in public consciousness due to one-dimensional media portrayals and ofttimes antagonistic architectural debate. ${ }^{35}$ Beyond a discussion of semantics, suburbs are more diverse than frequently appreciated, ${ }^{36}$ playing host to a wide array of personal experiences and associations. Moving forward, readers are invited to consider the term 'suburbia' in light of one's own familiarity with urban-adjacent places.

Both suburbs and all-inclusive resorts are characterized by their undifferentiated development, ${ }^{37}$ whose popularity is legitimized through shared consumer aspirations. Suburbia remains tied to the American Dream, ${ }^{38}$ just as Caribbean resorts levy their strong associations with tropical paradise. While these commercial draws remain distinct contemporary myths, this thesis explores how and where they overlap.

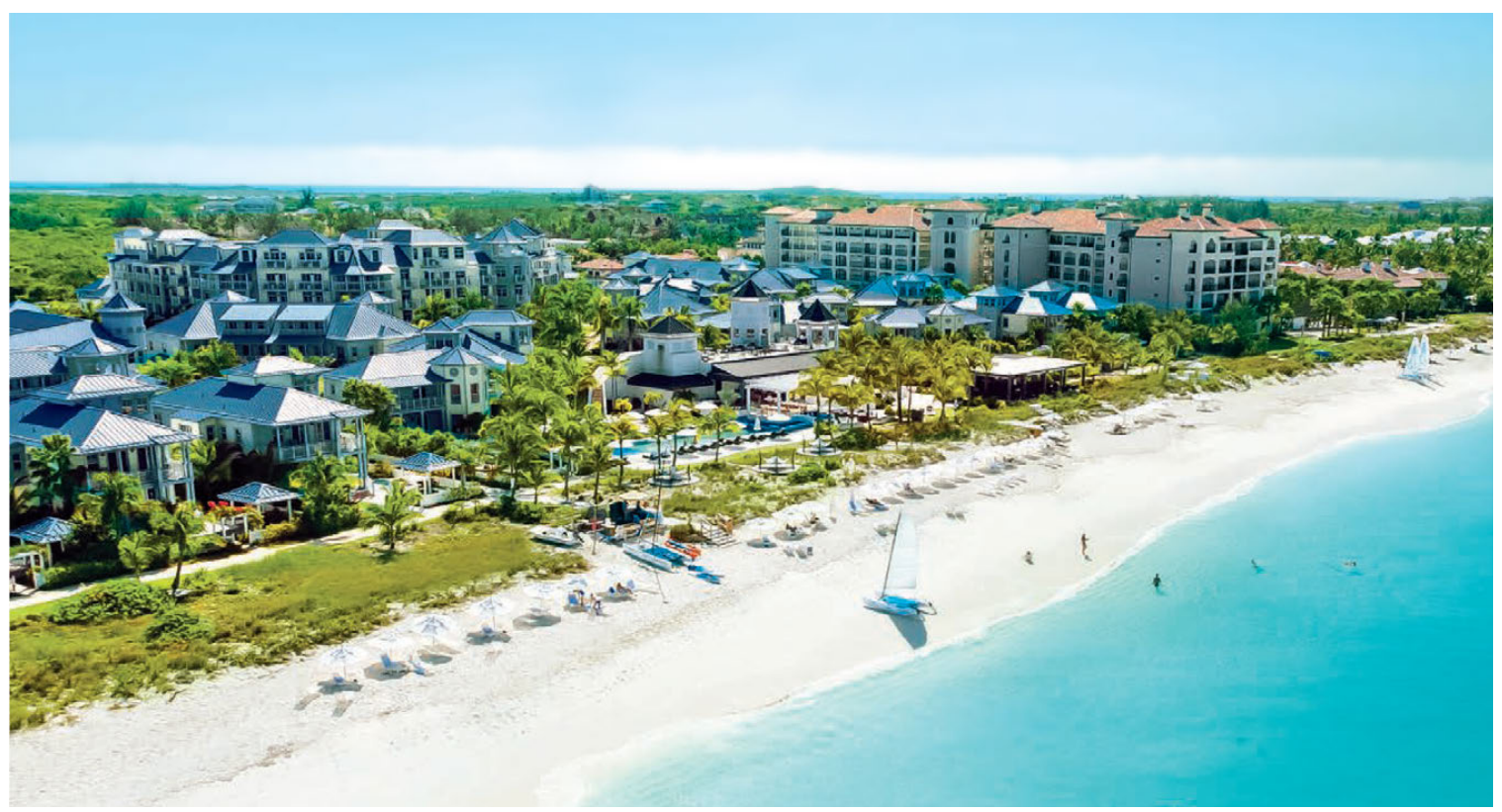


39 Coles, What, 236.

40 See discussions on the experience economy, particularly Klingmann, Anna. Brandscapes:

Architecture in the Experience Economy. Cambridge, MA: MIT Press, 2007.

41 Archer, Architecture, xvii.

42 Edensor, T.

"Performing Tourism,

Staging Tourism: (Re)

producing Tourist Space

and Practice." Tourist

Studies 1, no. 1 (2001):

79

43 Ritzer,

McDisneyization, 99.

Figure 06: "Sanda/s"

Resort in Grenada.
This project trajectory begins to engage the architectural contradictions inherent with all-inclusive tourism. Online and in glossy catalogues, budget airlines promote access to a pseudo-nostalgic realm of tropical paradise, while concurrently promising all the securities of home. Tourists subsequently enter spaces that are simultaneously contrary to and connected with the familiarity of suburbia. The infrastructure facilitating this activity provides both separation and connection, permitting all-inclusive resorts [and residential subdivisions] to balance accessibility with distance, inclusion with exclusion. ${ }^{39}$

At the intersection of these apparent contradictions lies a presentation of ownership..$^{40}$ By investing upfront in a tailored travel experience, budget airlines subtly declare that tropical paradise can be purchased for a pre-determined period of time. Similar to how the suburban identity may be defined by themes of "privacy, property and self-hood" (xvii) ${ }^{41}$ it is speculated that all-inclusive tourists seek the sensations of anticipation, isolation and assurance tied to ownership. This sensibility operates as an intangible design device, reflecting mass tourism's broader homogenizing influence ${ }^{42}$ through evolving expectations of reliability and predictability. ${ }^{43}$ While travelling to encounter sameness remains a puzzling cultural phenomenon, the greater appeal of all-inclusive tourism unquestionably lies in this irony.

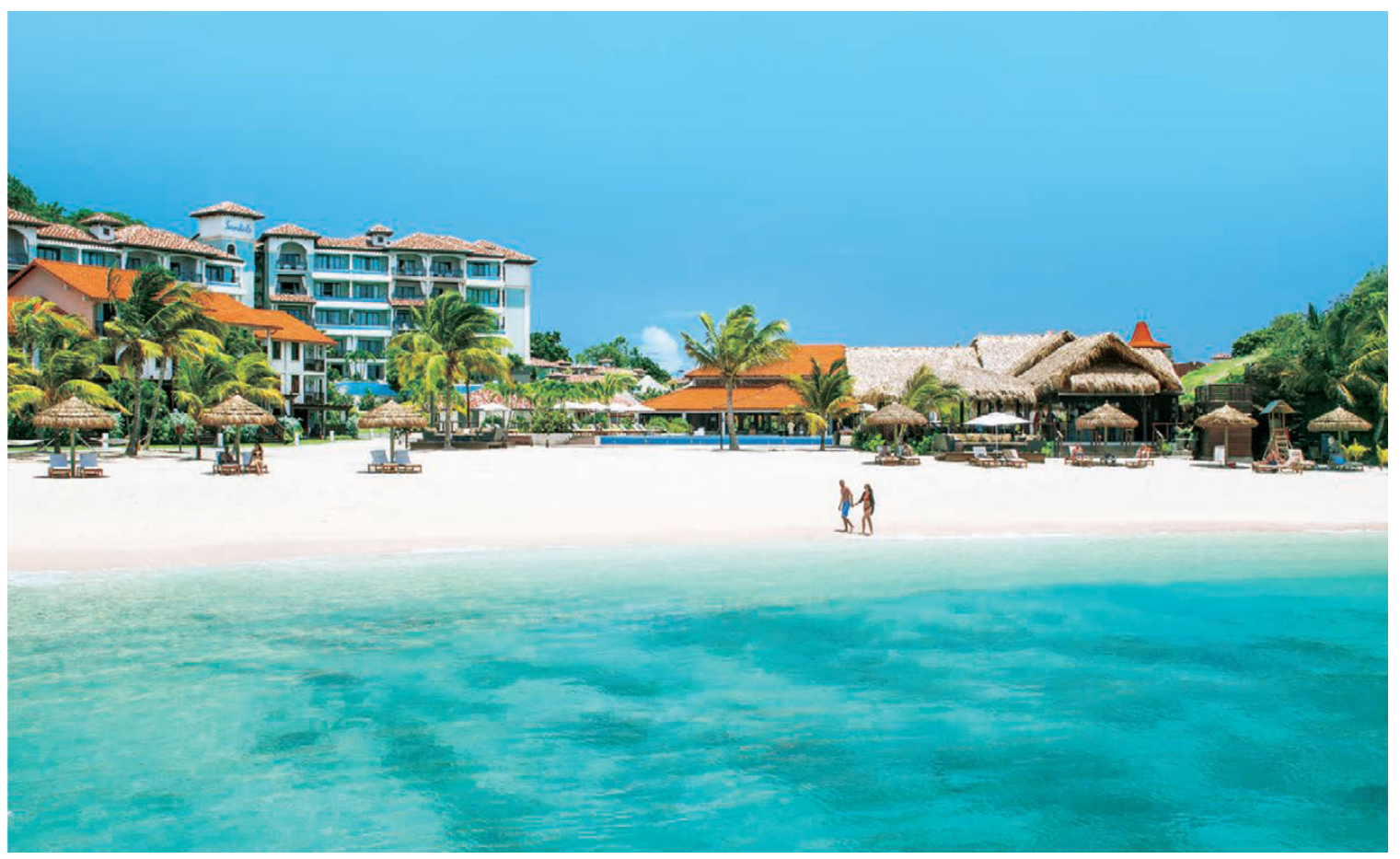


44 Coles, What, 238.

45 See Thomas

More's Utopia, and an

introduction by Clarence

H. Miller (2001). More

derived the word 'Utopia'

from the Greek 'ou' ("not")

and 'topos' ("place"),

combined to mean 'no-

place.' In a clever play on

words, 'ou' may be

substituted for 'eu'

("good"), changing

utopia's meaning from

'no-place' to 'good-

place.' Current colloquial

usage of the word

aligns most closely with

the latter definition,

often describing real

spaces with utopic

characteristics.

46 Le Corbusier.

"Frontspiece to Pictures

of the Epic of the Air." In

Aircraft: The New Vision,

13. London, UK: Trefoil

Publications, 1987.

47 Foucault, Michel. "Of Other Spaces: Utopias

and Heterotopias."

Architecture/Mouvement/

Continuité, October 1984.

48 Koolhaas, Rem.

"Coney Island: The

Technology of the

Fantastic." In Delirious

New York: A Retroactive

Manifesto for Manhattan,

29-80. New York, NY:

Monacelli Press, 1994.

49 One example would

be the discouragement of tipping, since it promotes

direct financial interaction between workers and

guests.

50 Foucault, Of Other, 6.

51 Edensor, Performing

59-81.

52 Simpson, Mapping,

30 .

53 Sheller, Mimi.

"Infrastructures of

the Imagined Island:

Software, Mobilities,

and the Architecture of

Caribbean Paradise."

Environment and Planning

A 41, no. 6 (2009): 1386-

403.
Relating to general architectural sentiment, this uniformity often leads architects to adopt a condescending attitude towards both allinclusive resorts and suburbia at large. This patronizing mindset generally contrasts that of the consumer, who likely enjoys their vacations ${ }^{44}$ and is proud of their home. This thesis does not define authentic versus inauthentic development, nor does it seek to condemn and/or subvert the all-inclusive model. In fact, it suggests that allinclusive resorts are worthy of extensive architectural discussion.

Historically, architects and theorists have been charmed by the para-utopic ${ }^{45}$ qualities of bounded spaces similar to all-inclusive resorts. Consequently, the majority of related architectural writing fixates on the atypical traits of these urban anomalies. Reflecting on a flight over Algeria in $1935,{ }^{46}$ Le Corbusier remarked that "the airplane carries our hearts above mediocre things," describing the oasis city of Ghardaia as a "delightful spectacle of water and verdure... [where every house] is a place of happiness, of joy, of a serene existence..." (I3) Michel Foucault later cited Polynesian vacation villages in his proposition of heterotopias, ${ }^{47}$ while furthermore, Rem Koolhaas characterized Coney Island as a laboratory for Manhattan's own unique mythology. ${ }^{48}$ Between all authors, such unusual enclaves are consistently positioned away from normalized space, serving as foils to dominant urban patterns.

Through persuasive advertising, all-inclusive resorts are also imbued with a detached, mythic character when accompanied by spectacular sites, manufactured settings, subtle behavioural expectations, ${ }^{49}$ and controlled portals of entry. ${ }^{50}$ Accordingly, all-inclusive resorts may be considered a performance of paradise $\mathrm{e}^{5 \mathrm{I}}$ - a paradox of commercial architecture where no money is exchanged.

While touristic enclaves undeniably deviate from standard urban environments, solely understanding them as "inverted spaces of exception" $(30)^{52}$ stunts the conversation about their broader relevance today. In the context of mass Caribbean tourism, focusing on difference not only becomes a limiting analytical approach, it further empowers the contemporary mythology of tropical paradise. This is inherently problematic as our modern pursuit of paradise involves the deregulation of global economies, compromising of fragile ecologies and often extreme marginalization of local populations..$^{53}$ 
54 Archer, Architecture, 351.

55 Sheller,

Infrastructures, 1386.

56 Picon, Antoine. "Urban Infrastructure, Imagination and Politics:

From the Networked Metropolis to the Smart City." International Journal

of Urban and Regional Research 42, no. 2 (2018): 263.
These issues are too vast to address sensitively over the course of a two term thesis, thus the objective of this work is to re-represent tropical paradise in a manner that begins to disengage some of its cultural mystique and credibility. Paralleling the development of all-inclusive resorts with the popularity of suburbia opens a channel of enquiry into how touristic enclaves are similar to the environments they allegedly oppose. By situating resorts within the broader budget airline network, these spaces may be discussed more thoroughly at a scale beyond their obvious property extents.

Here it is worth nothing that suburbia itself is not at the core of the social, ecological and economic problems surrounding all-inclusive tourism, rather it can be understood as a datum..$^{54}$ All-inclusive vacations are widely considered to be a leisure investment, not an intrepid adventure abroad. Consequently, it is reasoned that tourists carry domestic assumptions of 'home' on vacation, dramatically heightening their travel expectations of restorative isolation. Notions of suburbia, in its range of individual subtleties, thus stand as a familiar point of reference through which consumers may evaluate their vacation.

Subsequently, this thesis aims to re-frame aspirational spaces in unusual ways, investigating how 'normal' space may inform one's perceptions of 'enclavic' space. In doing so, this work seeks to directly engage with the collective imagination of tropical paradise, which is far more influential than its physical manifestation in resorts alone. While this thesis does not propose a 'new' or 'better' all-inclusive resort, it encourages architects and architectural consumers to question how they participate in ongoing negotiations brought about through the widespread popularity of mass tourism.

Positioning all-inclusive resorts as a global extension of suburbia has the potential to re-contextualize mass-touristic development, leading to a hybrid understanding of existing built conditions. While this hybridity may be intuitively known, its direct acknowledgment promotes an important discussion between architects and architectural consumers. As all-inclusive developments integrate natural enclaves into greater metropolitan flows, increasingly peripheral locations are pulled into the scope of global cities..$^{55}$ By altering the social imagination ${ }^{56}$ of conventional touristic infrastructure, new connections may be established across global spectrums of freedom, mobility and affluence. 
57 McRae, L. "Rethinking Tourism: Edward Said and a Politics of Meeting and Movement." Tourist

Studies 3, no. 3 (2003):

238.

58 Sheller, Demobilizing, 13.

59 Sheller, Mimi. "Natural Hedonism." In Tourism in the Caribbean: Trends,

Development, Prospects, 23 - 38. London, UK:

Routledge, 2004.

60 Nixon, Rob. "Stranger in the Eco-Village." In Slow Violence and the Environmentalism of the Poor, 174. Cambridge, MA: Harvard University Press, 2011.

61 Urry, The Tourist, 3.
All-inclusive vacations are significant annual milestones for many tourists, generating intense excitement and anticipation. Once abroad, a tourist's degree of satisfaction is directly correlated to how sufficiently the holiday fulfills their travel expectations. ${ }^{57}$ Since vacation packages are marketed as a commercial product, these expectations are formed before a tourist ever leaves home. ${ }^{58}$ Shaped by the advertising of international places, people ${ }^{59}$ and nature ${ }^{60}$ travel assumptions are generated and perpetuated through marketing mediums such as travel brochures and an array of non-tourist disciplines such as literature, cinema and TV ${ }^{6 r}$ Before studying all-inclusive resorts through a distinctly suburban lens, the Air Canada Vacations 2018/2019 'Sun' e-brochure will be analyzed to understand how all-inclusive resorts are ordinarily represented by the budget airline industry.

Featuring a repetition of signs, symbols, imagery, short text and data, travel catalogues cohesively portray the industry's common definition of tropical paradise. While this repetition effectively illustrates relational patterns, it poses challenges to studying resort concentrations with any site specificity. Consequently, this section will additionally use the 2018/2019 'Sun' e-brochure to determine three areas of interest which will be further studied at the regional level.

\section{Air Canada Vacations Imagery}

Air Canada Vacations advertises over 700 resorts throughout the greater Caribbean region; however, 522 resorts are directly featured in the 2018/2019 'Sun' e-brochure. Of these 522 resorts, IIO resorts receive fullpage spreads in the catalogue. Each full-page spread contains the resort's name, location, travel time from the closest airport, a primary image, one to two secondary images and basic resort information (i.e. number of rooms, restaurants and types of amenities available). Figures 07 to 09 tile IO8 of the IIo full-page resort images. 


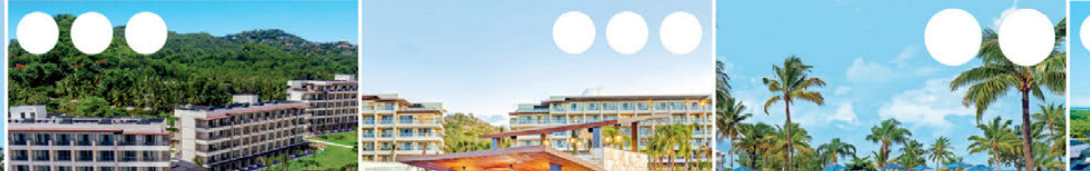

I) $\Rightarrow$ $\infty$

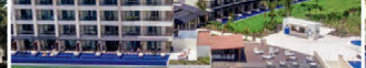

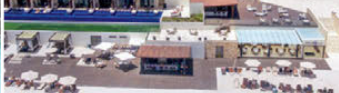

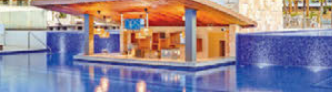

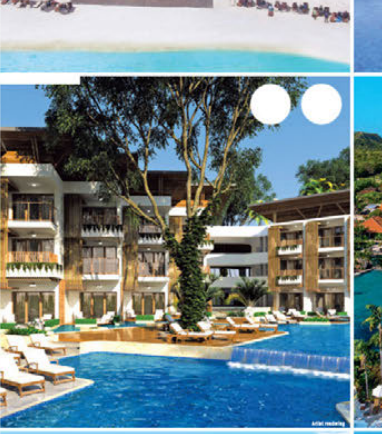

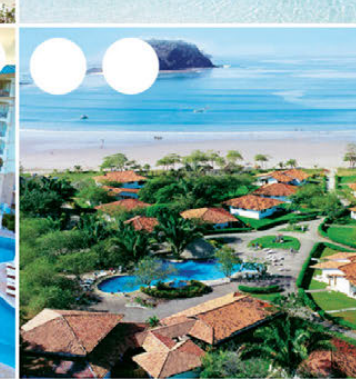

\section{0}

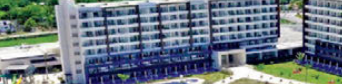

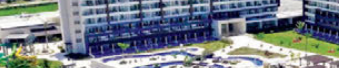

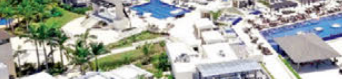
104 4 (1)

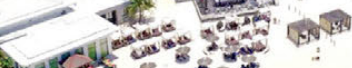

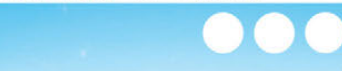
(5)

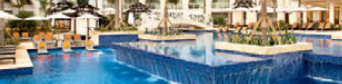

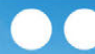

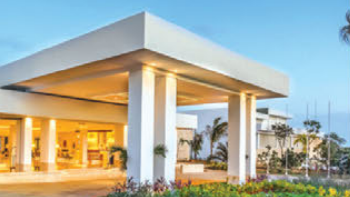

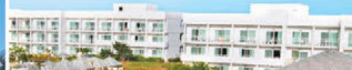

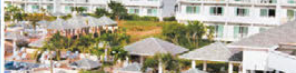
20.

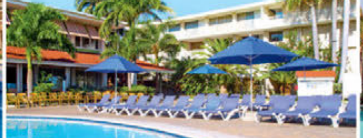

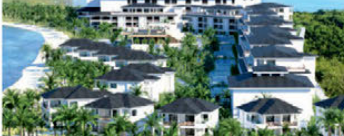

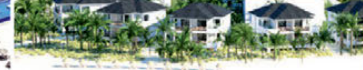

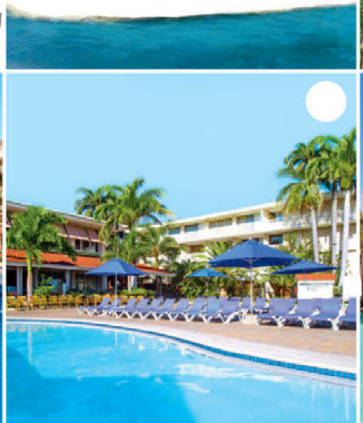
$: x \leqslant$

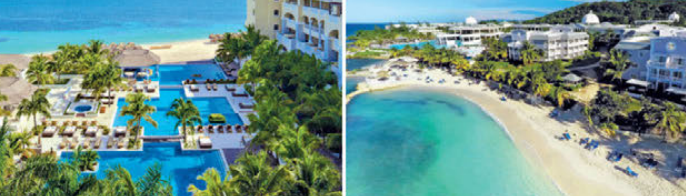

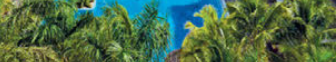
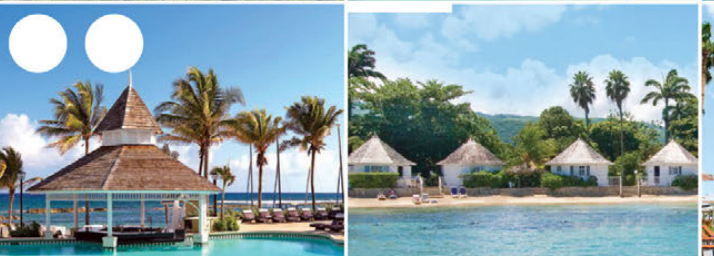

3.
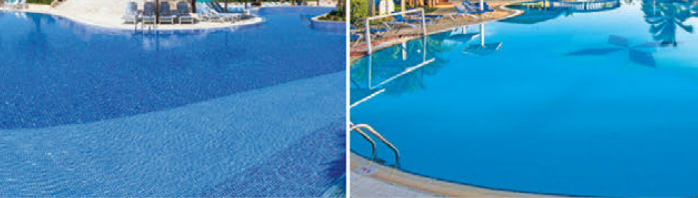

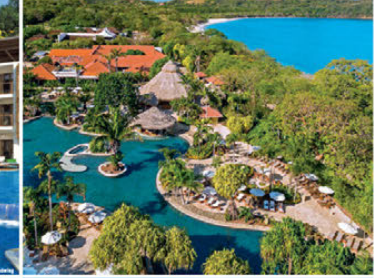

\section{0 do}

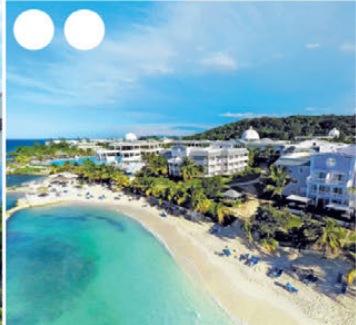
Hind a

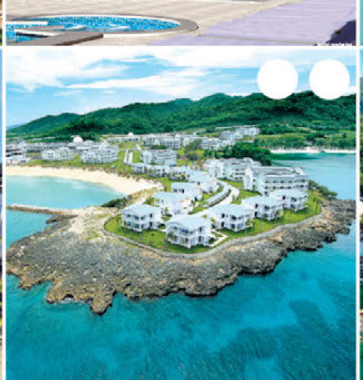

2115in

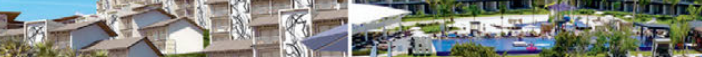
*

\section{1.}

00
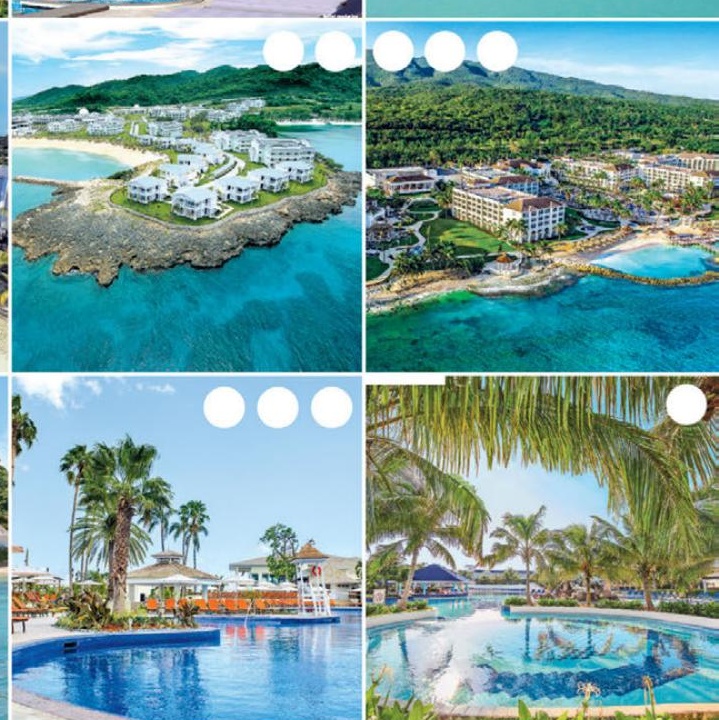

10

-750
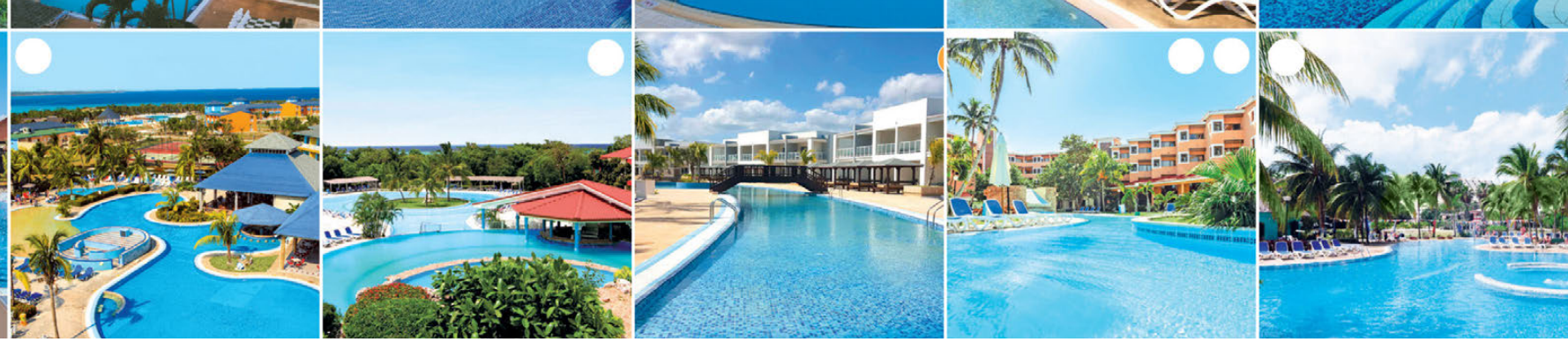

*Promotional icons

have been masked.

Figure 07: Selection

of resorts accessible

through Air Canada.

[panel 1 of 3] 



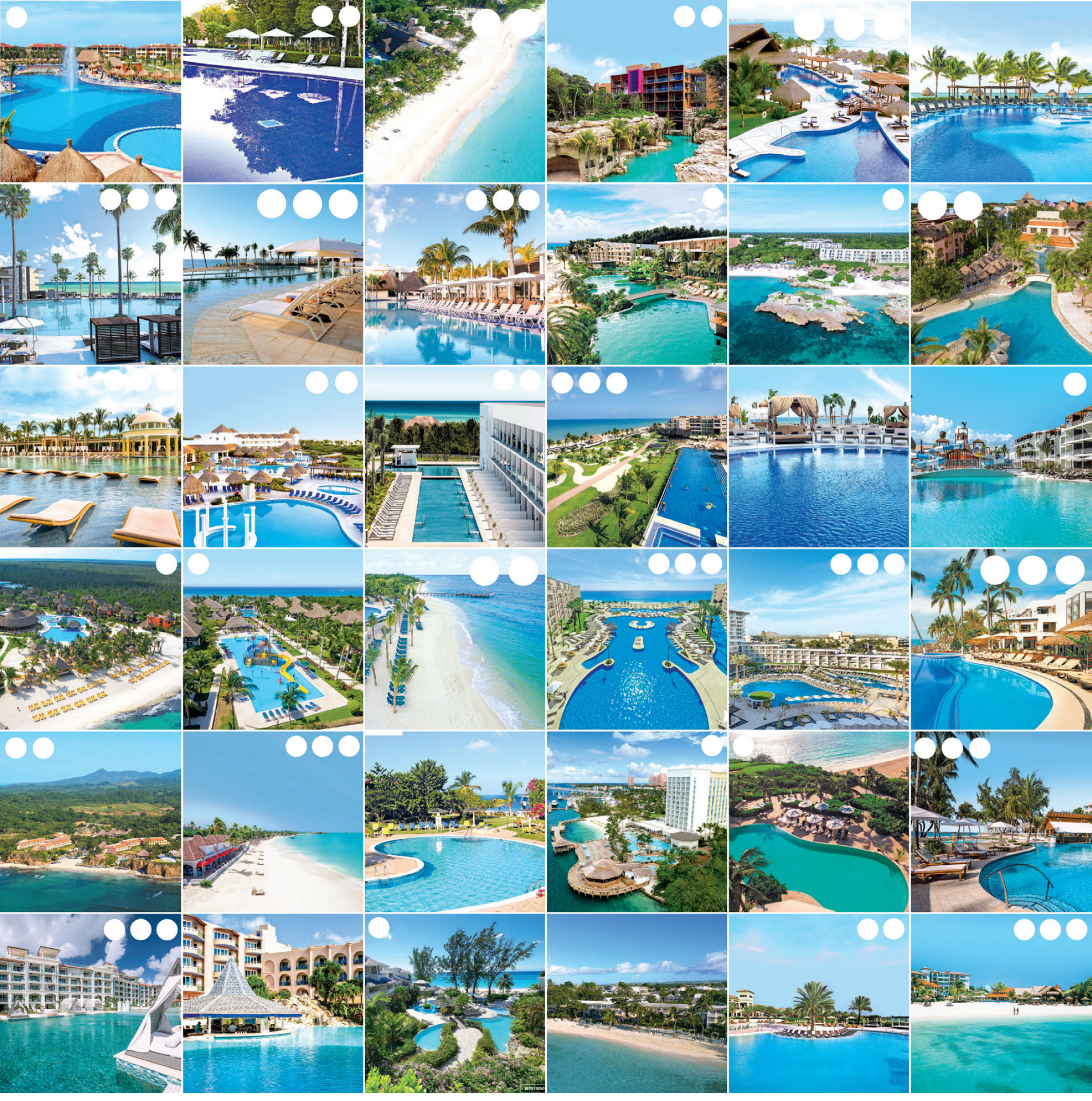




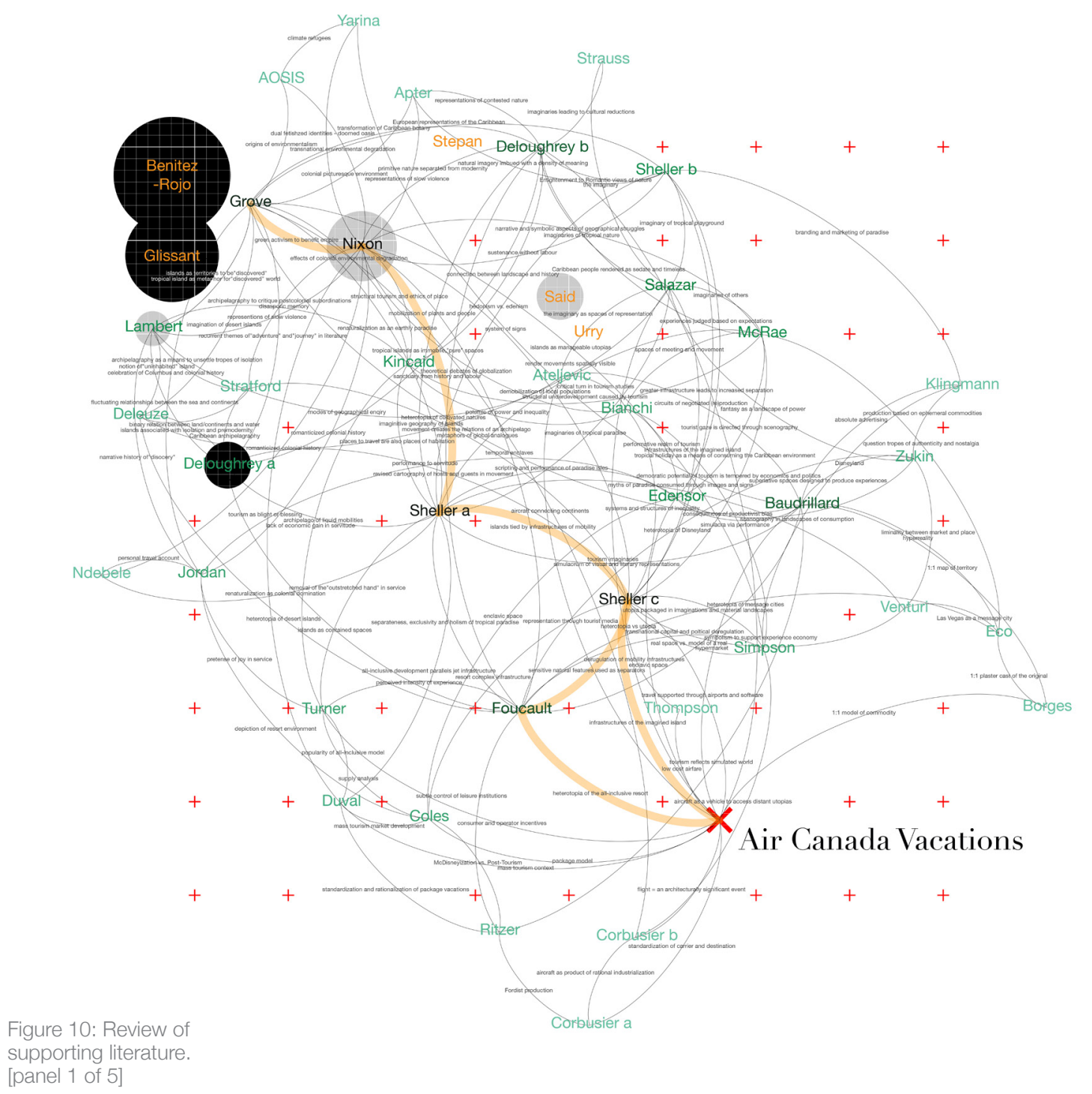

\section{Air Canada Vacations Text}

Based on the prior matrices, it is apparent that resorts viewed in series are nearly indistinguishable. Figures to to I4 seek to uncover the archetypal motifs influencing how all-inclusive resorts are consistently documented. Figure io illustrates a review of supporting literature, mapped in the same manner as the continental flight network. Not all sources relate directly to all-inclusive construction, though all are included due to their tangential relationships to catalogue material. 


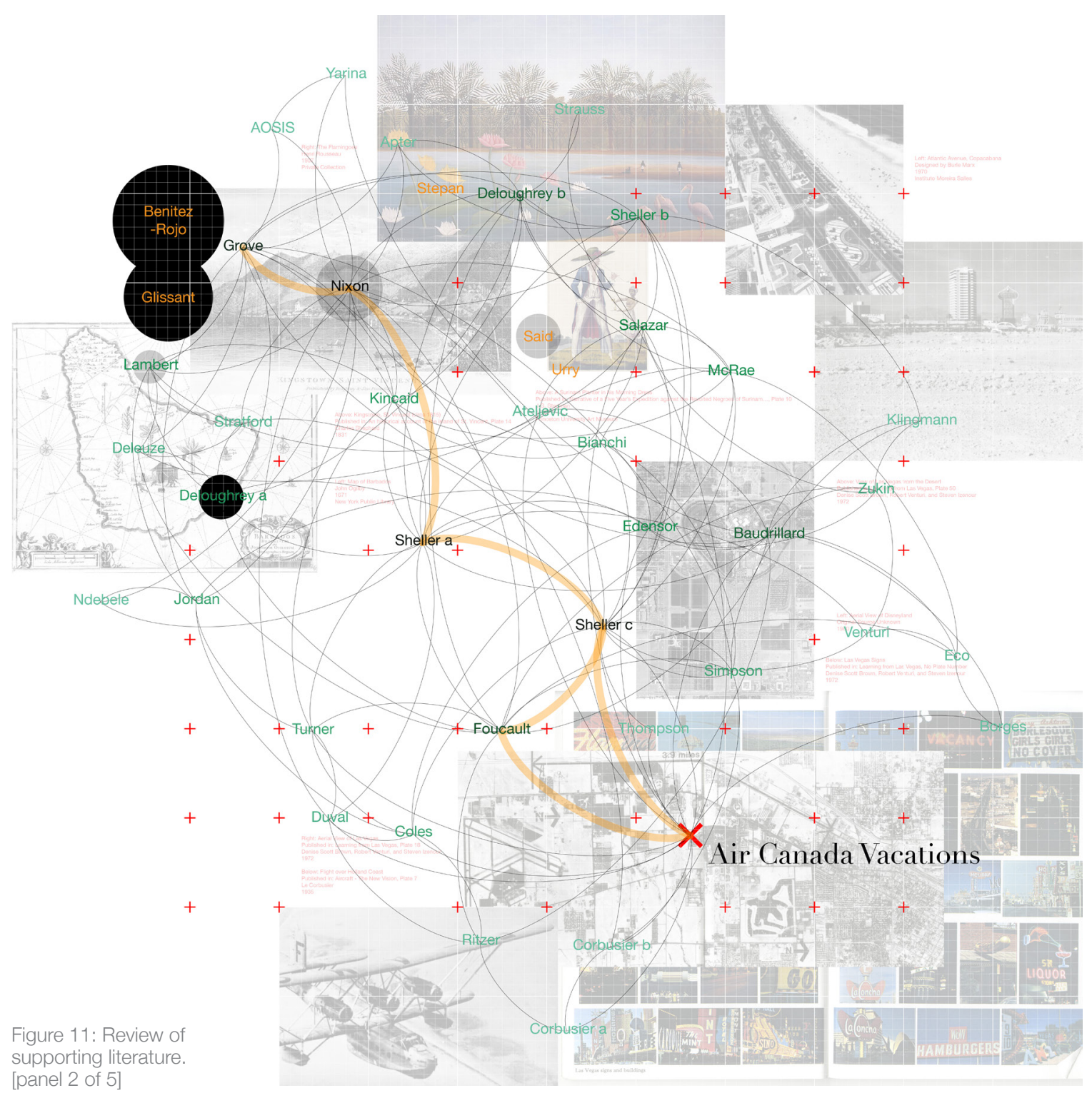

Despite the scope of related literature, the social imagination of physical infrastructure follows an image-based system, ${ }^{62}$ not a text-based system. While literature is capable of crafting immersive settings, in practice, travel marketers rely on the immediate impact of persuasive graphics. As such, Figures II and I2 distill the previous literature map to its associated imagery. 


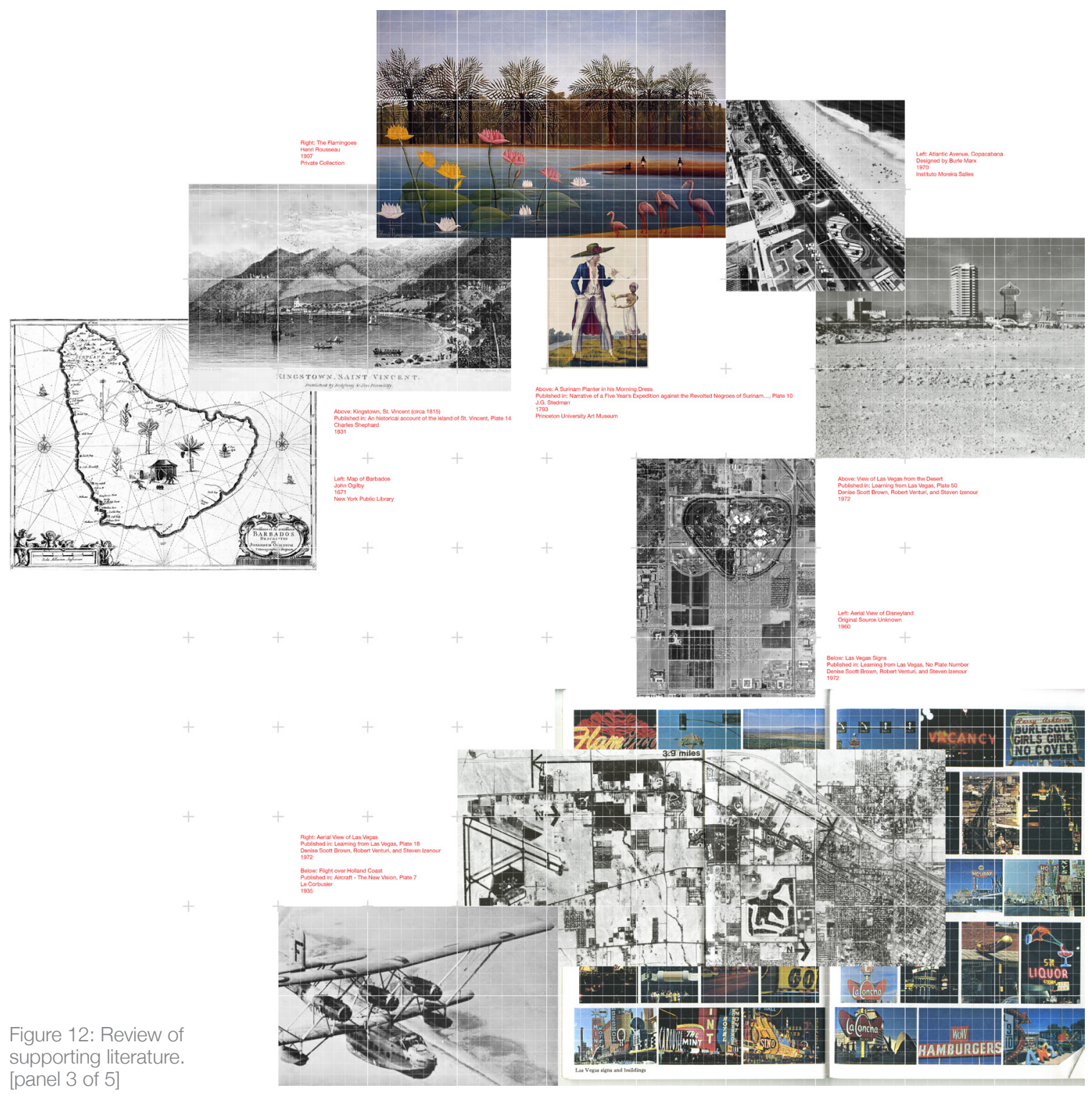

Within these images, several thematic clusters can be identified that tie into the historical representation of Caribbean travel. The first cluster relates to island environments and the presumption surrounding their exotic origins (left/top). The second cluster relates to ideas of tropical nature, particularly in relation to collected gardens and society's search for Eden (top). The third cluster addresses hyperreal landscapes and selfreferential systems of commercial signs (right). These thematic layers will be further investigated in a regional-scale analysis of three sites. 


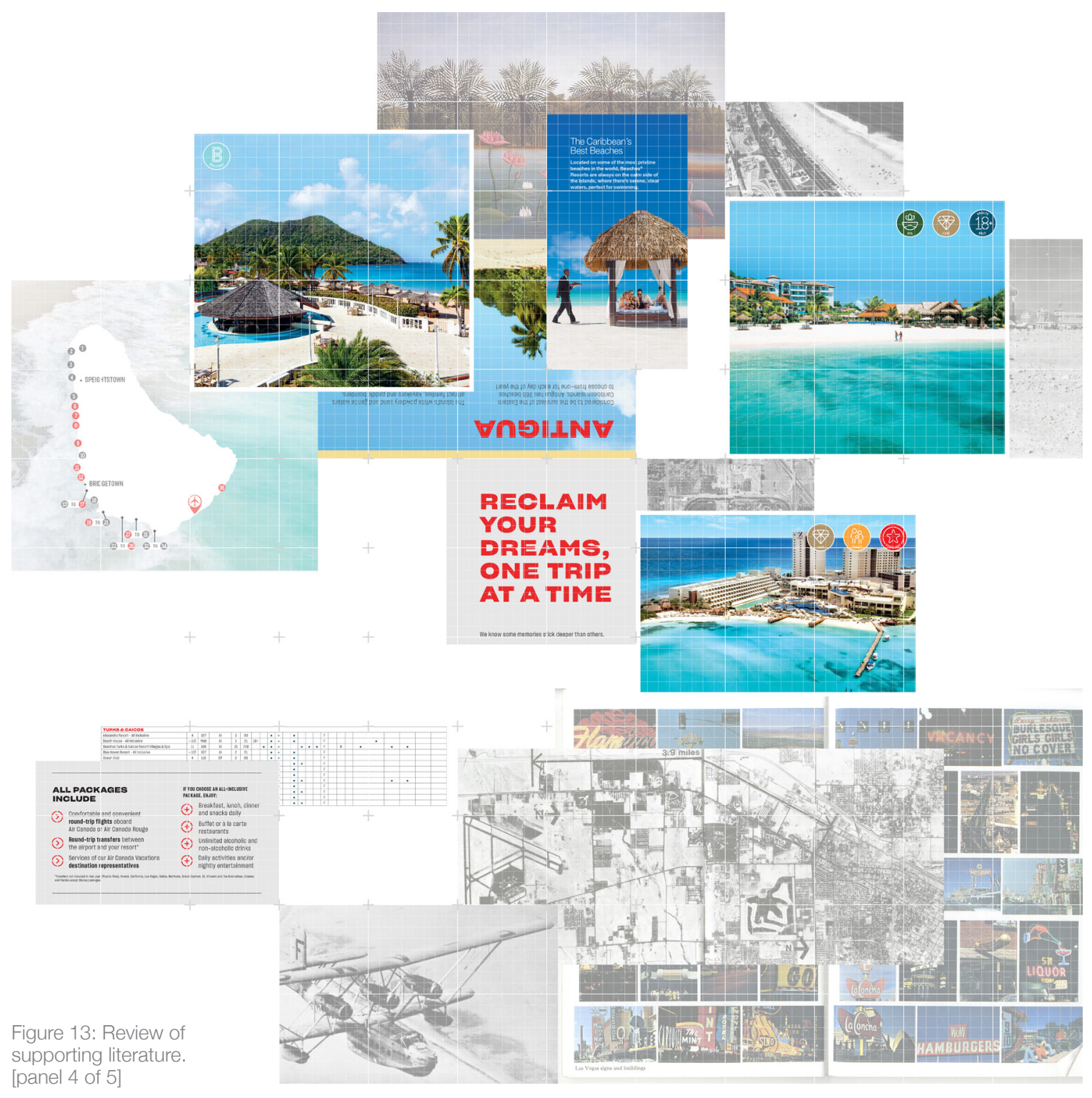

Many intersections can be drawn between the previous imagery and the contemporary photography contained within the 2018/20I9 'Sun' e-brochure. Essential architecture servicing assumptions of domestic privacy and comfort recede to the background of each photo's spatial composition. In contrast, prominent landscape features such as sand beaches, meandering pools, palm trees and thatched accessory structures occupy the foreground of most arrangements. All-inclusive resorts thus exhibit a foundation of common residential development, layered with precisely designed traces of the exotic. 


\section{Anticipation}

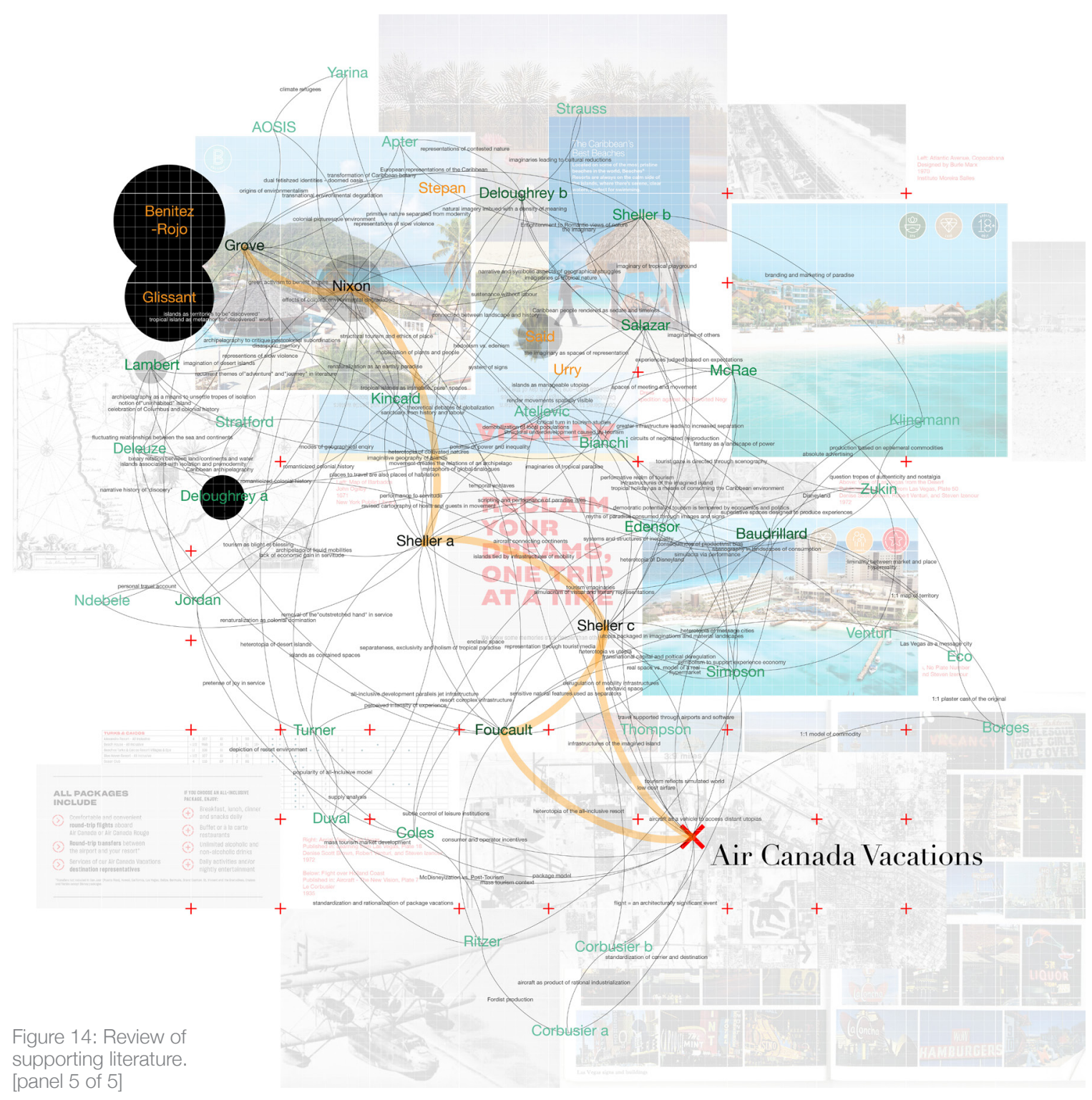

Figure I4 shows all literature connections and related imagery overlaid together in a single map. 
632018 figures, as published by the World Travel \& Tourism Council (WTTC).

64 Number of allinclusive hotel rooms as advertised by Air Canada Vacations, not the total number of all-inclusive resort rooms constructed (this figure is not readily available).

65 Represented through overall airport interconnectivity, see page 7 and Figure 03 for more information.
In order to study the interface between all-inclusive resorts and North American suburban development, key areas of interest within the greater Caribbean must be determined. The 2018/2019 'Sun' e-brochure gives little insight into the local configuration of resort concentrations, instead portraying all-inclusive resorts as isolated pockets of development. This representational strategy is commercially provocative, though fundamentally inaccurate, since all-inclusive resorts typically cluster around international airports.

Figures I5 to I7 map Air Canada Vacations' resort data in relation to 'gateway' airport distribution, giving a scalar indication of resort density throughout their scope of service. For a more comprehensive understanding of the economic impact attributed to resort development, tourism's overall contribution to Gross Domestic Product ${ }^{63}$ is also thematically mapped. Finally, the number of all-inclusive hotel rooms ${ }^{64}$ per country citizen is documented, giving a loose indication of a country's reliance on the employment generated by all-inclusive resorts.

Figure I5 plots airport locations using their 3-letter IATA codes, scaled according to the airport's degree of interconnectivity. American airports such as the Hartsfield-Jackson Atlanta International Airport and Miami International Airport visually dominate this analysis. In contrast, Figure I6 plots the same airport codes, scaled according to the airport's all-inclusive resort room access. These two maps suggest a nearly inverse relationship between global economic presence ${ }^{65}$ and all-inclusive resort development. Instead, the intensity of all-inclusive development most closely correlates with the scale of major coastal sand deposits, and population of adjacent service communities. 


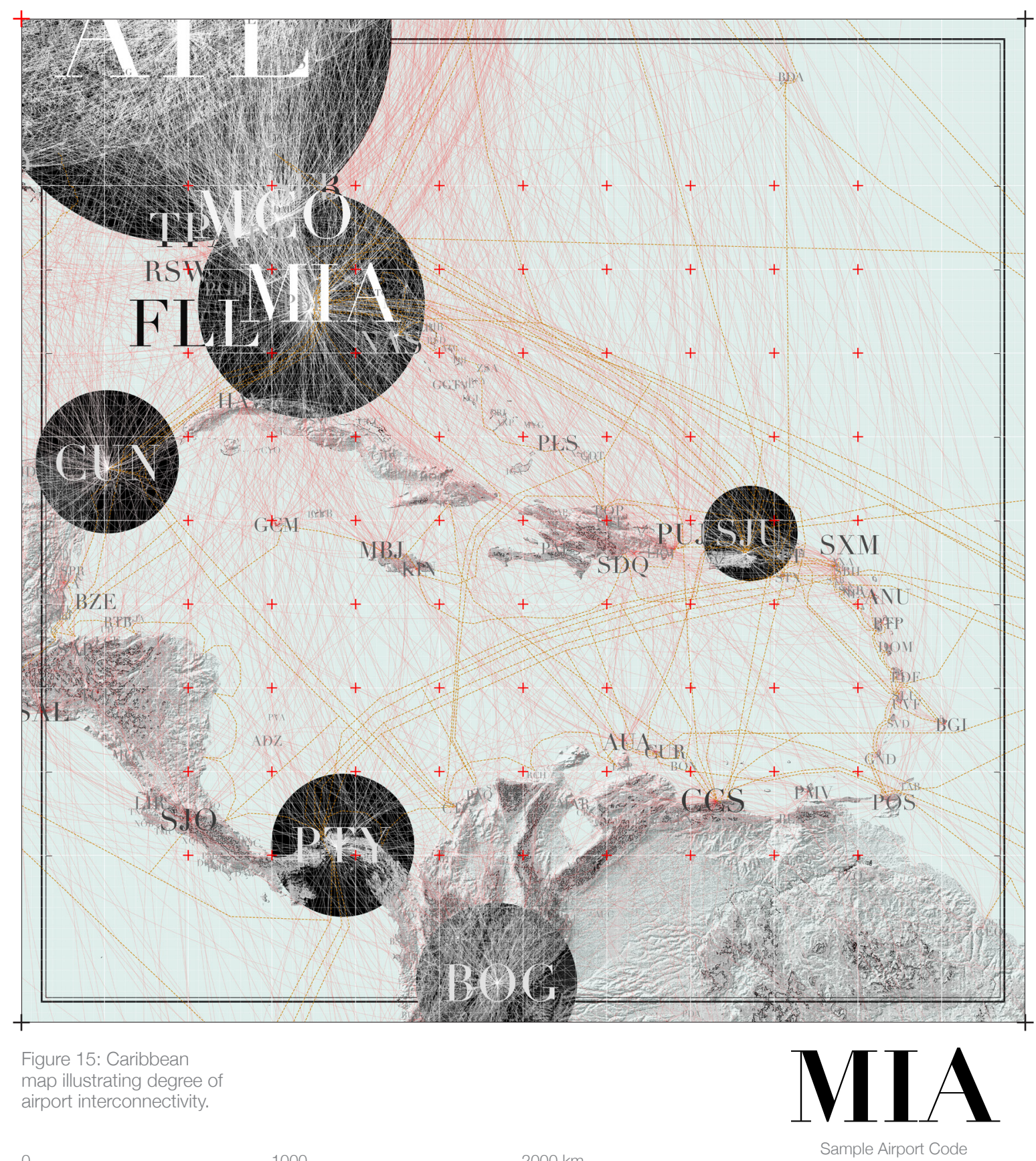

Flight Path

Undersea Data Cable 


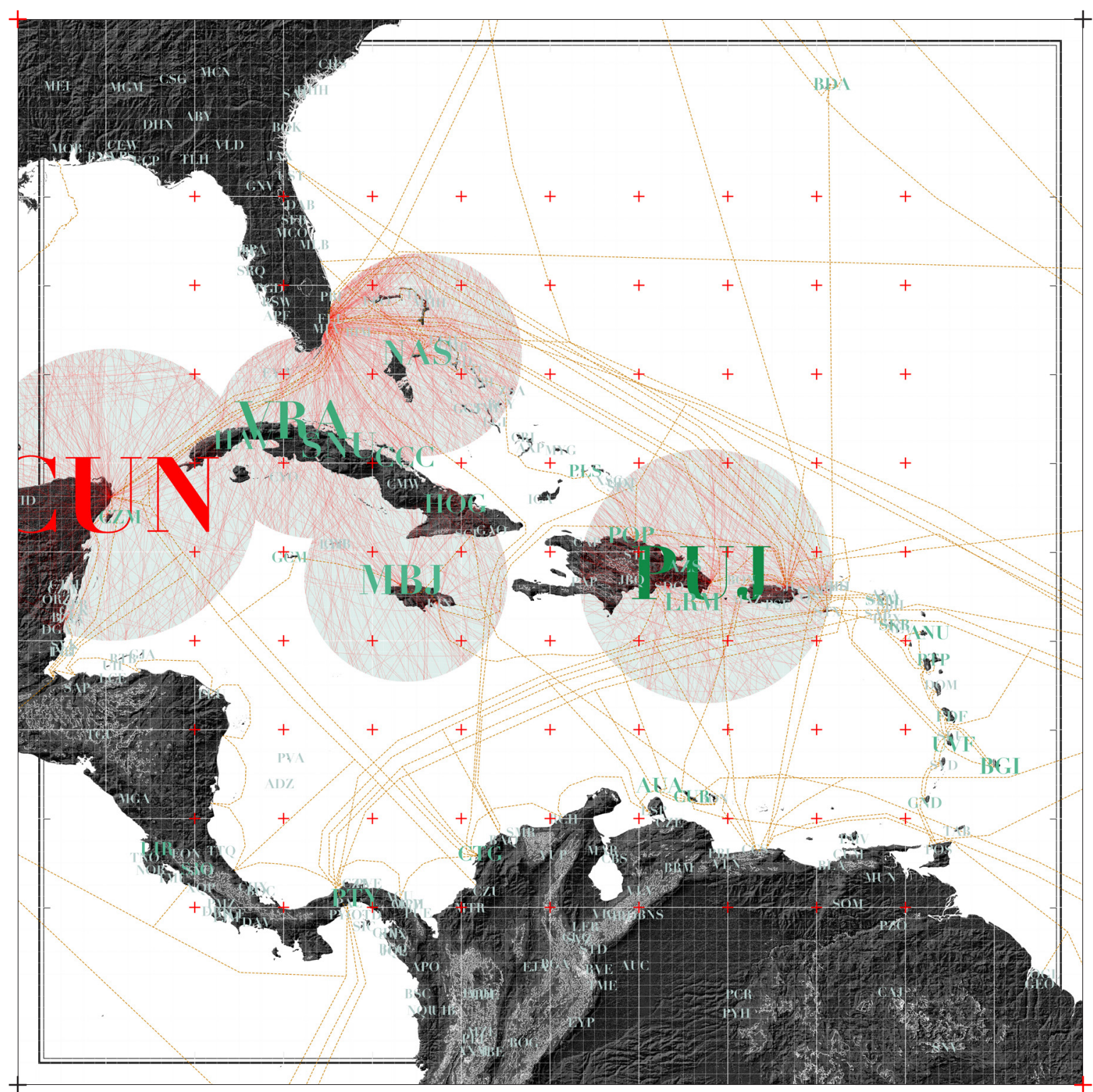

Figure 16: Caribbean

map illustrating access

to all-inclusive resort

rooms.

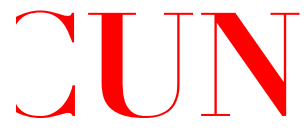

I

1000

$2000 \mathrm{~km}$

PUJ

VRA

MBJ

SNU

NAS 9190 Rooms 


\section{Anticipation}

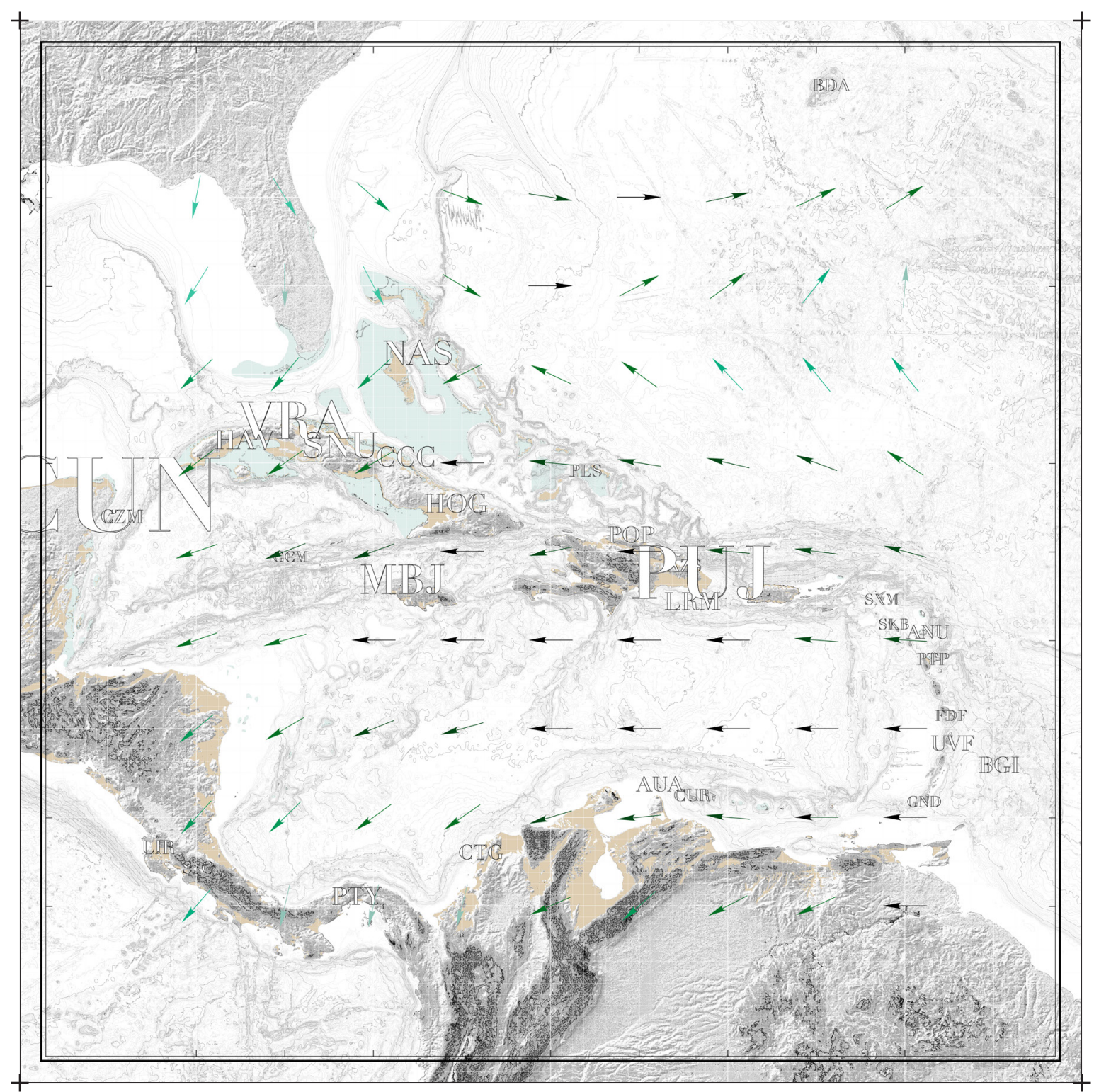

Figure 17: Caribbean map

illustrating airports and

coastal sand deposits.
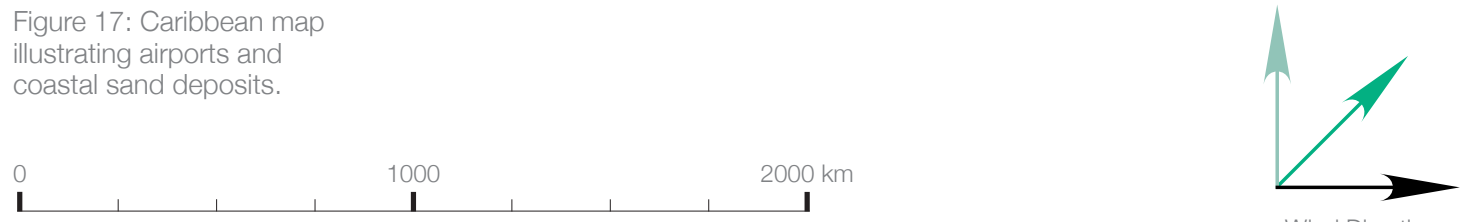

Wind Direction

Bahama Banks 


\section{Anticipation}
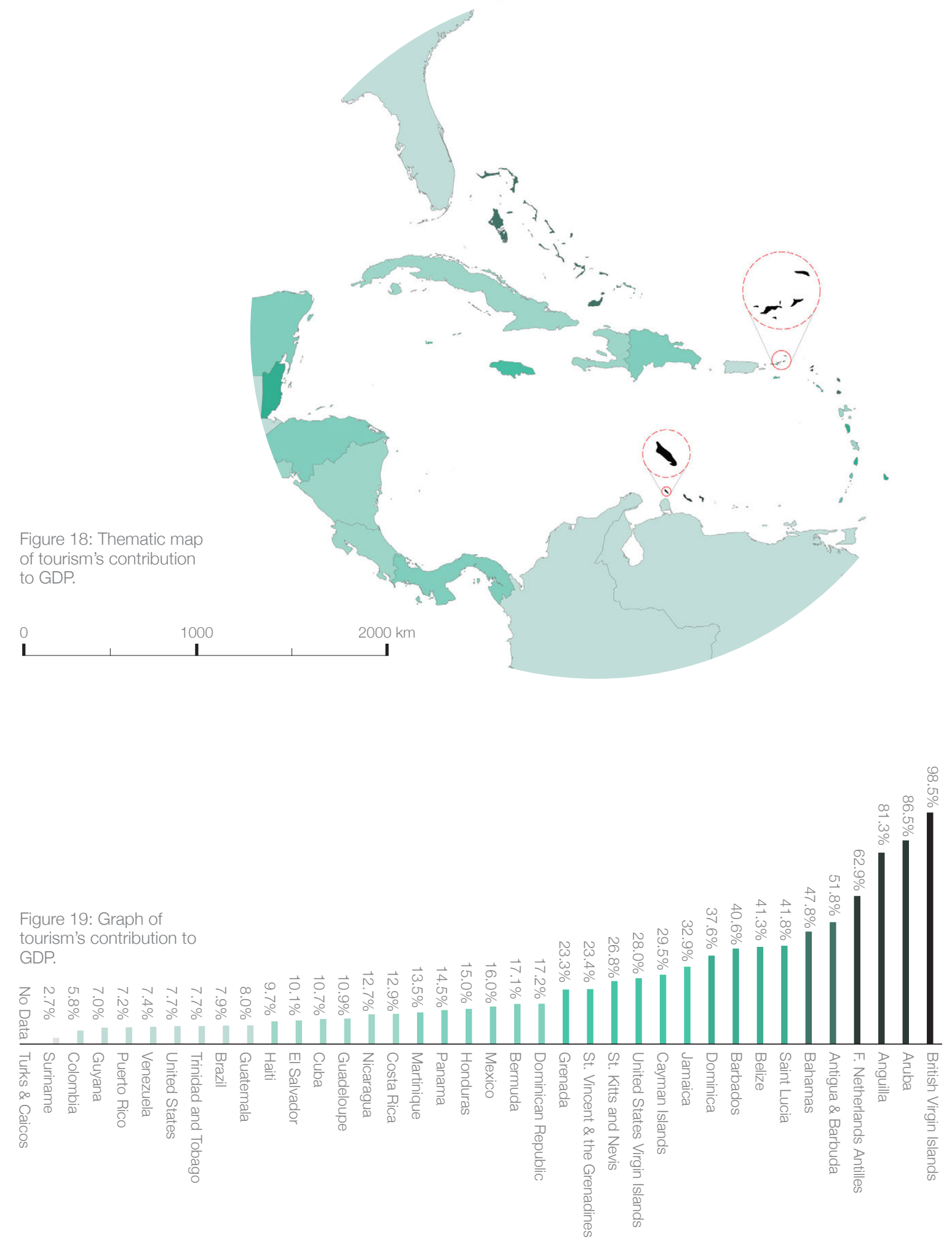


\section{Anticipation}

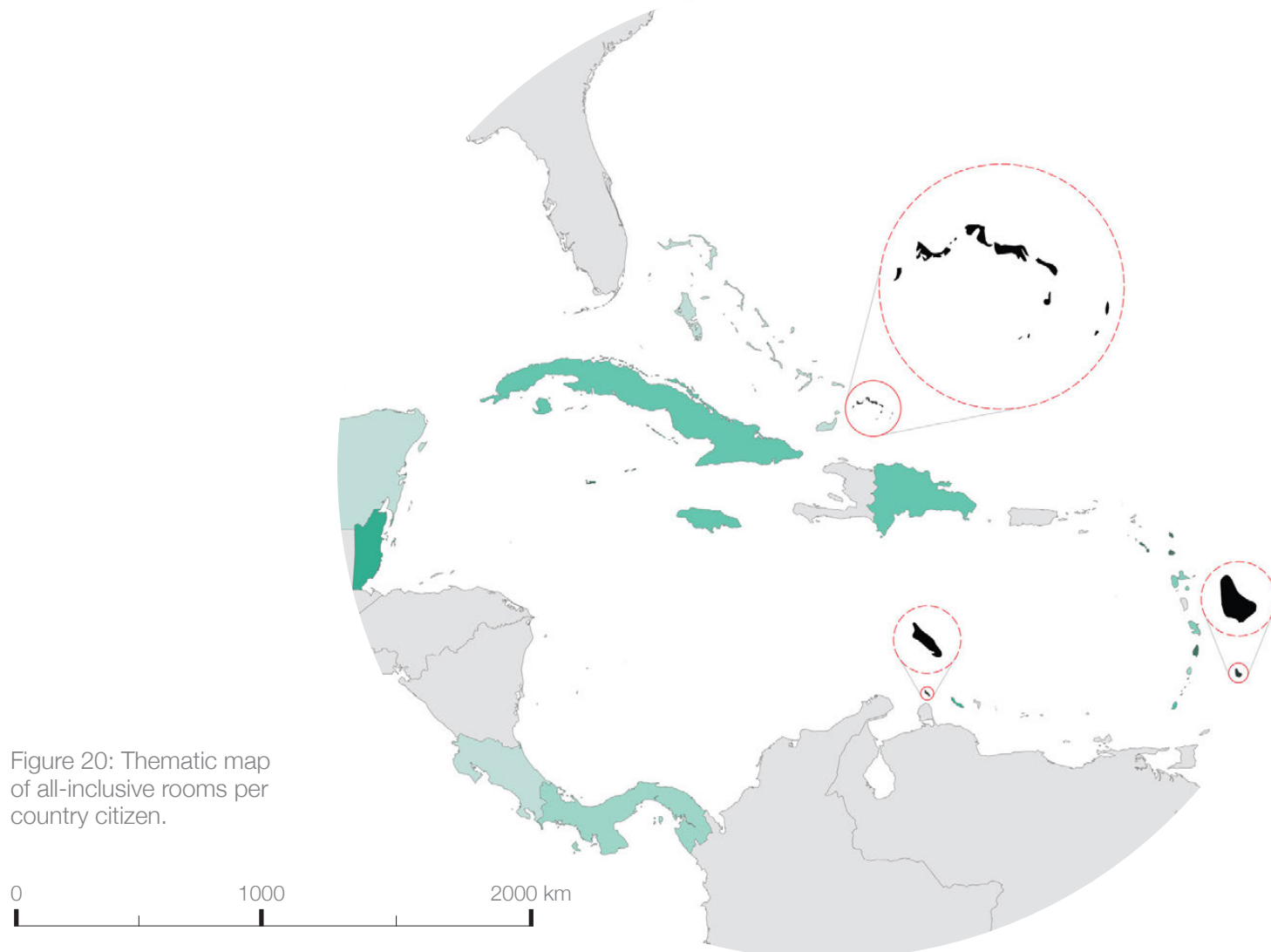

Figure 21: Graph of all-inclusive rooms per country citizen.

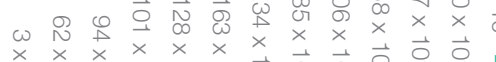

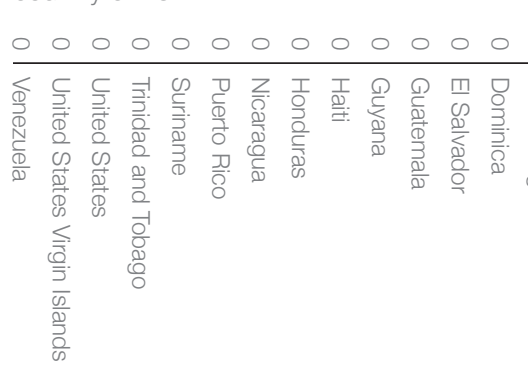

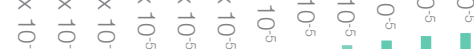


66 Note, these areas can all be classified as 'depositional landscapes' since their coastal landforms are created through the gradual deposition of sediment by ocean waves. These landscapes include bars, spits and cays.

67 Based on resort data in the Air Canada

Vacations catalogue.

68 Since Americans are not permitted to travel to

Cuba as tourists.

69 Turks and

Caicos contains a

large population of

undocumented Haitian

migrants. These

individuals are often

employed by the

hospitality industry. See

Sheller, Infrastructures,

1386-403.

70 As per the 2012

census. https://

en.wikipedia.org/wiki/

Providenciales\#cite_note-

2

Figure 22: Key plan noting three regions of interest:

A) Cancun (Mexico);

B) Varadero (Cuba); and

C) Providenciales

(Turks and Caicos).

1000
Based on the prior mapping exercises, three areas of interest were selected to be further studied at the regional scale. These areas are Cancun (Mexico), Varadero (Cuba), and Providenciales (Turks and Caicos). These areas are all touristically developed, yet strongly differ in their urban contexts and landscape configurations. ${ }^{66}$

- Cancun was selected because it is the most developed ${ }^{67}$ all-inclusive resort region in the greater Caribbean. Resorts are densely constructed along a $\sim \mathrm{I} 2 \mathrm{~km}$ sand bar.

- Varadero was selected because it is the third most developed allinclusive resort region, yet notably caters to a Canadian tourist market. ${ }^{68}$ Resorts are concentrated along a $\sim 20 \mathrm{~km}$ spit.

- Providenciales, the most populous island in Turks and Caicos, was selected because it ranks exceptionally high in its ratio of local residents to number of all-inclusive resort rooms. Grace Bay contains many large all-inclusive resorts, despite the island only having a permanent [and documented] ${ }^{69}$ population of 23769 people..$^{70}$

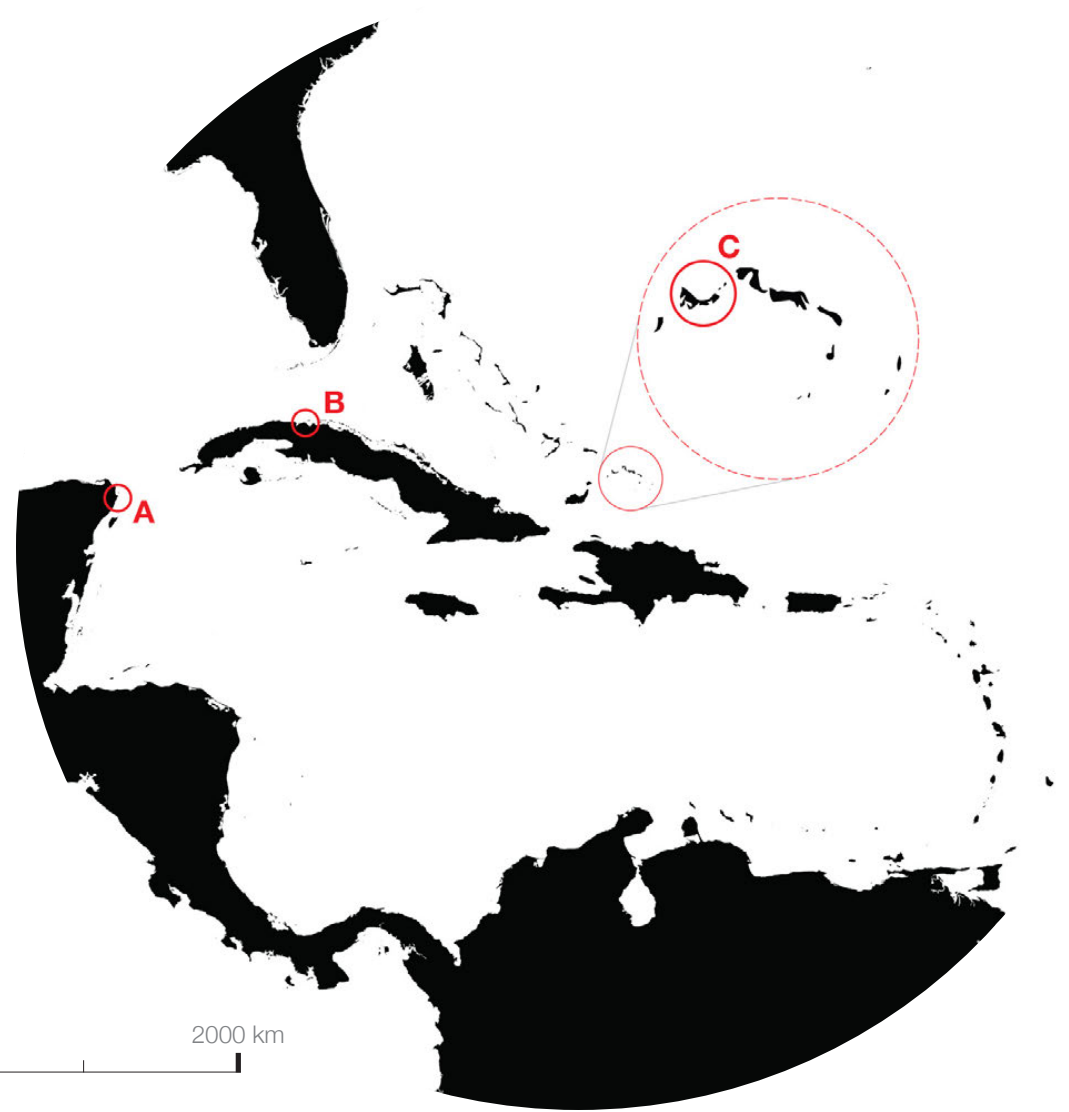




\section{Anticipation}

Figure 23: Satellite image of Cancun (Mexico).

Figure 24: Satellite image of Varadero (Cuba).

Figure 25: Satellite image of Providenciales (Turks and Caicos).
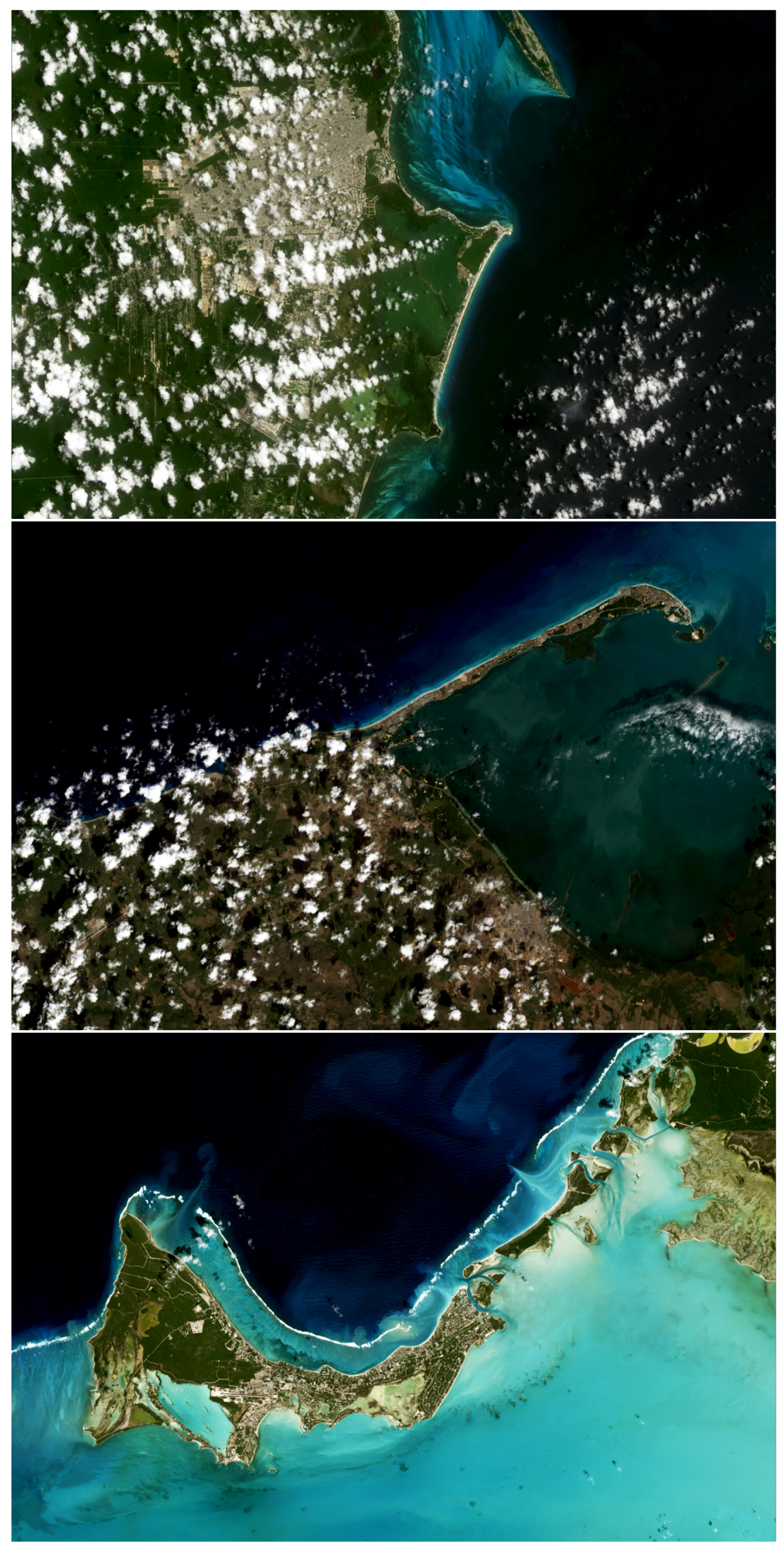
When merely a generic fantasy, imaginaries of tropical paradise remain largely intangible; however, these may be mobilized through a variety of physical conduits. ${ }^{71}$ This section highlights the infrastructural circuits and site configurations that spatially fabricate tropical paradise.

Tracing shared proximities across three zones of interest, this section utilizes terrain models and aerial photography to suggest a regional pattern of suburban sprawl. Translated into a series of analytical drawings, this section investigates how concentrations of all-inclusive development may function as a speculative suburban domain at a regional scale. Despite widely varying site configurations, all three areas of interest demonstrate efficient connections between local airports and beaches, while achieving relative isolation from adjacent urban centres. This seamless transition between airport and resort greatly influences one's perception of surrounding landscapes, reinforcing staged notions of tropical paradise.

Acting as a pivot point between project scales, this section bridges continental data relationships established in Section 2 with their physical expression at the scale of the site and body in Section 5 . 
72 At a scale of

1:30 000, each sectional slice was nominally flat.

DEMs were subsequently amplified $3 x$ in Cancun

and $10 x$ in Varadero to

accommodate for wood

depth and resin viscosity.
To systematically record the city-resort relationship across three varied site conditions, a $3.5 \mathrm{~km} \times 30 \mathrm{~km}$ sample area was captured across each region of interest. These linear samples were oriented so that each region's urban core, primary resort zone and major water boundaries could be bisected in a single section. Since the entire island of Providenciales closely resembles the narrow, sandy land masses of Cancun's bar and Varadero's spit, two samples were oriented vertically from this location.

Satellite photography was then used to illustrate each region's pattern of urban development. Images were exaggerated in contrast and inverted, allowing dark tones to indicate development intensity. Using amplified Digital Elevation Models, ${ }^{72}$ the samples were subsequently translated into I:30 ooo terrain models, fabricated out of CNC-milled ambrosia maple and clear resin. Through the subtraction of solid wood material and addition of liquid resin, the models are able to uniformly convey thresholds between land and shallow water across three distinct site conditions.

Each of the models were finished to the level of a commercial product, mimicking the indulgent content and glossy finish of the 2018/2019 'Sun' e-brochure. As a way of ironically capturing the superficial marketing of popular vacation destinations, the final topography models contain no depth or surface texture, instead seeming smooth, reflective and alluring. When presented during Colloquium II, building patterns were laid over the models as a thin film (see Figures 44 and 45) and correlated to full-colour satellite photos. The models were then radially translated into a closed circle, with the region's urban core placed at the midpoint. Figures 46 to 48 illustrate this concentric layout, annotating each resort zone as an offset ring. 
Isolation

Figure 26: Key plan of

Cancun (Mexico).

Figure 27: Key plan of varadero (Cuba).

Figure 28: Key plan of Providenciales

(Turks and Caicos).
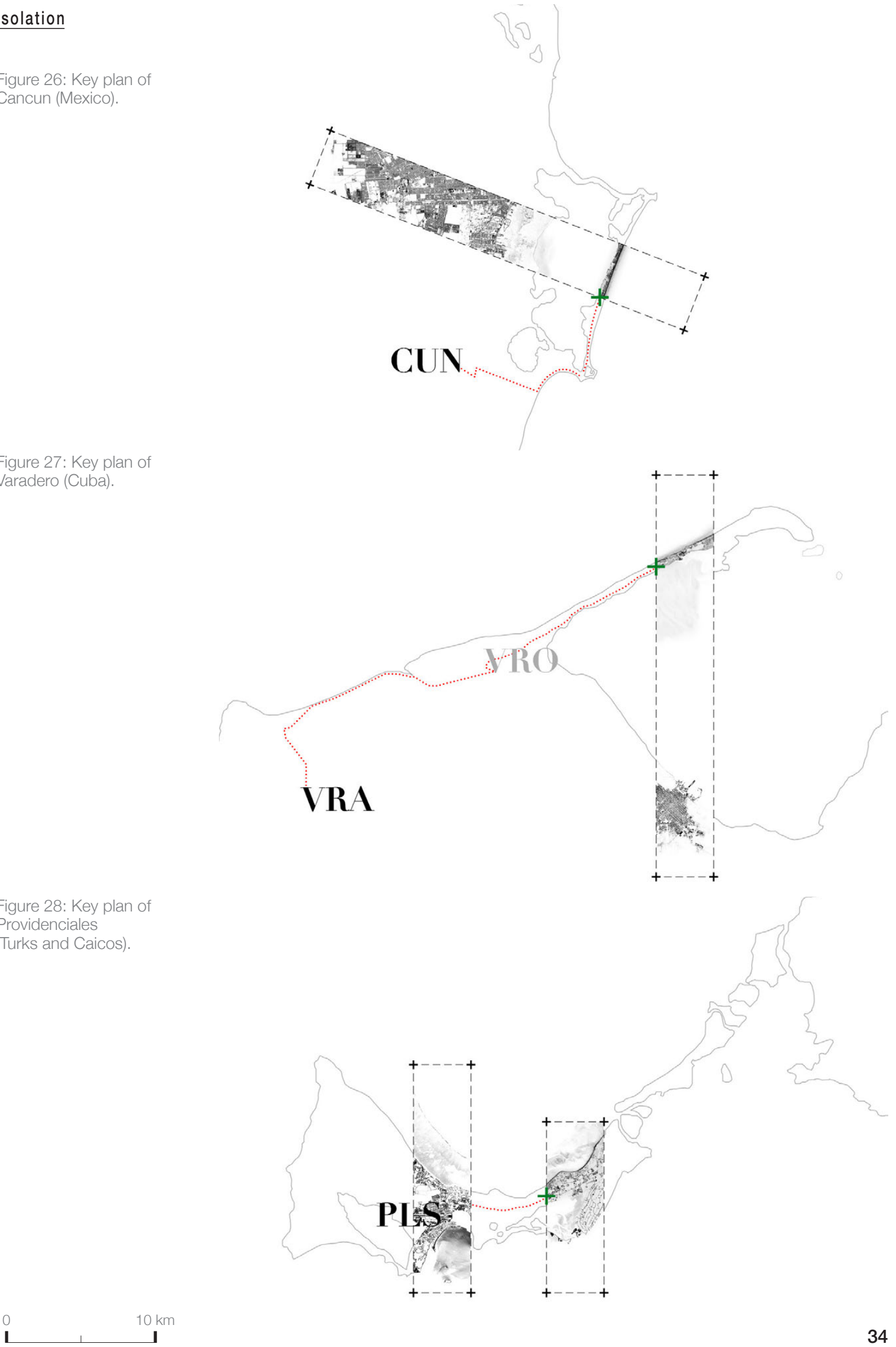

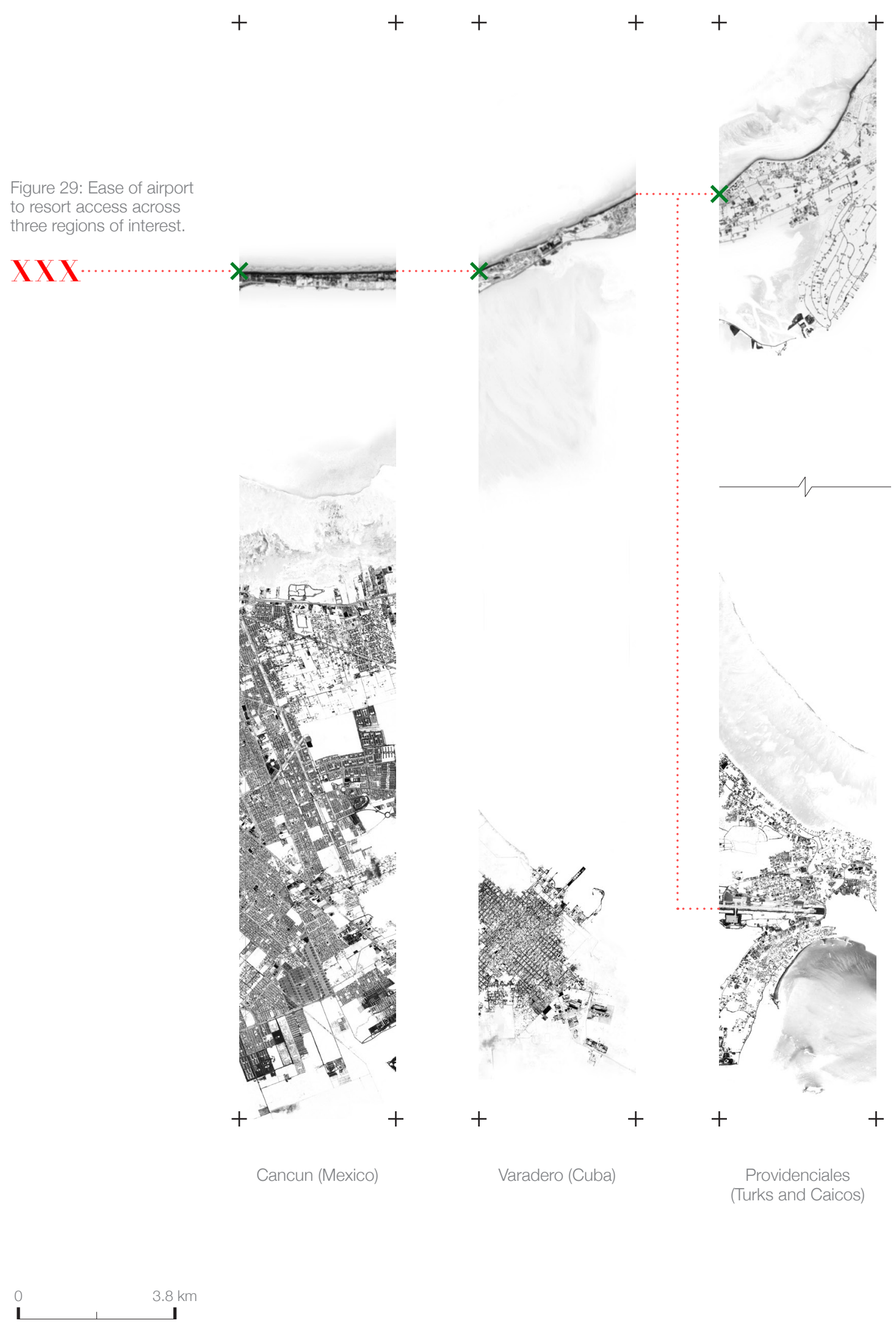
Figure 30: Regional slices translated to 1:30 000 terrain models.

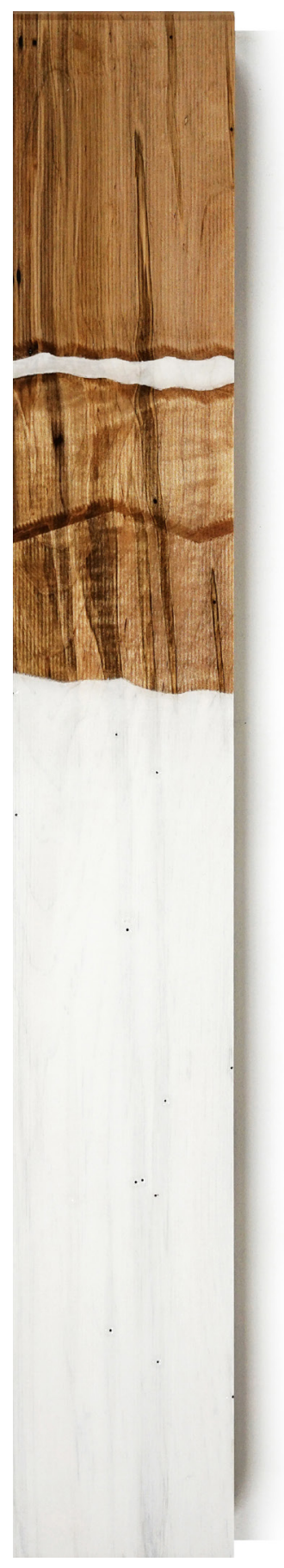

Cancun (Mexico)

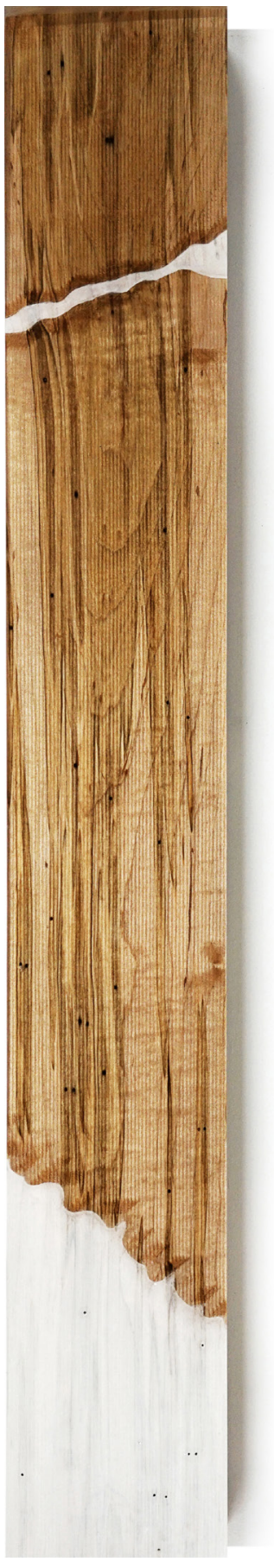

Varadero (Cuba)
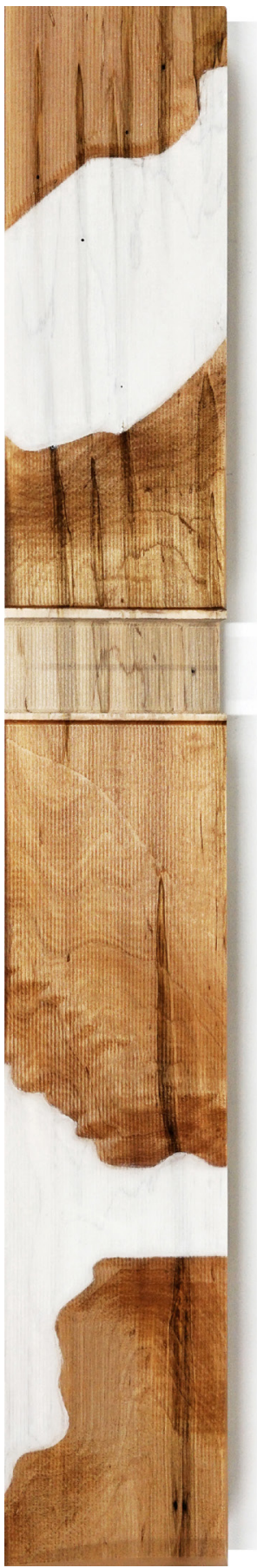

Providenciales (Turks and Caicos) 
Figure 31: 1:30 000 terrain models with acetate overlay.
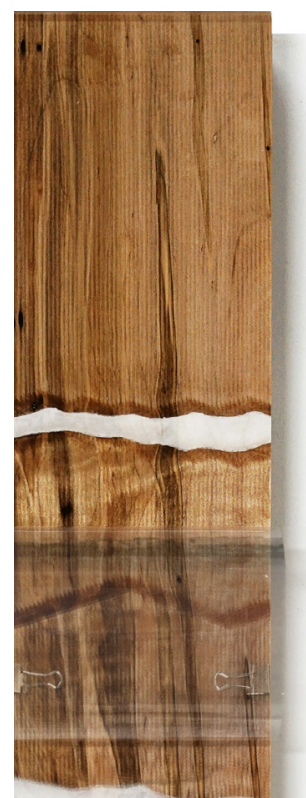

3

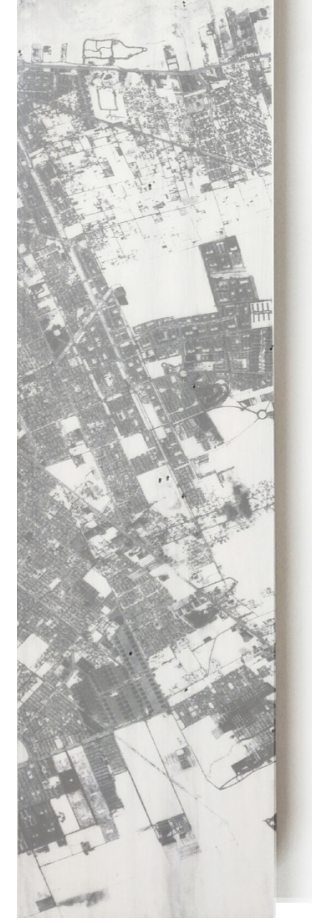

Cancun (Mexico)

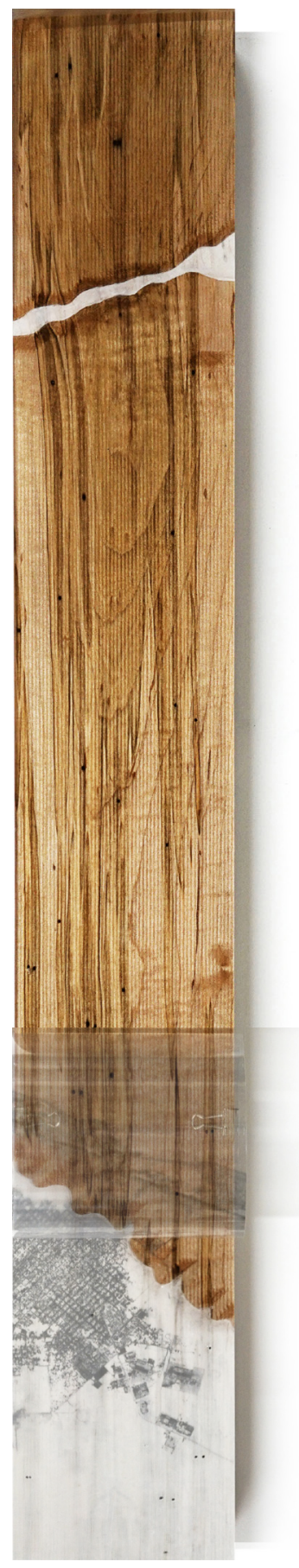

Varadero (Cuba)
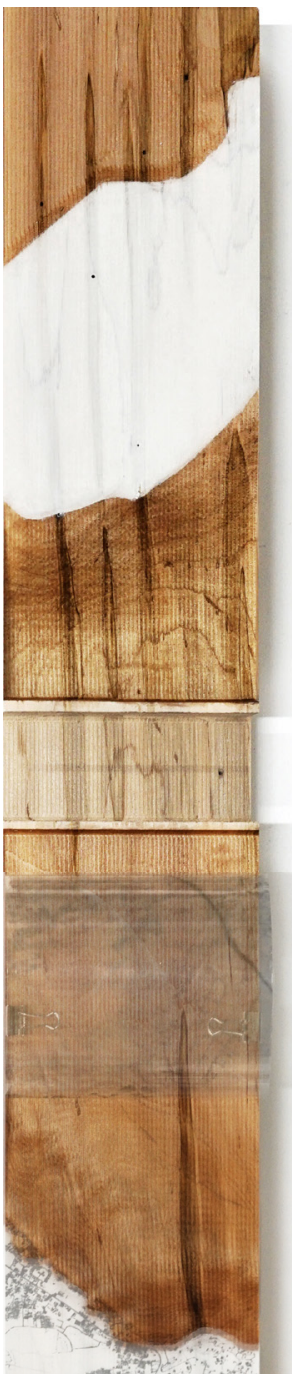

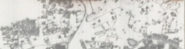
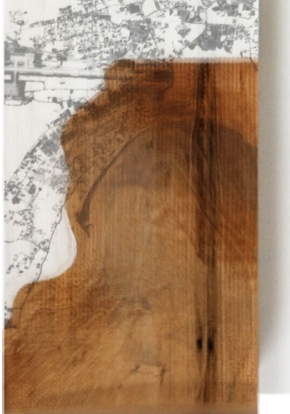

Providenciales

(Turks and Caicos) 
Isolation
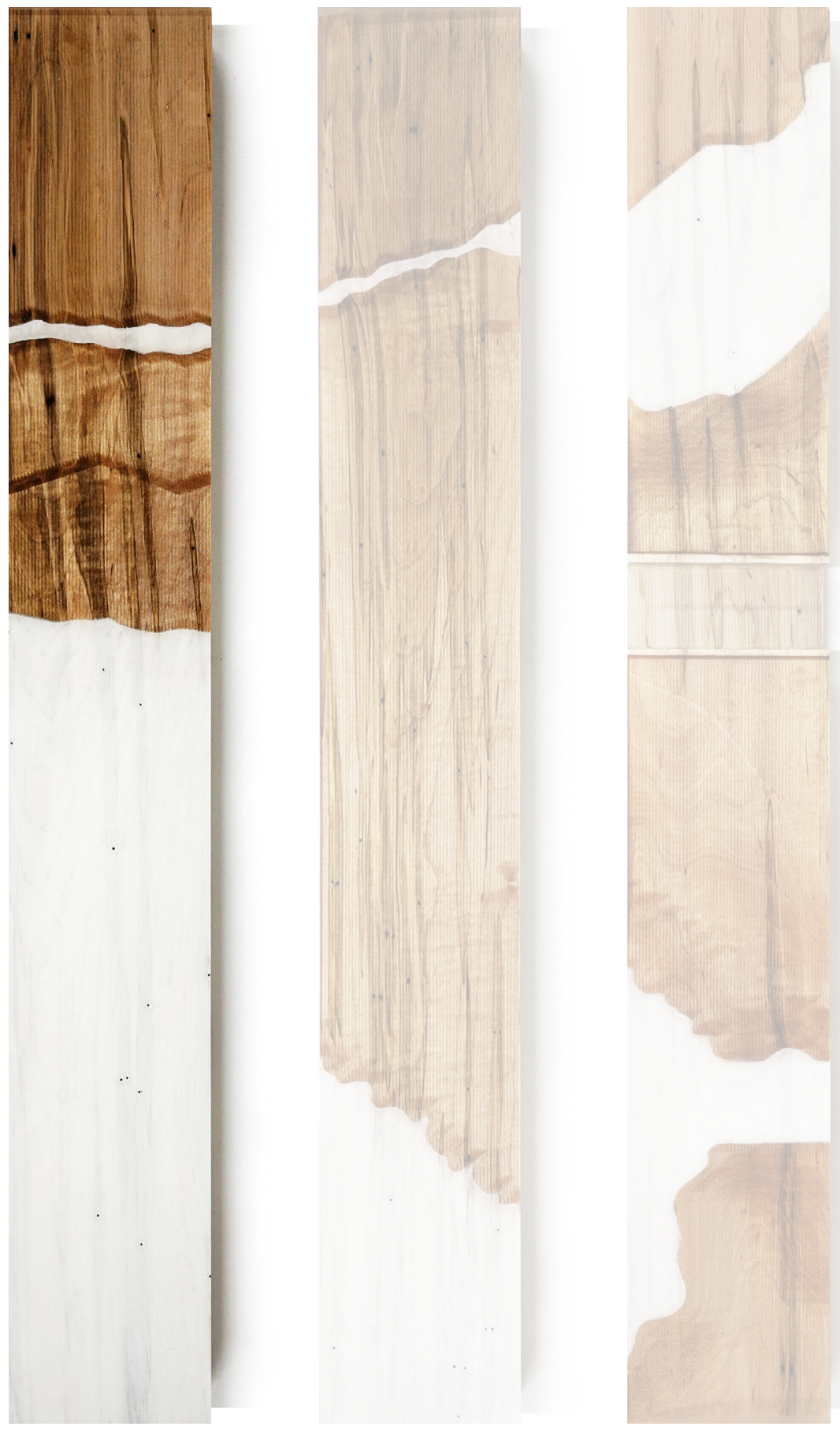

Cancun (Mexico)
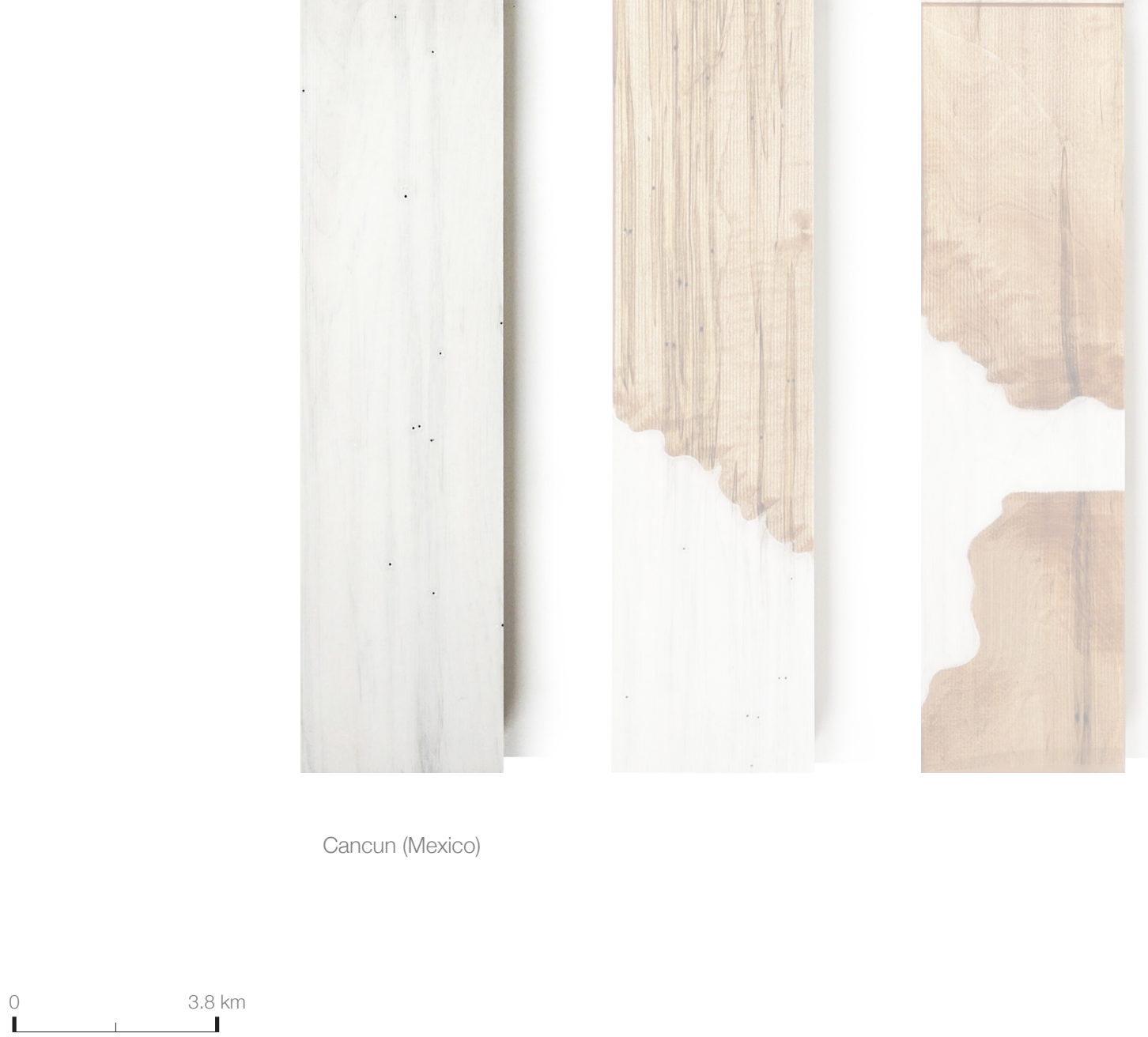
Isolation

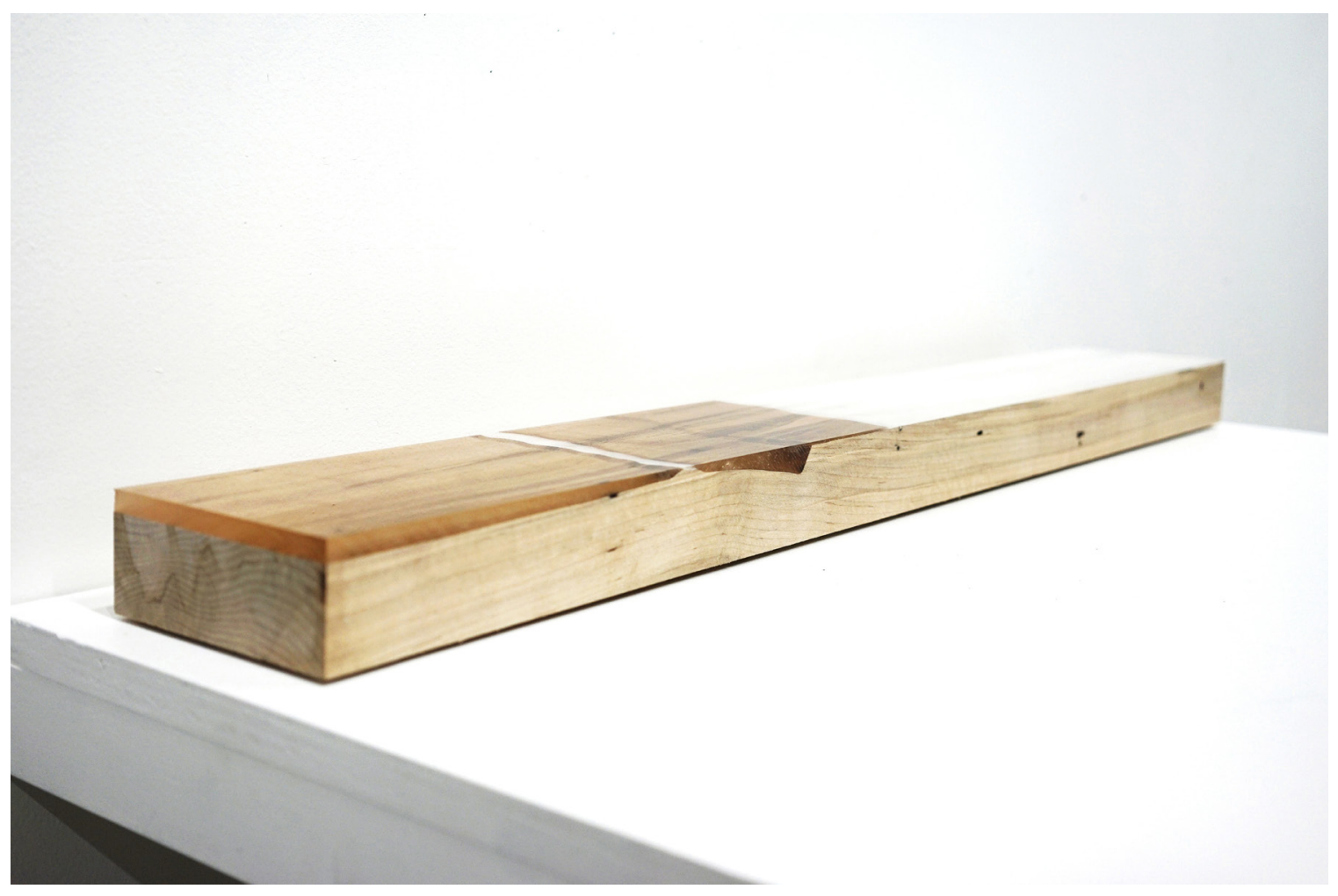

Figure 32 \& 33: Cancun terrain model details.

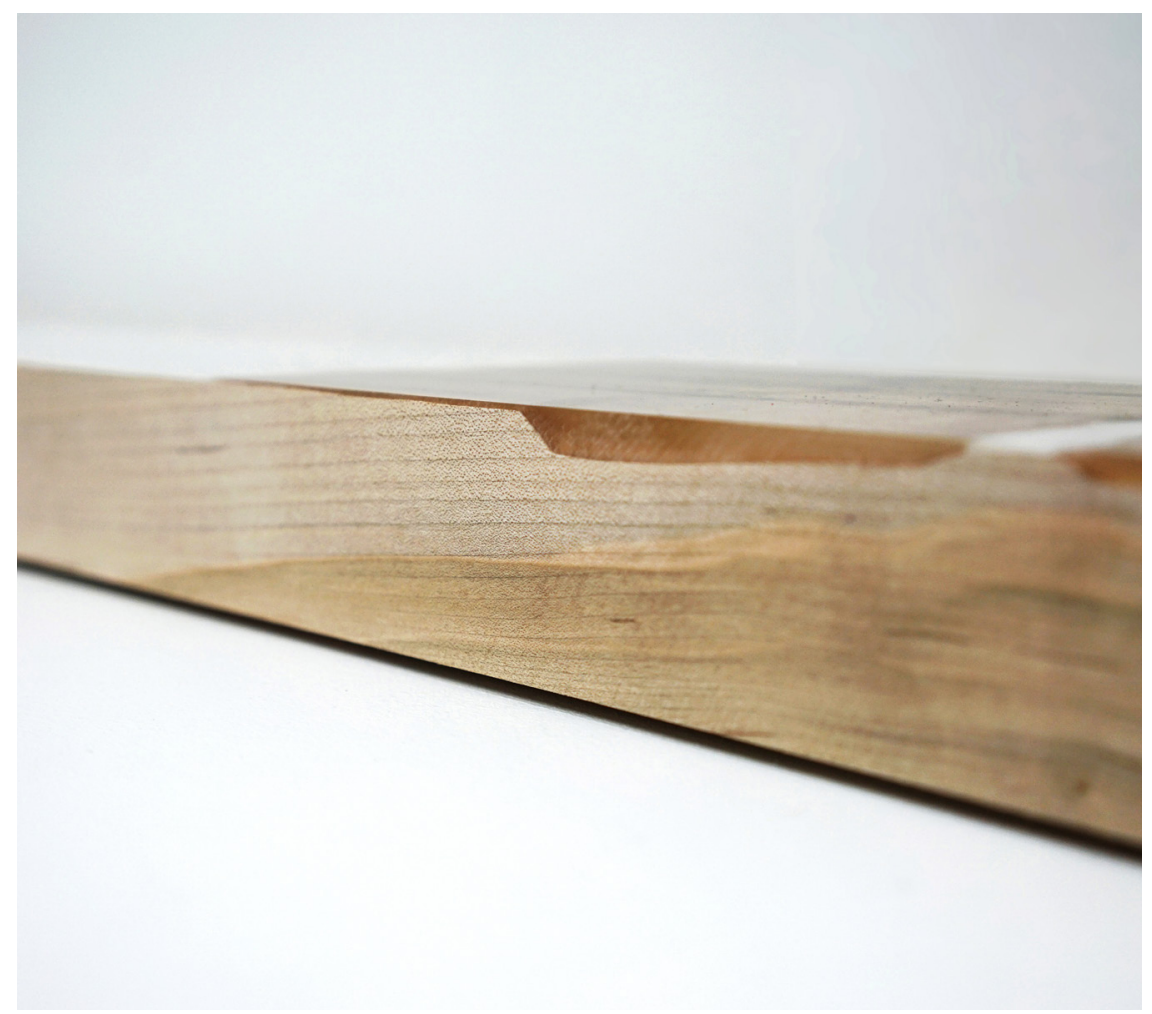


Isolation

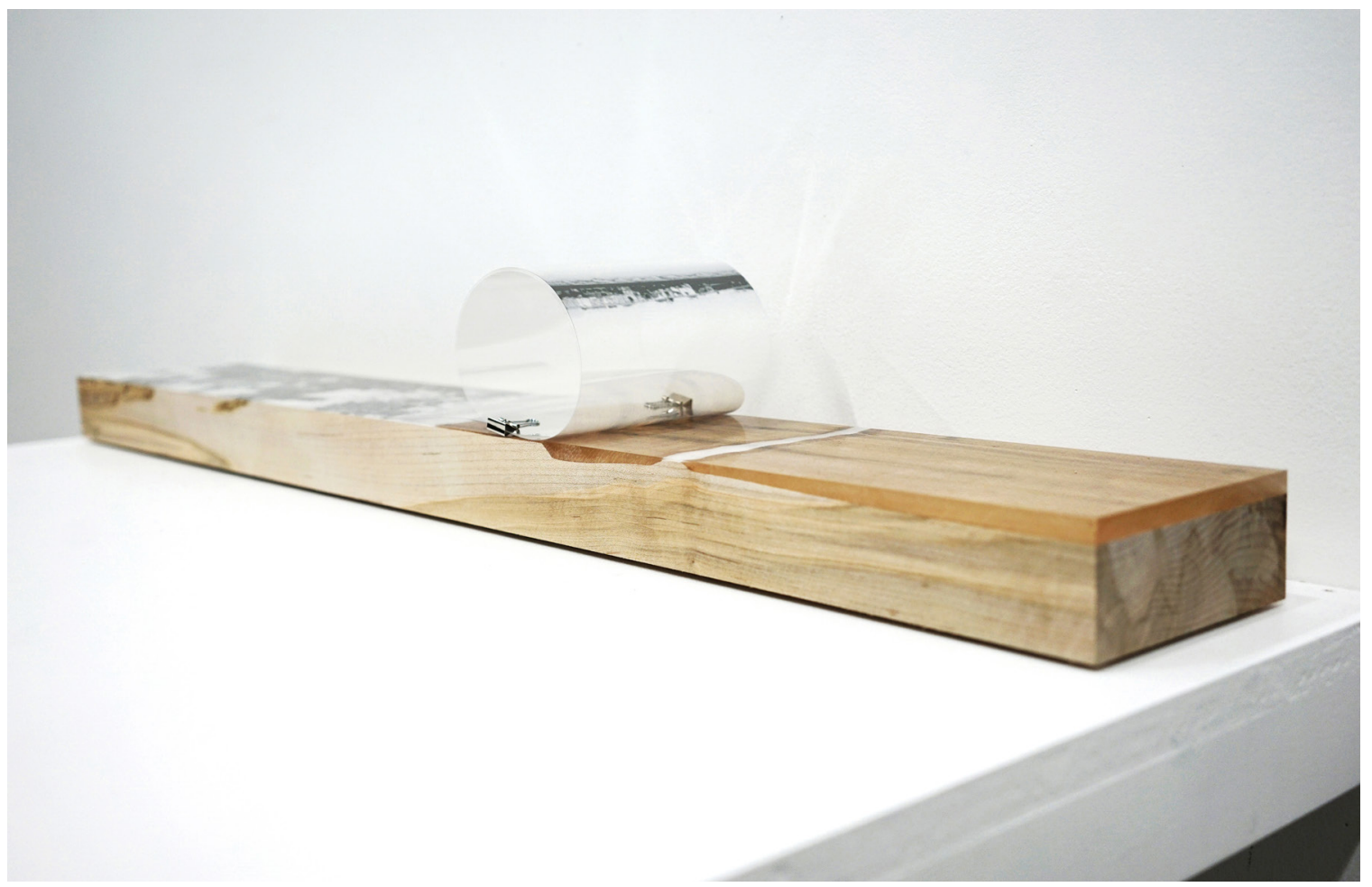

Figure 34 \& 35: Cancun

terrain model details.

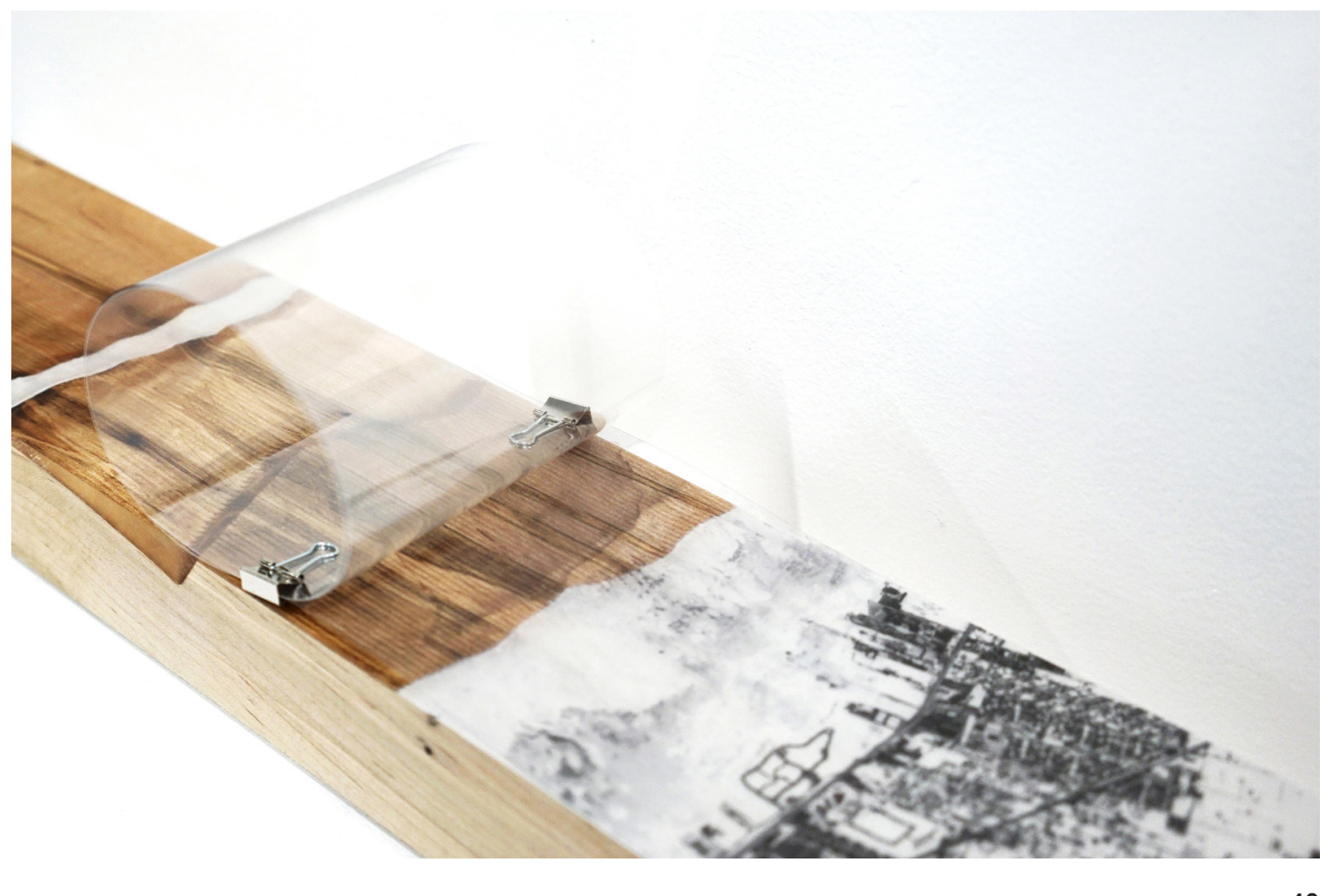


Isolation
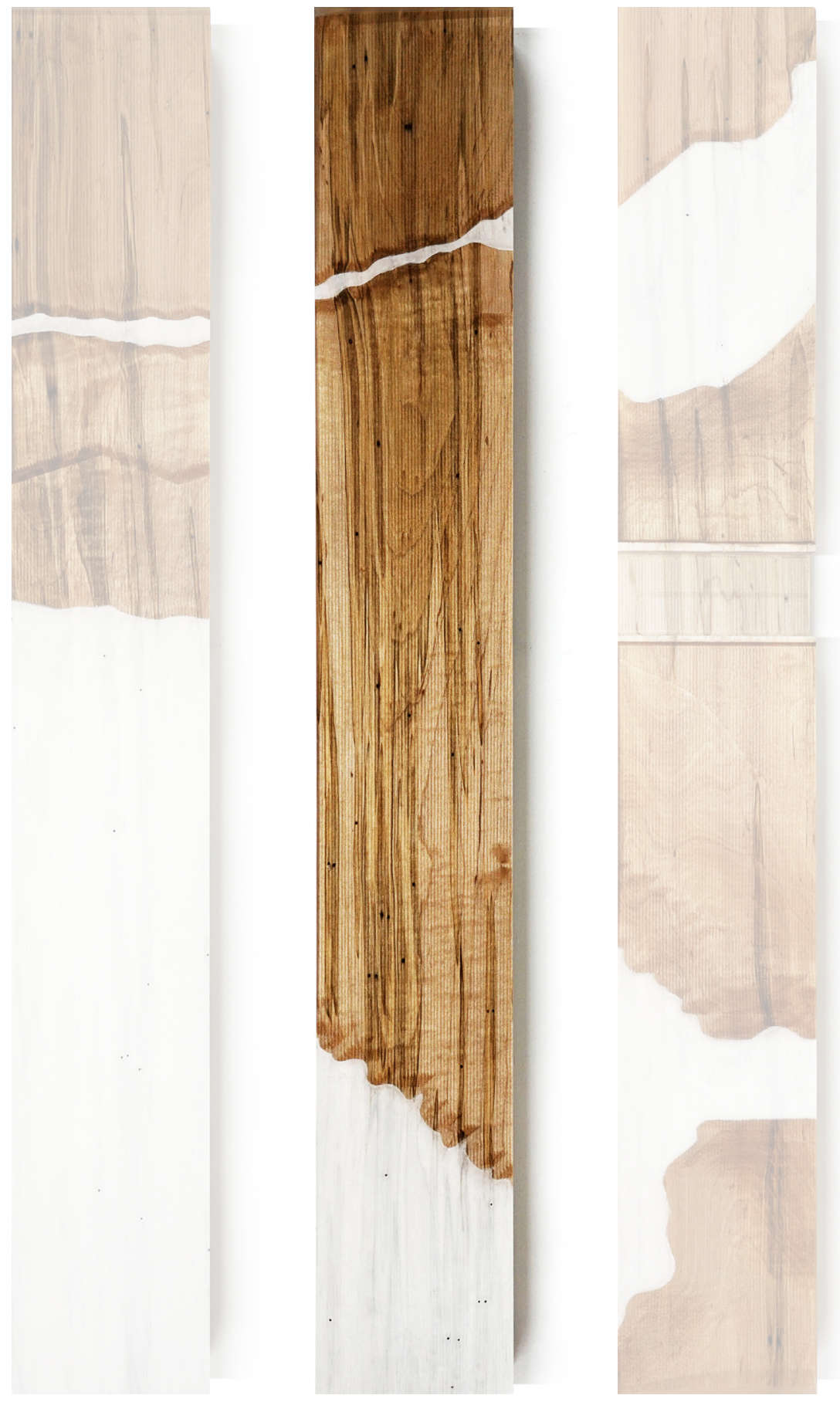
Isolation

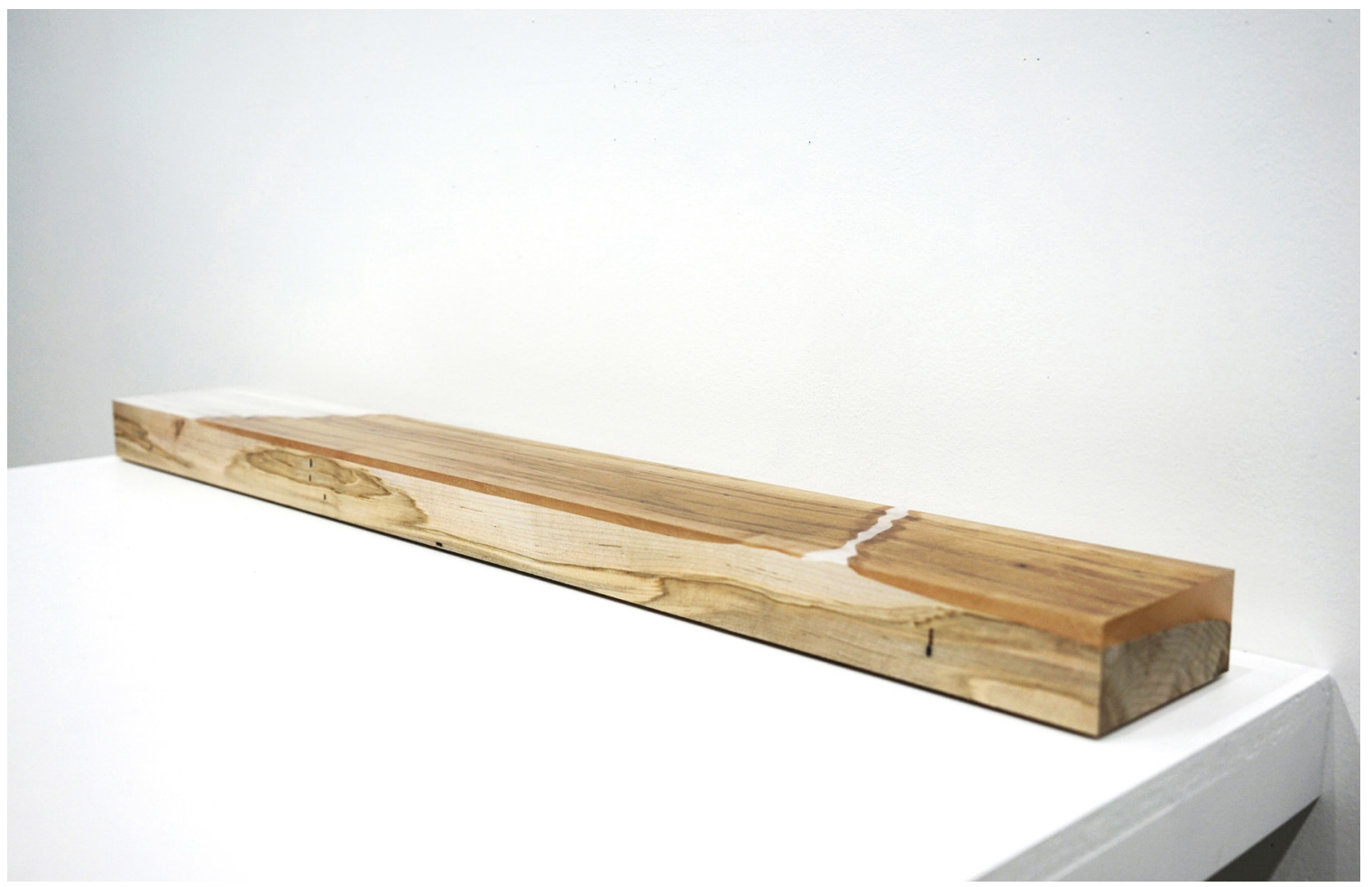

Figure 36 \& 37: Varadero

terrain model details.

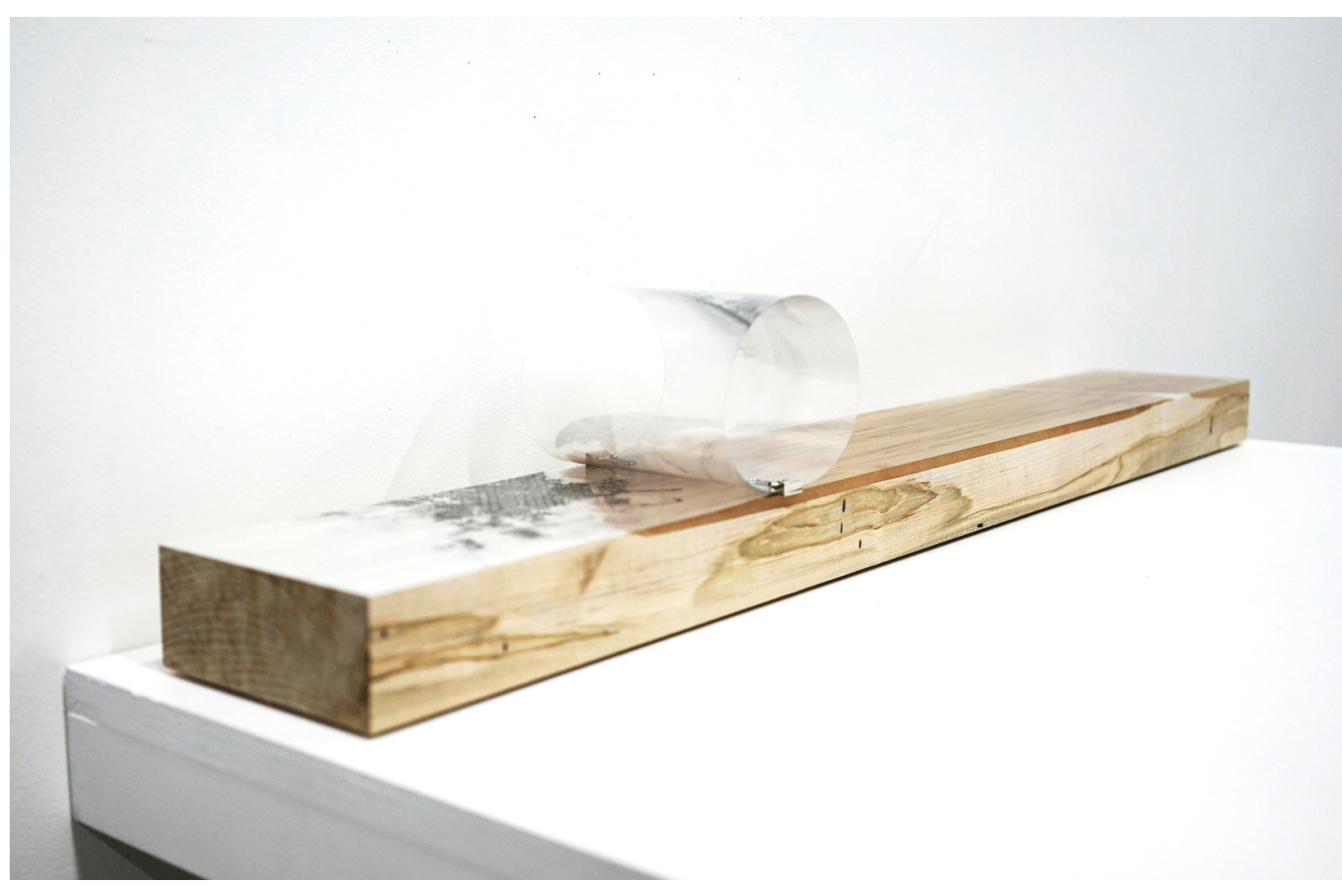


Isolation

Figure 38 \& 39: Varadero terrain model details.
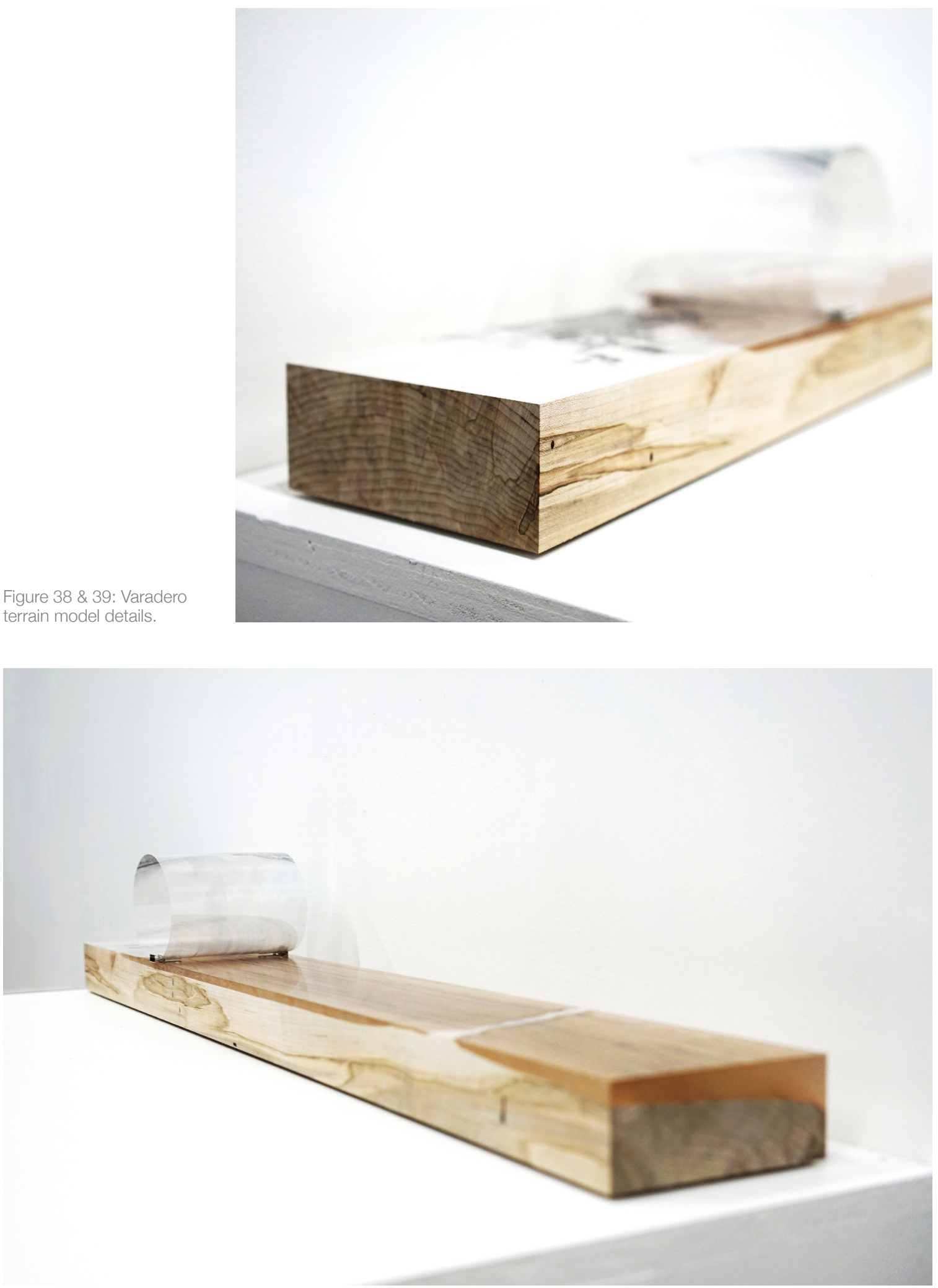
Isolation
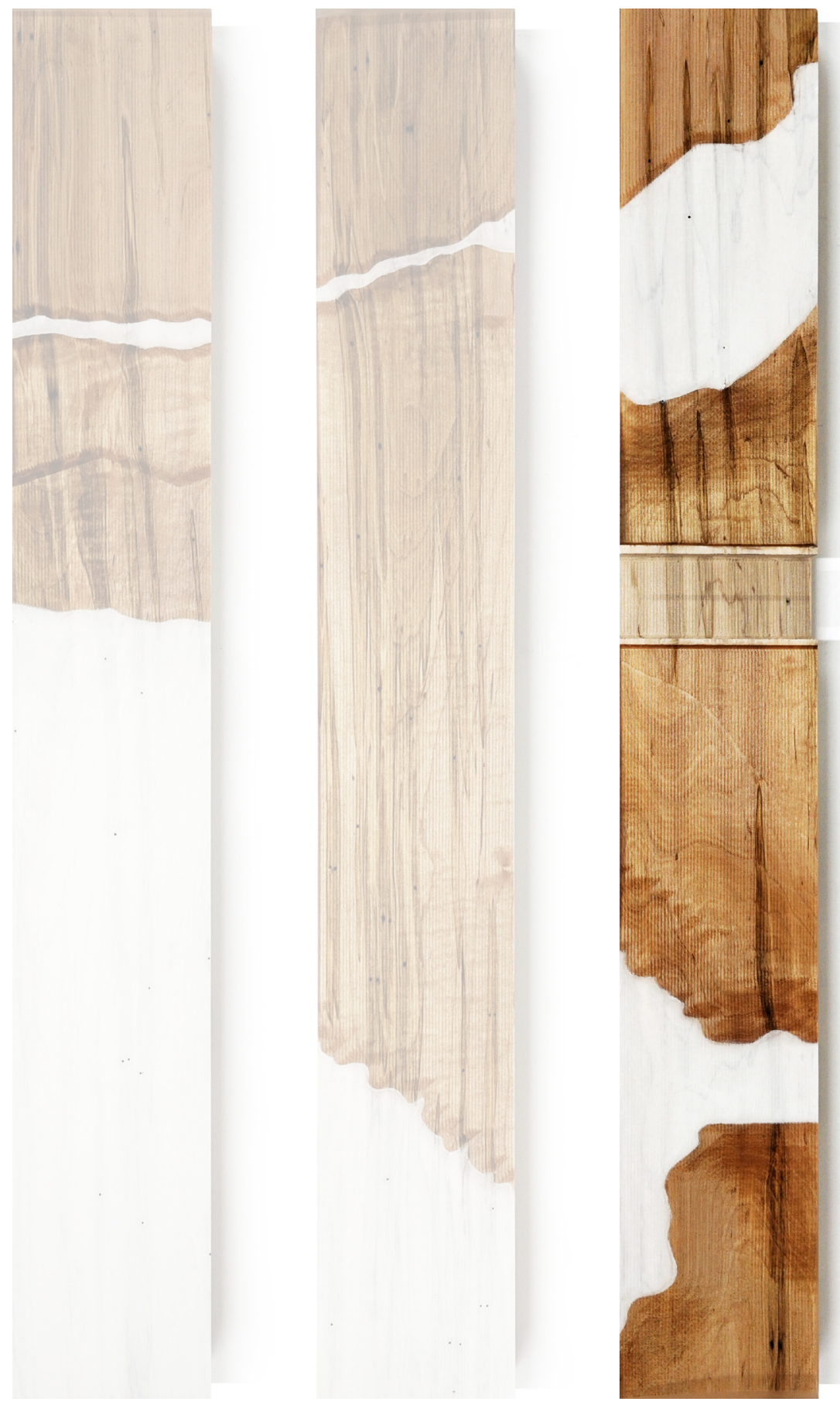

Providenciales

(Turks and Caicos)

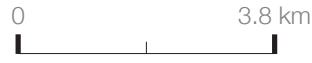


Isolation

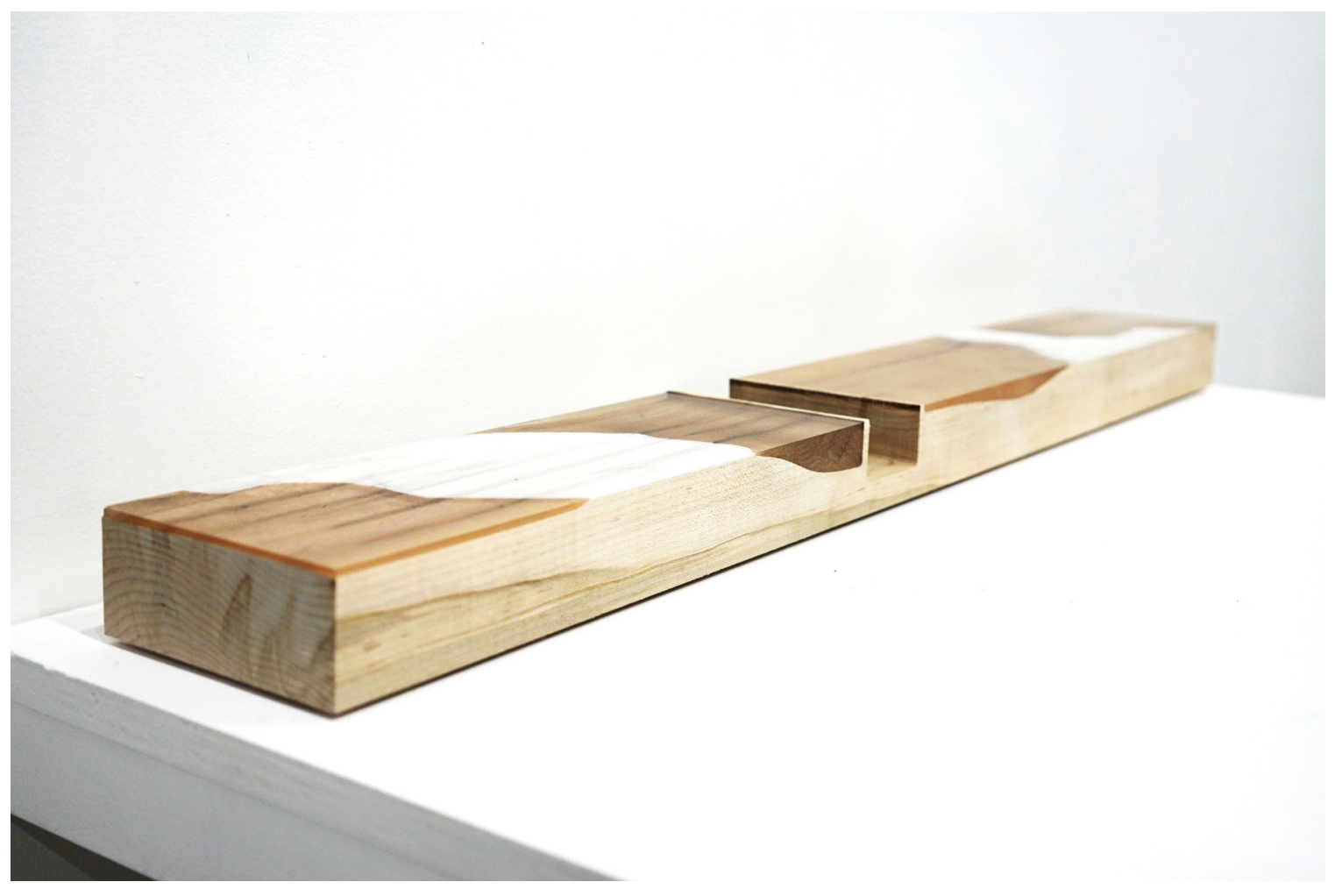

Figure 40 \& 41: Prov. terrain model details.

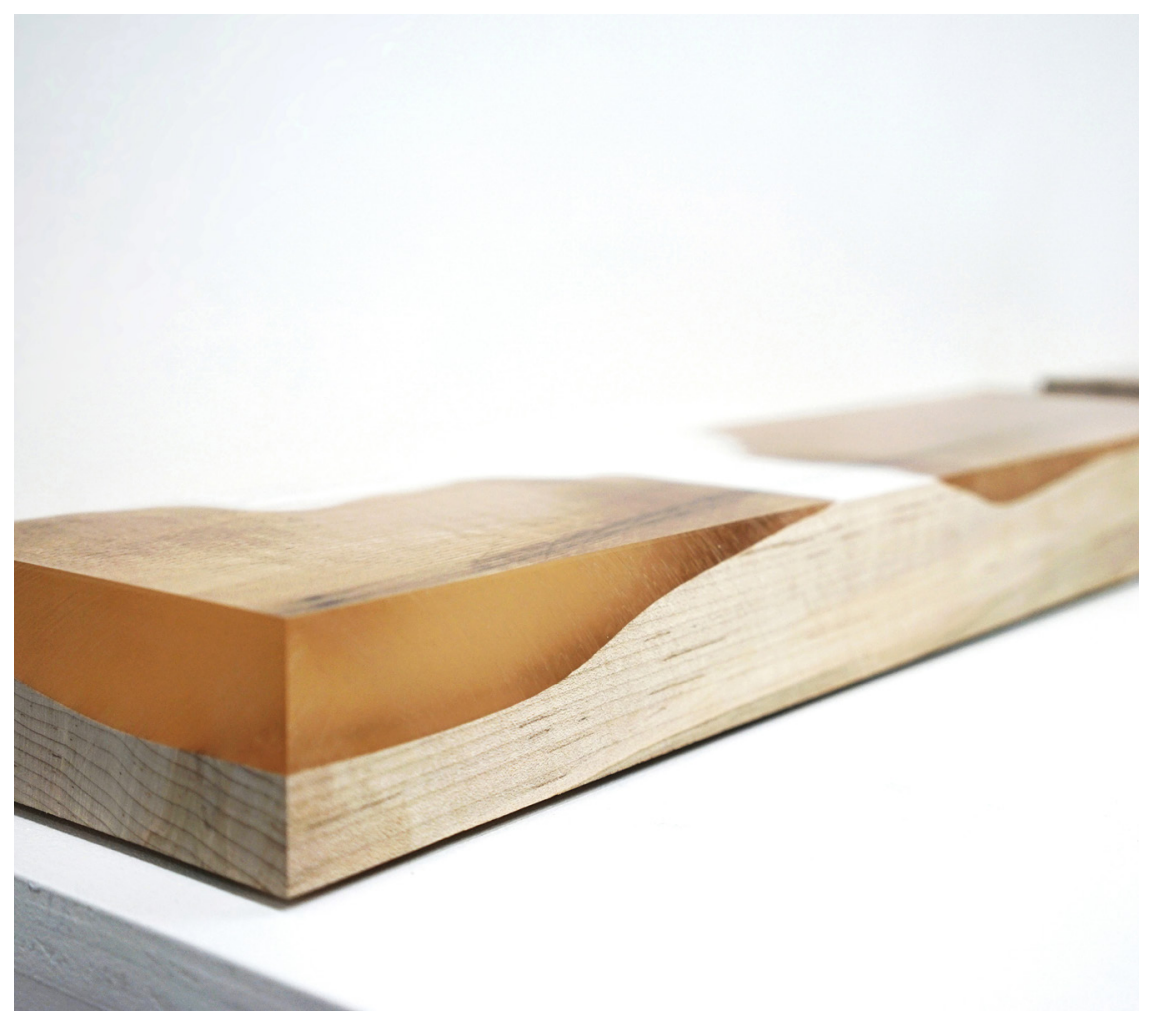


Isolation

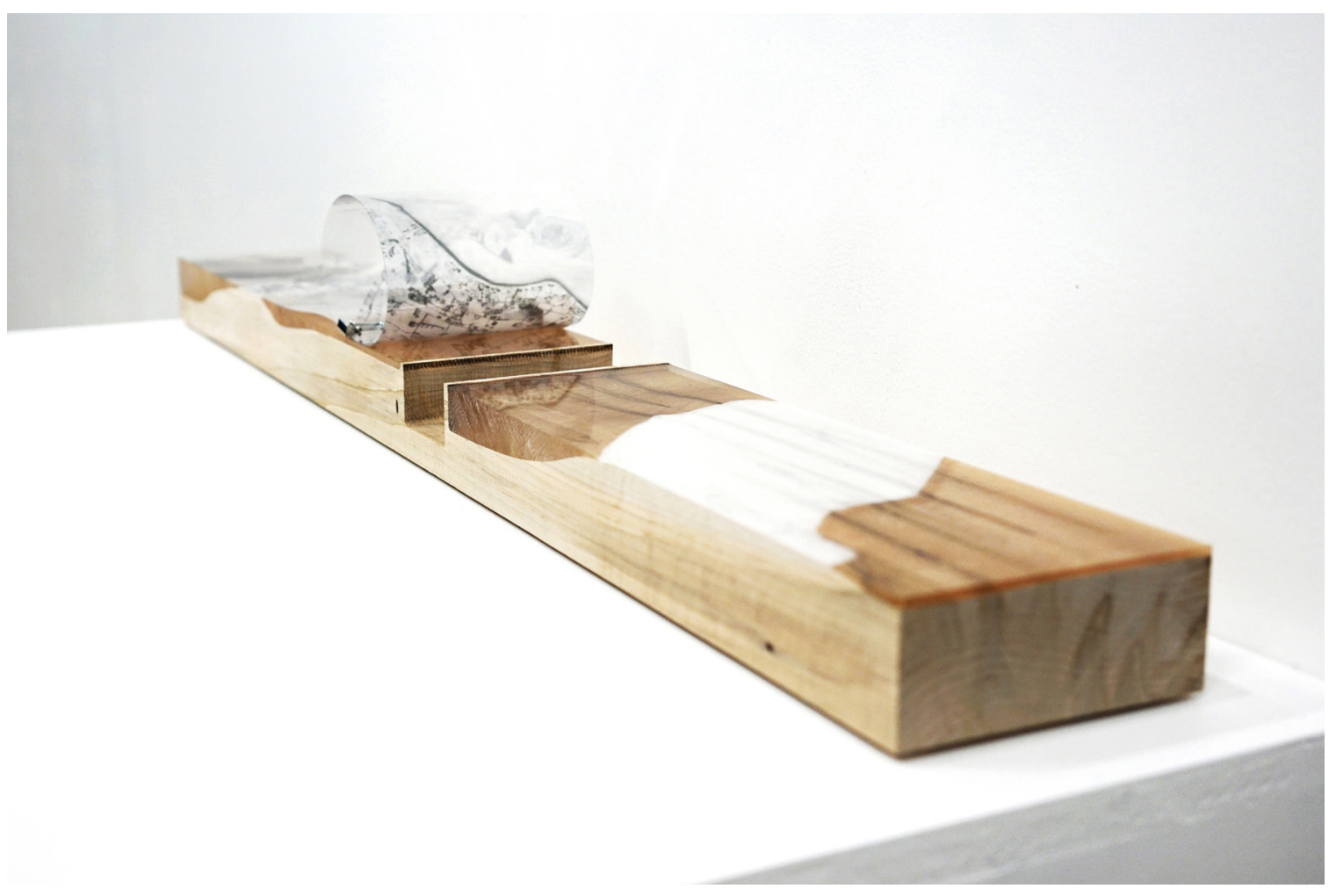

Figure 42 \& 43: Prov. terrain model details.

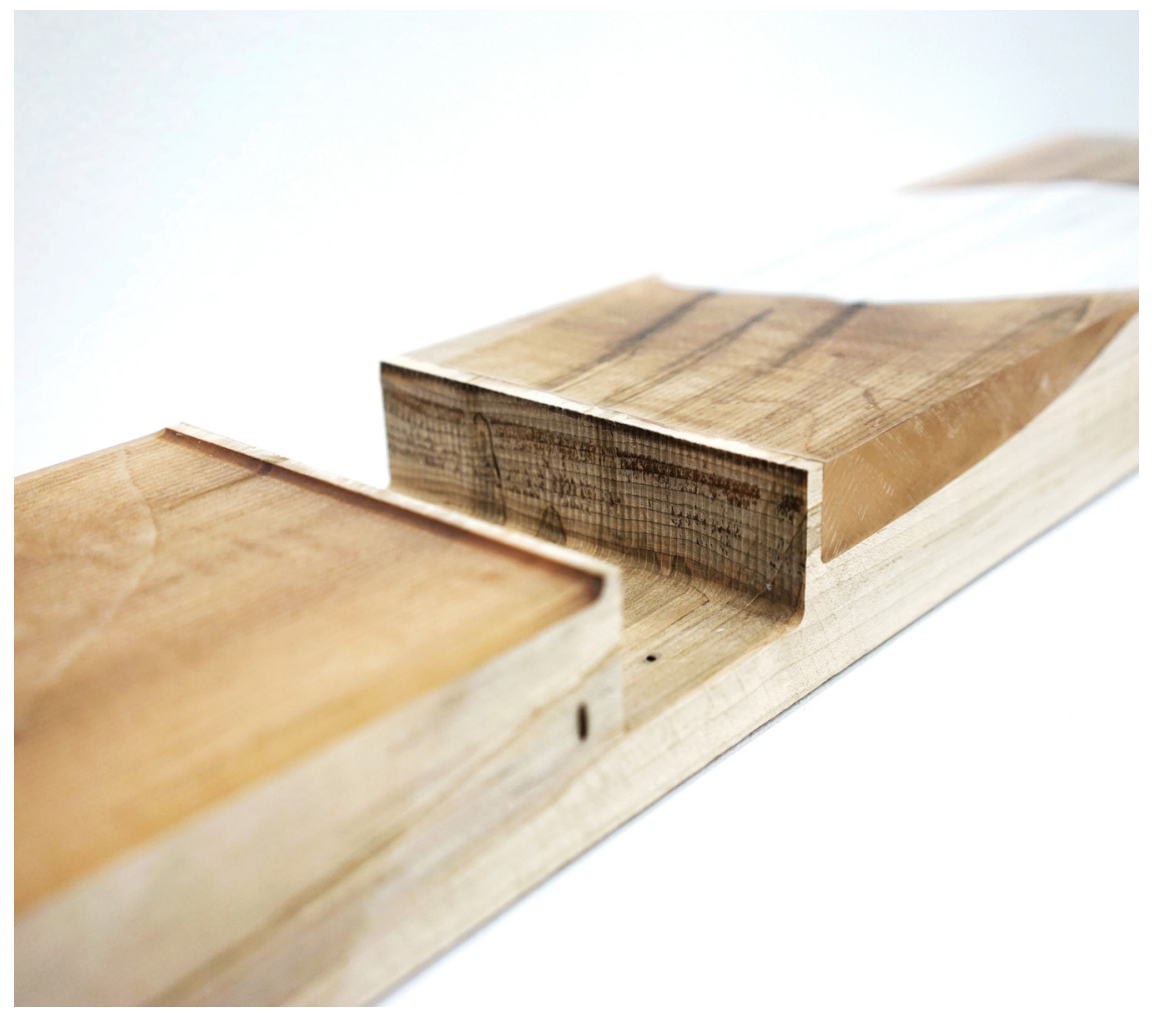




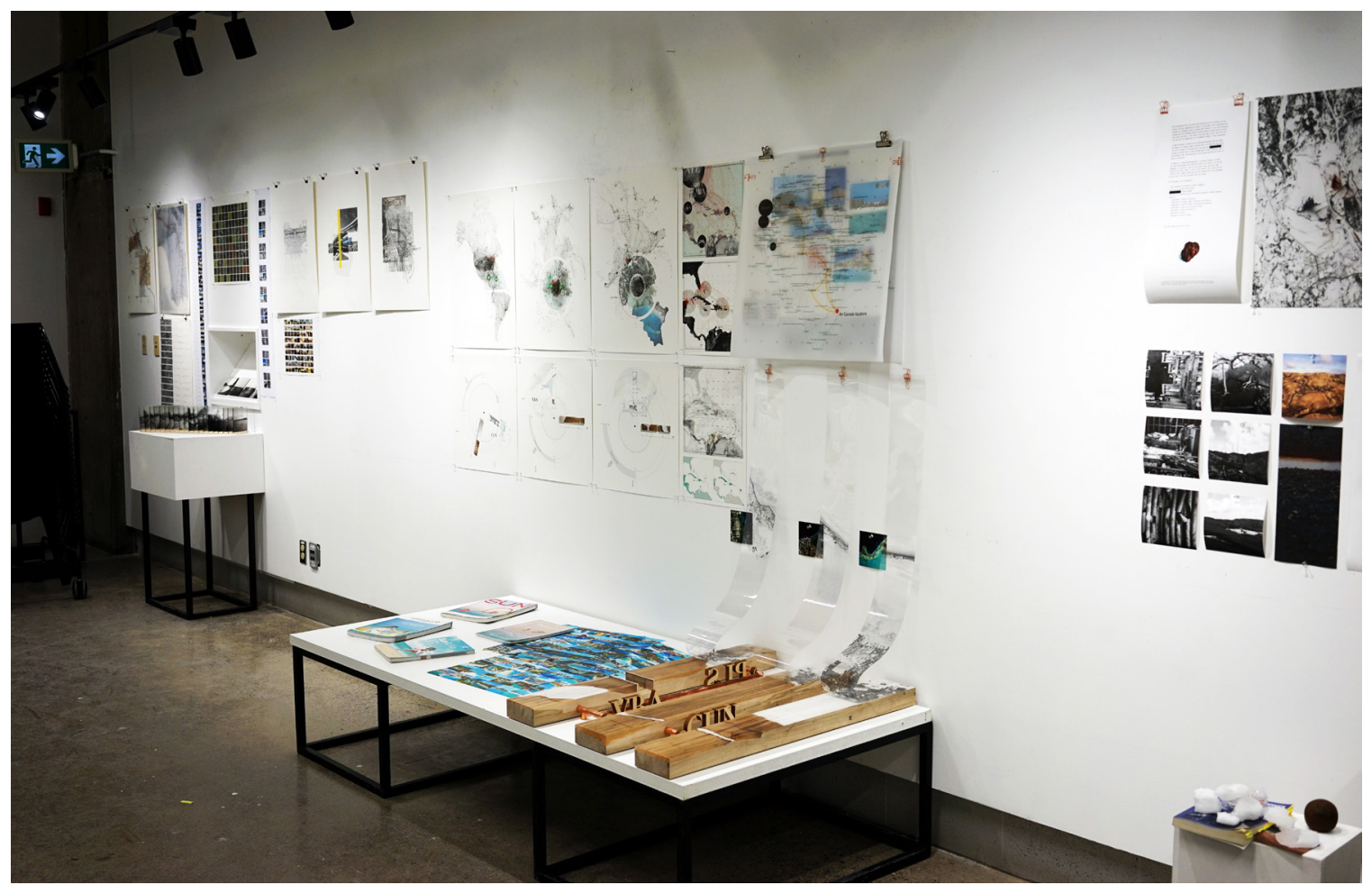

Figure 44 \& 45:

Colloquium II material.

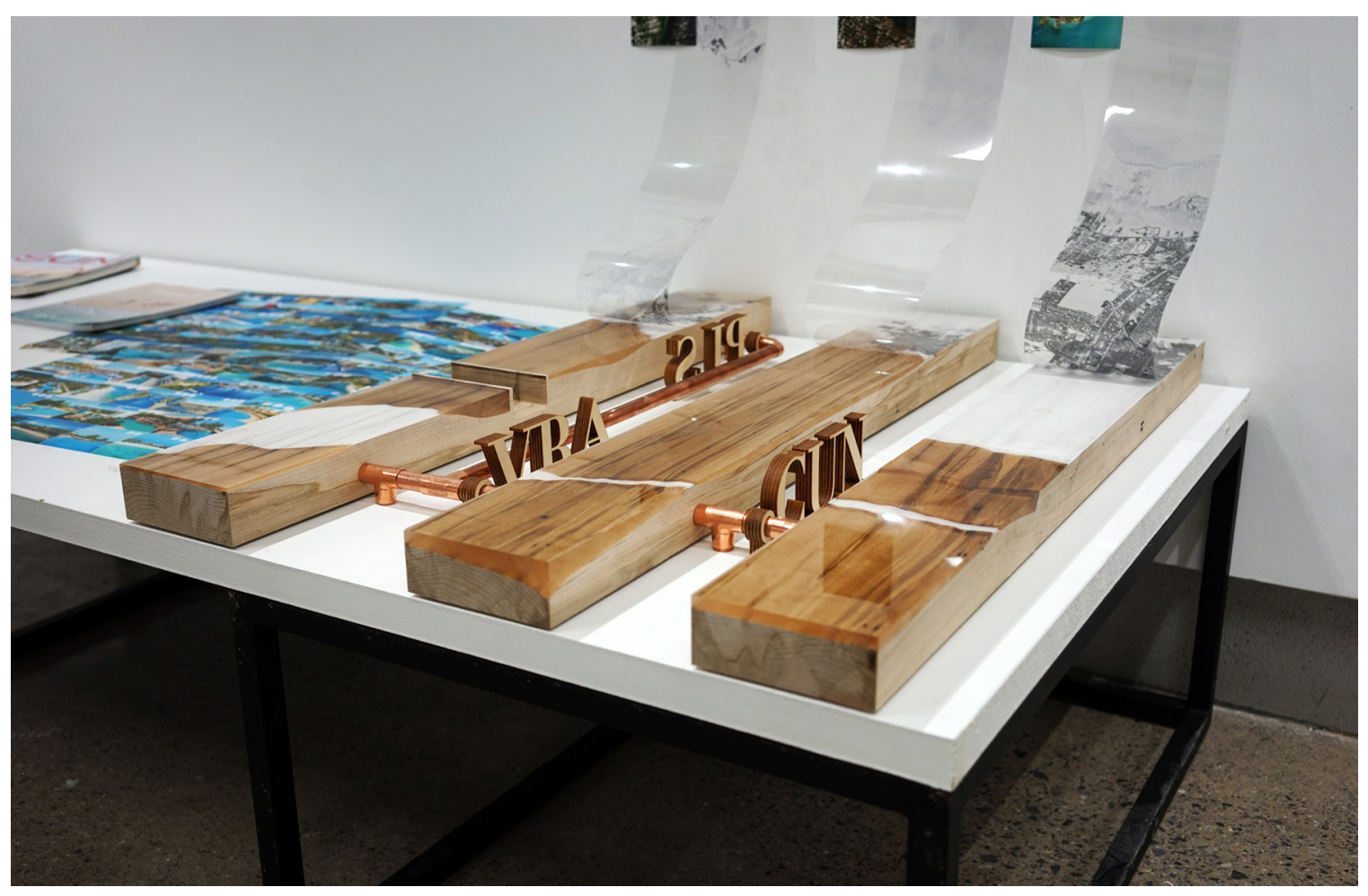


Isolation

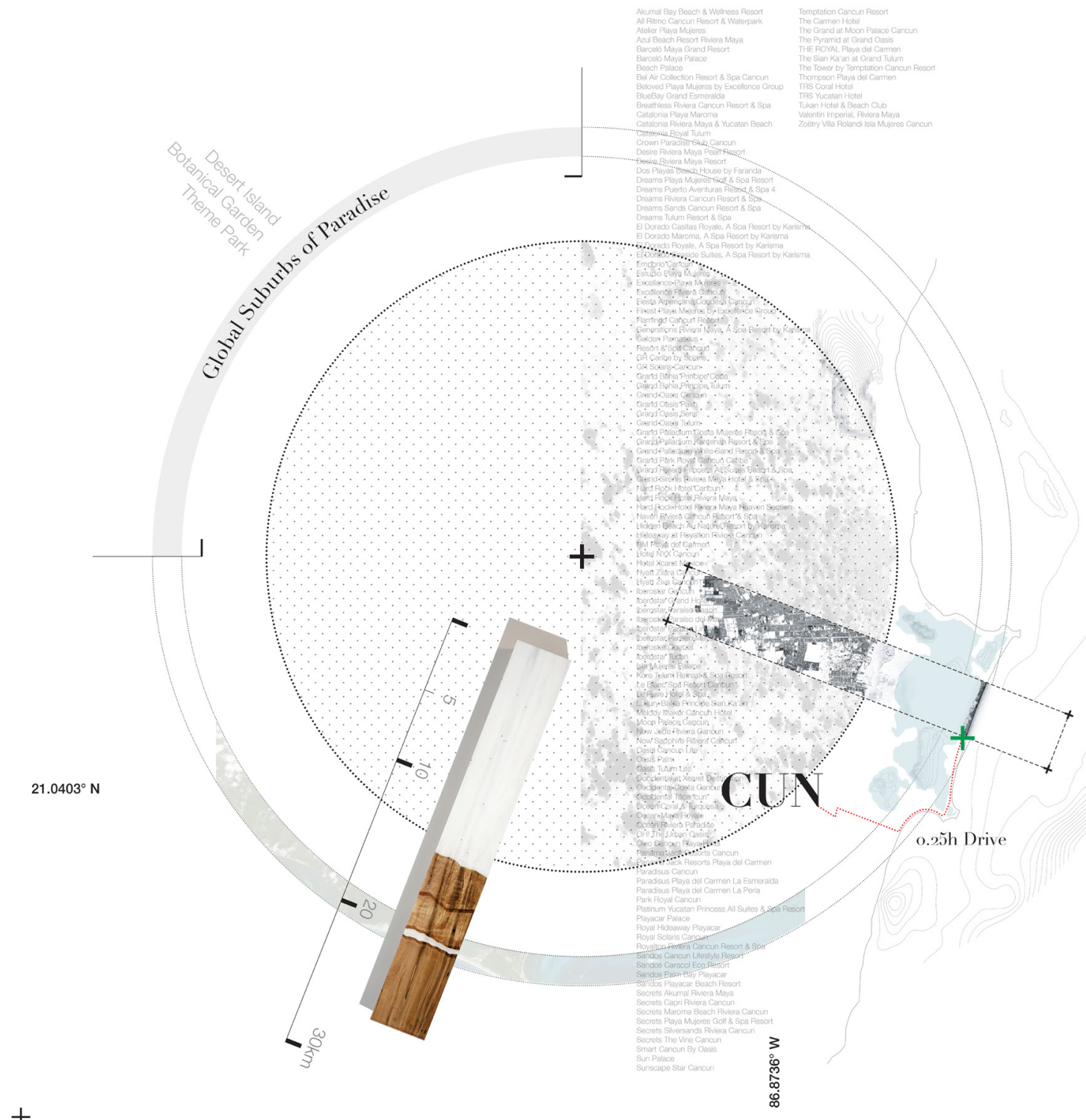

$+$

Figure 46: Radial

configuration of 'suburbic'

paradise in Cancun. 
Isolation

$+$

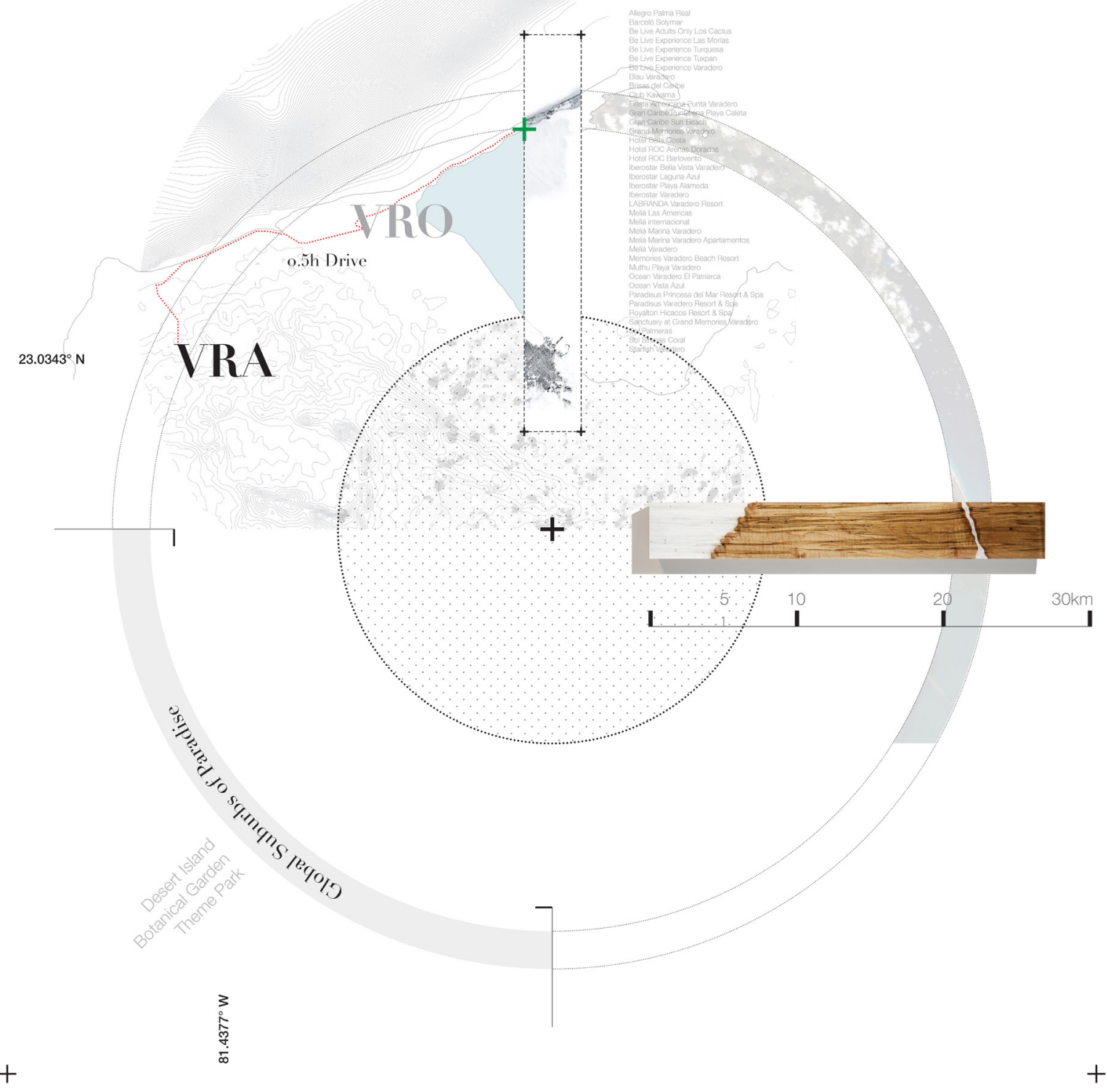

Figure 47: Radial

configuration of 'suburbic'

paradise in Varadero. 
Isolation

$+$

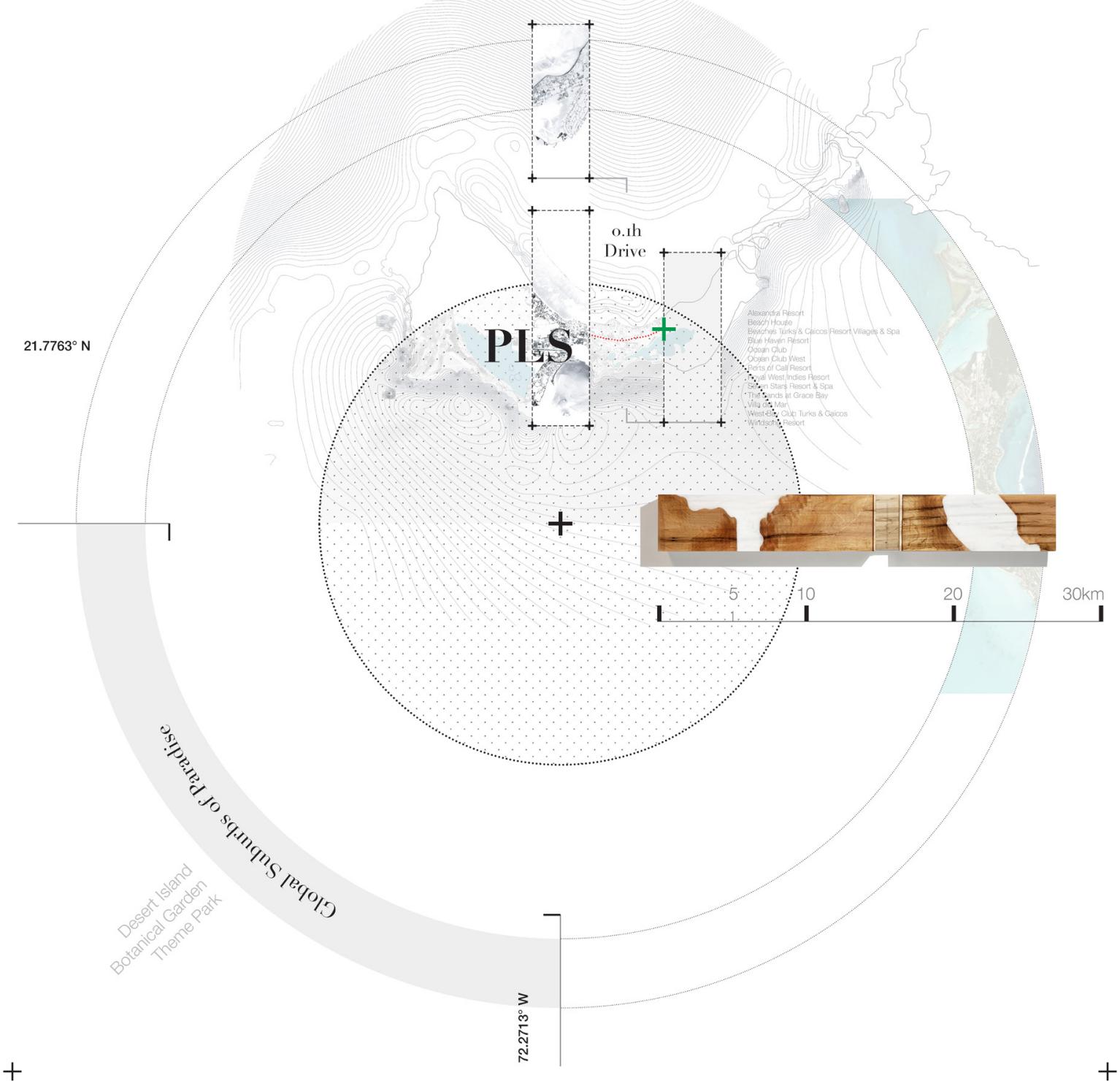

Figure 48: Radial

configuration of

'suburbic' paradise in

Providenciales. 
$\underline{\text { Isolation }}$

73 While these major beach formations are regularly intervened

upon to maintain sand

volume and quality, they remain significant natural anomalies of coastal deposition.

74 Edensor, Performing 70.

75 Archer, Architecture,

4.

76 Ibid., xv.

7 Sheller, Demobilizing, 18

78 The areas immediately surrounding airports are often sparsely developed in larger metropolitan centres.
Proportional similarities can be noted across all three regions of interest, suggesting a series of urban proximities ideal for all-inclusive development. Through the natural ${ }^{73}$ configuration of spectacular beach formations, a high degree of separation is achieved between all-inclusive resorts and adjacent urban communities. Collectively, these three radial diagrams suggest a hybrid form of suburban sprawl, prioritizing the connection to international airports, while selectively concealing a region's layered, complex landscape. ${ }^{74}$

This physical detachment from a region's context enables avoidant touristic practices, as meaningful local engagement is made totally optional and extremely inconvenient. A similar scenario occurs in traditional North American suburbs. Over the course of the 19th and 2oth centuries, single-family dwellings became increasingly isolated, placeless, and estranged from their socio-economic surroundings. ${ }^{75}$ Both the 'American Dream' and tropical paradise are distinctly insular realms, oriented around the commercial fulfillment of the individual self. ${ }^{76}$ Today, if a North American consumer is able to afford a suburban home and an all-inclusive vacation, then each commodity's associated infrastructure permits a secluded lifestyle and travel experience. This systemic insularity dramatically manipulates the perception of touristic settings, perpetuating the sense that tropical paradise is "untouched yet within reach" (I8)..$^{77}$

Analyzing each region's particular site configurations, it becomes apparent that water plays a key role in distancing resorts from metropolitan centres. Coastal deposition processes organically generate landforms which are distinct from major land masses. Due to highly site-specific wind, wave and tidal patterns, thin strands of sand creep out into the sea or gradually collect over sub-aqueous banks. These sand formations become critical sites of all-inclusive development, delicately touching larger land masses at narrow, controlled points. In the case of Providenciales, with its limited land area, urban development compresses into the space ${ }^{78}$ immediately surrounding its airport. Across all sites, shallow water fills the voids between land and sand, acting as a natural barrier between resorts and local people. This arrangement guides the linear parcellation of all-inclusive properties, featuring water on both their front and back orientations. From the perspective of the tourist, this configuration crucially evokes the sensation of being on a small island. 
79 Deloughrey,

Elizabeth. "'The Litany

of Islands, The Rosary

of Archipelagos":

Caribbean and Pacific

Archipelagraphy." A

Review of International

English Literature 32, no.

1 (2001): 22

80 Lambert, Leopold.

"Archipelagos and

Indigenous Imaginaries."

In The Funambulist:

Politics of Space and

Bodies 9 (Jan. \& Feb.

2017).

81 Deloughrey, Elizabeth. "Island Ecologies and Caribbean Literatures." Tijdschrift Voor

Economische En Sociale

Geografie 95, no. 3

(2004): 300.

82 Sheller, Demobilizing, 13

83 Deleuze, Gilles. "Desert Islands." In

Desert Islands and Other Texts: 1953-1974.

10. Los Angeles, CA:

Semiotext(e), 2004.

84 Grove, Richard. "Introduction." In Green Imperialism: Colonial Expansion, Tropical Island

Edens and the Origins of Environmentalism, 1600-

1860, 5. Cambridge, UK: Cambridge University

Press, 1995.

85 Scafi, Alessandro.

"Mapping Eden:

Cartographies of the

Earthly Paradise." In

Mappings, 68. London,

UK: Reaktion Books,

1999.

86 Deloughrey, Island,

302.

87 Kincaid, Jamaica. A Small Place. New York, NY: Penguin Group,

1988.

88 See The Tempest

by William Shakespeare

or Robinson Crusoe by

Daniel Defoe.

89 Sheller, Hedonism, 30.
Island connotations are especially provocative, as they're embedded with a particular colonial ethos. ${ }^{79}$ Historically approached by the sea, tropical islands have stood since the $15^{\text {th }}$ century as places to be 'discovered' and colonially appropriated. ${ }^{80}$ Presumed to be 'uninhabited', this denial of indigenous presence initially painted Caribbean islands as awaiting European arrival. ${ }^{81}$ Today, the imagined remoteness of islands continue to increase their economic and romantic appeal, resonating in the minds of visitors "due to their intangible qualities of separateness, exclusivity, and holism" (13). ${ }^{82,83}$

Early explorations of the greater Caribbean additionally satisfied Europe's longstanding quest to locate Eden, introducing an ambitious new layer of imaginative symbolism onto small island territories. ${ }^{84}$ This dramatically increased the region's vulnerability to colonial aspirations, as tropical paradise became a place that was cartographically fixed and real. ${ }^{85}$ Whole Caribbean islands subsequently functioned as 'new Edens, ${ }^{\prime 86}$ operating as collected botanical gardens in support of profitable industries. The resulting agricultural development of Caribbean islands triggered a mass-transplantation of people and crops ${ }^{87}$ cultivating and curating skewed notions of viewing tropical nature. ${ }^{88}$

While tourists now predominantly access Caribbean destinations via aircraft and cruise ships, contemporary modes of viewing tropical nature remain equally ideological. Prospective tourists are inundated with images of glittering, beckoning beaches and seemingly empty resorts before ever formally booking a vacation. Consequently, visitors travel to the Caribbean with preconceived notions of its physical and cultural landscapes, ${ }^{89}$ largely informed by sanitized visual scenes. Tropical paradise is thus a commercial fantasy which cannot exist in occupied space - a hyperreal condition with no basis in geographical reality. ${ }^{90}$

While a tourist's imagination inevitably influences how real Caribbean sites are viewed, in practice, great effort is undertaken by resort operators and municipal governments to spatially construct expected Caribbean settings. In Cancun, Varadero and Providenciales, Figures 46 to 48 illustrate that tourists are guided along each region's suburban radius, moving between airports and resorts in under half an hour. Within this radius, a limited number of manicured routes ties each destination together. These routes often give prominence to 
Isolation

90 Baudrillard,

Simulacra, 1.

91 Nixon, Slow, 184.

92 Ibid., 181.

93 Simpson, Mapping, 31.

94 Edensor, Performing, 69.

95 Deloughrey, Island, 300. ornamental planting, establishing critical divisions between productive and unproductive land. This strategic crafting of regional pathways thus creates a labour-free appearance of effortless sustenance, ${ }^{91}$ where agricultural and industrial processes are concealed to visitors.

Through this designed separation of tropical nature and labour, all-inclusive destinations may be readily projected as 'pure' and timeless spaces. ${ }^{92}$ In turn, tourists are methodically released from domestic routine and responsibility, immersed in environments that are tactfully staged to produce pleasurable experiences. ${ }^{93}$ Upon entering resort properties, local workers greet guests in familiar languages, performing their roles with deference and cheerfulness. ${ }^{94}$ In these liminal spaces of consumption, workers are skillfully positioned away from the forces of modernity and mobility that define the tourist, ${ }^{95}$ establishing a dubiously comfortable inequality between host and guest. 
To further investigate these perceptual relationships, another shift in project scale is necessary. While suburban connections may be suggested through the re-mapping of urban networks, these connections remain nearly imperceptible to tourists who are isolated on commercial pathways. On reflection, where previous drawings maintained a level of abstraction and graphic ambiguity, future exercises must investigate how data-driven relationships may be manifested through the construction of tangible architectural space.

Following the mapping of suburbia at continental and regional scales, the subsequent sections of this thesis will explore how the tactile design of tropical paradise may be suburbically-informed at the scale of the site and body. With this shift in scale, several question emerge:

- How may common notions of suburbia operate as a new frame of reference for interpreting architectural spaces abroad?

- What specific spatial tactics are employed by resort planners to satisfy domestic expectations of predictability and exclusivity?

- Finally, how may distinctly suburban assumptions of touristic architecture influence one's behaviour and interactions? 


\section{Architecture of Assurance $\quad \mathbf{5 5}$}

Club Med Cancun, 2009 and 2019

Paradise as a Village $\quad 58$

Escape and Enclosure $\quad 69$

Trope \#1: The Porch 72

Trope \#2: The Pool $\quad 76$

Trope \#3: The Garden Path $\quad \mathbf{8 0}$

96 Two major themes surrounding mass tourism are authenticity and nostalgia. See McRae, Rethinking, 237.
Transitioning from regional to site-specific scales, this section investigates how traits of suburban construction enhance sensations of ease and security when travelling abroad. This analysis began with a trip to Club Med Cancun, an all-inclusive resort that I first visited as a teenager in 2009. In operation since 1976, Club Med Cancun is one of the oldest resorts in the region, and remains a deeply nostalgic ${ }^{96}$ setting for myself and my family.

Through spatially and temporally mapping my experience of the resort, numerous land-use strategies could be identified that heightened a guest's sense of ownership over the pristine landscape. Informing a second series of models, this section concludes with the fabrication and interpretation of three scenes based on material tropes of suburbia. 
In January, 2019, I spent four nights at Club Med Cancun. I spontaneously booked the vacation after a tiring week in November, when months of all-inclusive research proved to be too persuasive. In the moment, I wasn't booking a ticket to some far enclave of suburbia, I was booking a holiday! Despite being unsure of how my personal experience would reconcile with my thesis argument to date, the trip offered the potential to review all-inclusive resorts from a first-person perspective. With the intention of documenting Club Med Cancun as a general tourist, I captured photographic and observational data both systematically and intuitively.

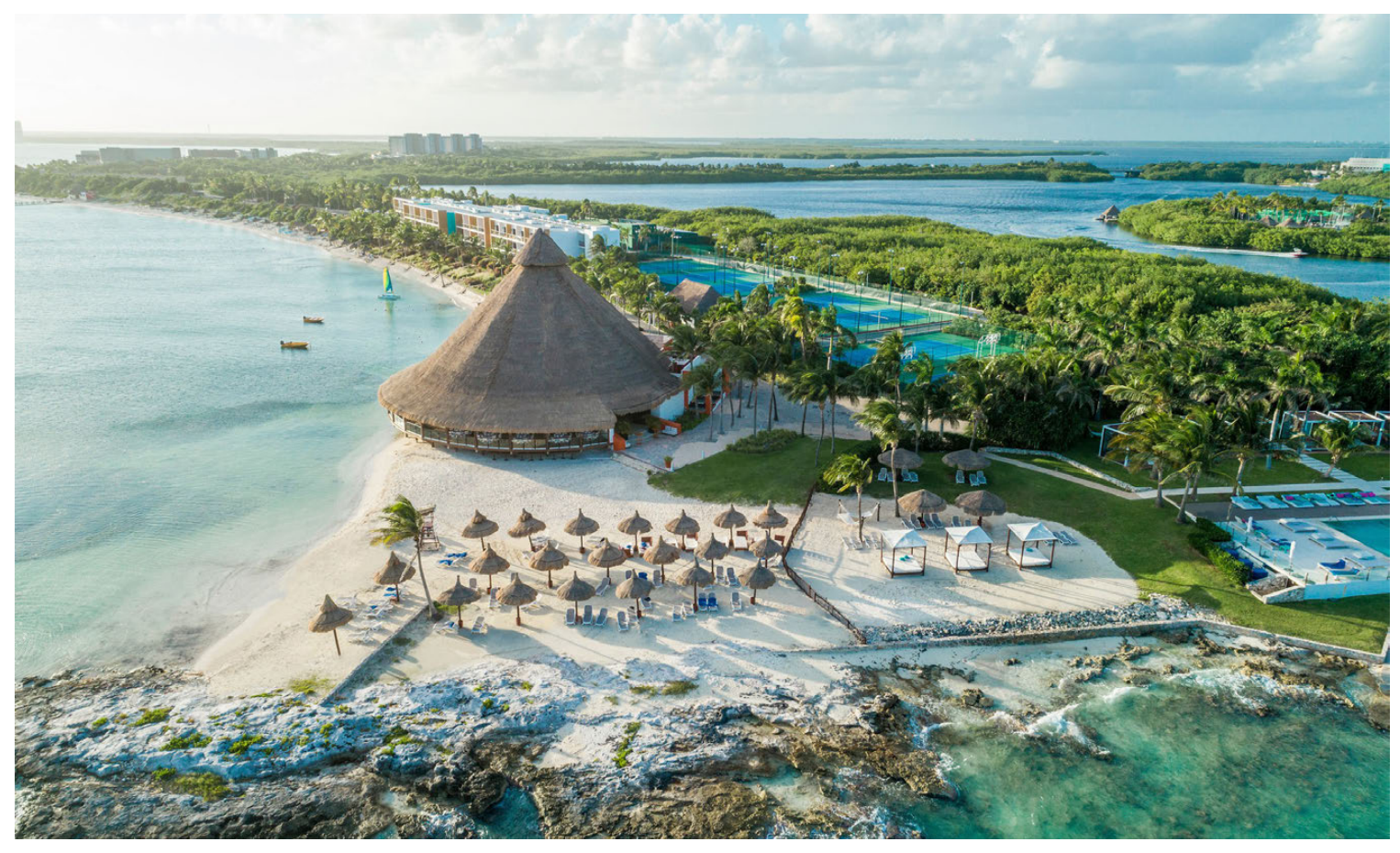

Figure 49: Aerial view of Club Med Cancun.
I first visited Club Med Cancun in 2009 with my parents and two younger siblings. I was fifteen years old and the trip remains one of my fondest family memories. Before leaving, I distinctly remember my mother saying that the resort held the "prime" location in Cancun. Perched on a thin, precarious strip of land between the Caribbean Sea and a small tidal lagoon, the resort felt like a secluded world only fifteen minutes away from the airport. While the stunning location certainly added to our excitement, it was a strong sensation of freedom that ultimately left the strongest impression on me as a teenager. 
With no work or household obligations, my parents seemed more lighthearted and relaxed. I had free rein of the resort and a level of independence beyond what I was accustomed to back in Canada. I especially idolized a global assemblage of staff dubbed 'Gracious Organizers' (a.k.a. G.O.s), whose eclectic backgrounds seemed far more intriguing than my own. Cumulatively, the resort felt much larger and more invigorating than my usual environments, and I believed that the space held much more potential for personal transformation than my tiny orbit between home and school.

Returning in 2019, my experience was markedly different. After being led to my room, I realized that much was wrong - it was too cold, the patio door wouldn't lock, and the shower wasn't working. More specifically, of two showerheads, the rain showerhead wasn't working. This was unacceptable. It compromised my guaranteed relaxation during a precious few vacation days.

On reflection, I had never felt so entitled while travelling. Eventually, my anticipation of the vacation gave way to an overwhelming sense of self-consciousness. While I had initially planned to document the resort in a manner that embedded blandness and predictability, this sense of detachment quickly disappeared when I realized that I looked and acted like nearly every other tourist in the resort. Caught between conflicting goals of research and relaxation, my interactions felt strained and intrusive. At the same time, the G.O.s either seemed bored or improbably energetic. Most disturbingly, they represented only a fraction of employees on the resort. While the G.O.s were obviously curated and mandated to interact with guests, the local employees were largely hidden from view.

During my time in Cancun, I only left the resort property for a few short walks along the beach. Stretching northwards for several kilometers were more all-inclusive resorts, all only accessible to their own guests. Surrounded by unlimited sweet, alcoholic drinks, I had to carry my own water bottle. While the beach was technically public, its width often became precariously pinched between pits of erosion and a myriad of privacy screens. Looking back, I can say that my vacation was technically unsuccessful. I thought I could relax while systematically documenting my travel, but I failed. The façade of tropical paradise was disrupted, and a decade later, it didn't possesses nearly the same magic. 
Despite dramatically different impressions of Club Med Cancun in 2009 and 2019, these experiences were unified through their apparent detachment from conventional urban contexts and routine. At the scale of the site, Club Med's setting could be described as an 'environmental bubble', where each resort property is finite, controlled and insulated from unpredictability or provocation. ${ }^{97}$ Here, Club Med introduces a poignant metaphor:

"Village is what we sometimes call our resorts because they're so private, safe, and intimate - and also due to the sense of community and family among our guests." 98

When marketing vacation packages in general terms, all-inclusive brands frequently use aspirational language, making their products seem restorative, luxurious and memorable. This tone noticeably changes when advertising the physical spaces of all-inclusive resorts, alternatively emphasizing separation, security and exclusivity. This shift in language articulates a setting where tourists may enjoy phenomenal scenes and amenities abroad without compromising on domestic expectations of privacy and comfort. Consequently, at the scale of the site, suburban design devices are not necessarily manifested as repeating houses or sprawling concentric planning, rather they capture the tangible structures providing assurance one is not far from 'home'.

Figures 50 and 57 map Club Med Cancun as a village. As illustrated in Figure 50, the resort possesses many functional components of a village, including vehicular circulation, pedestrian circulation, public space and private space. These components are defined through discreet boundary conditions, which may be identified between resort properties, at resort entrances, across resort frontages and within the resort itself. Two areas of particular attention are service cores located at the far southwestern extent of the property, and centrally within a large structure containing the main lobby, bar and restaurant. These zones

97 Urry, The Tourist, 7.

98 "First Time at Club Med." Club Med. Accessed February 2019 house functions such as equipment storage, food preparation, laundry and medical clinics. Occupied by 'back-of-house' employees, these spaces are carefully hidden from view, yet shrewdly assure guests that anything they may require can be found on premise. 


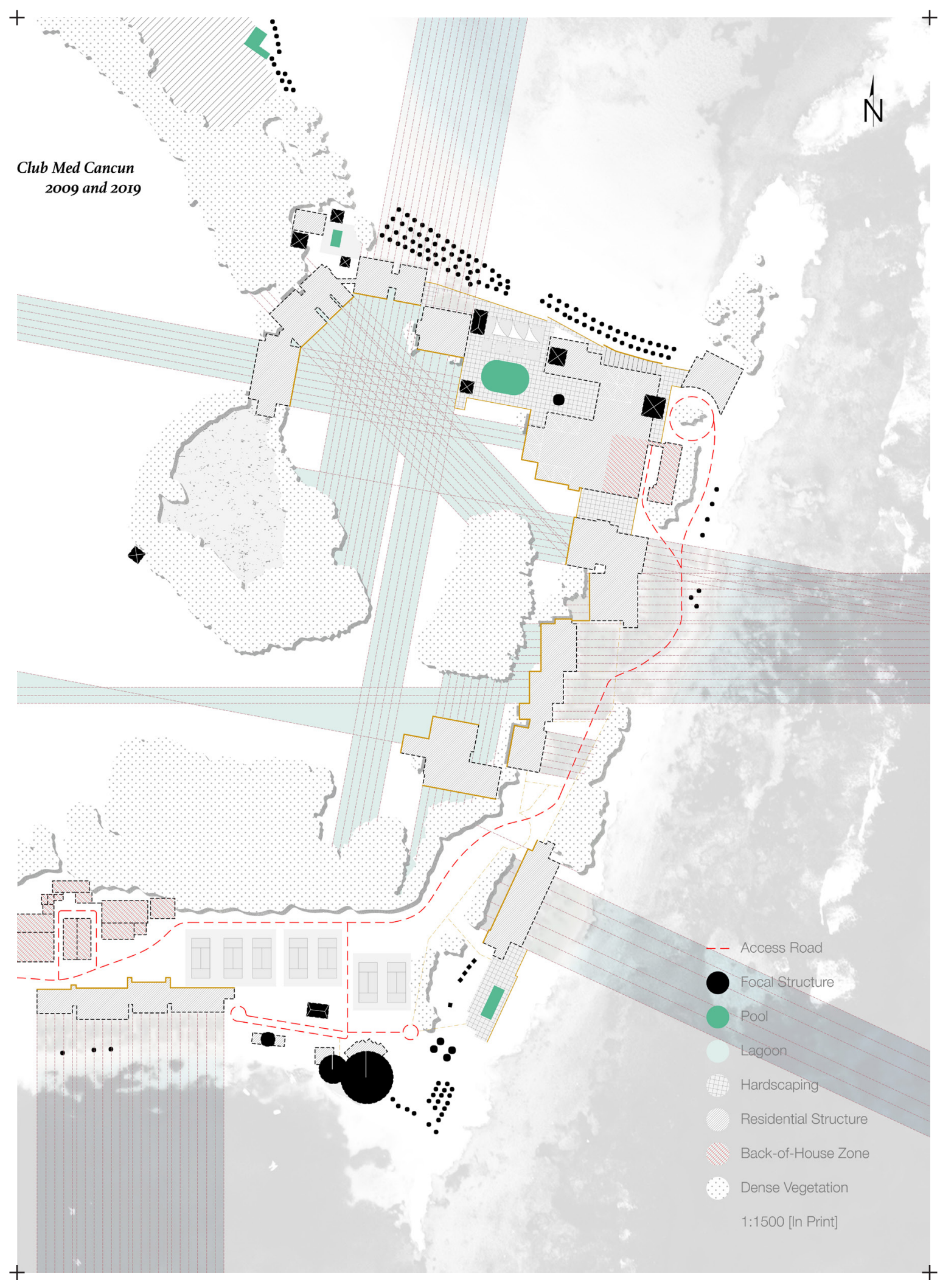

Figure 50: Site map

showing resort

organization and

parcellation.

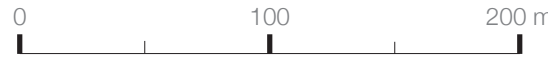


While a tourist's overt awareness of boundaries detracts from the scenography of boundless paradise, subtle barrier conditions offer an underlying sense of privacy and security. When entering an all-inclusive resort, guests first pass through a gated threshold. Once within the resort, various partitions establish a spatial hierarchy and secondary parcellation of the resort property. Most obviously, physical fences demarcate exclusive guest suites from areas of general access (see Figure 5I), closely mimicking the conditions of a gated community. Despite these partitions, each guest suite is configured to feel like a residential plot, irrespective of room class or category. Reflecting an effort to rationalize and subdivide the landscape, repetitive building gridlines allude to one's 'private' property extents within the resort. Sightlines are crafted to overlook water and/or terminate at dense vegetation, imparting a sense of ownership over a guest's slice of tropical paradise. More generally, this vegetation acts as a visual and auditory buffer between otherwise incongruent resort zones. Where not directly overlooking water, rooms are set back from roads by lawns and gardens.

Figure 51: Fence separating zones of exclusive resort access.

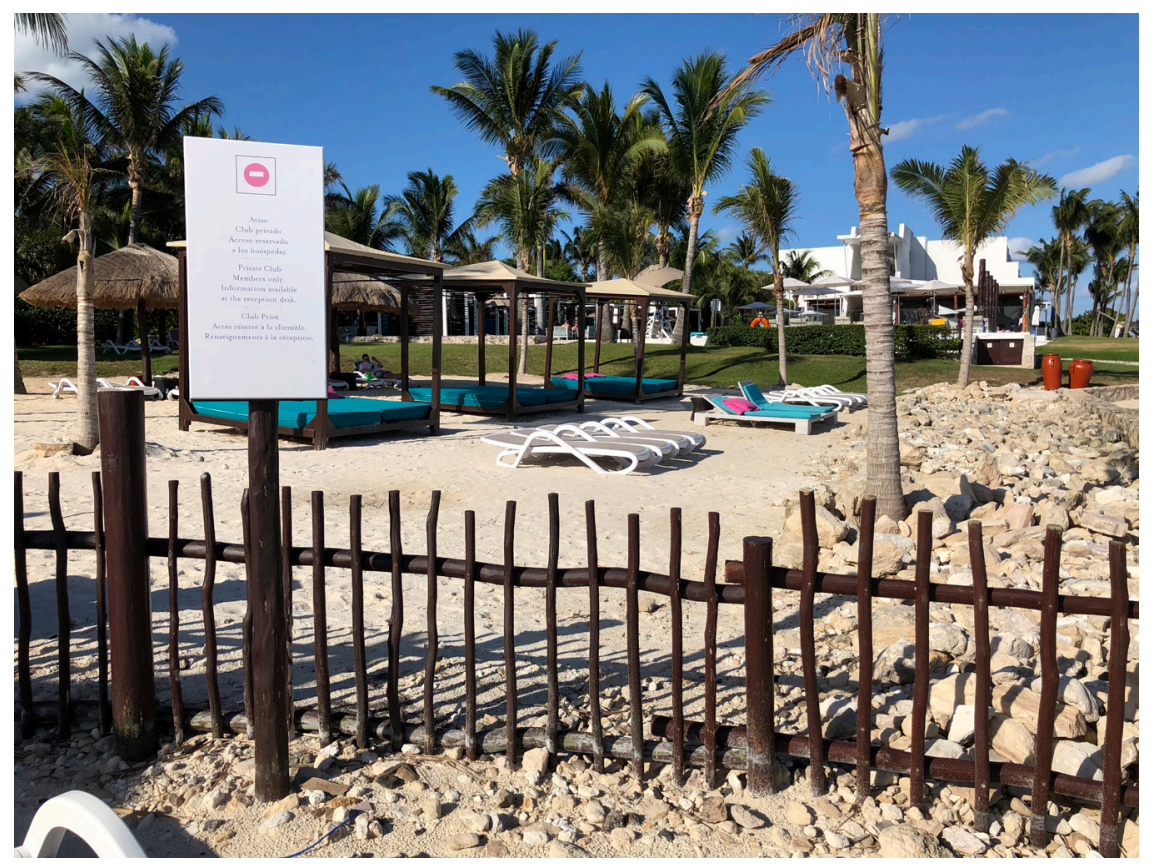


Elaborating on the configuration of guest suite parcels, repetitive objects such as beach parasols and cabanas define semi-private zones at the scale of the body. Guests may claim these zones for several hours at a time, leaving belongings such as towels and books to mark their presence. In many cases, these objects also encroach onto the public beach, demarcating it as territory of resort guests. As illustrated in Figure 52, informal elements such as rope or sticks may connect these objects, further delineating the resort's advancing frontage.

Figure 52: Ropes demarcating a semiprivate lounging region.
Figure 53: Unoccupied space between resorts littered with trash.

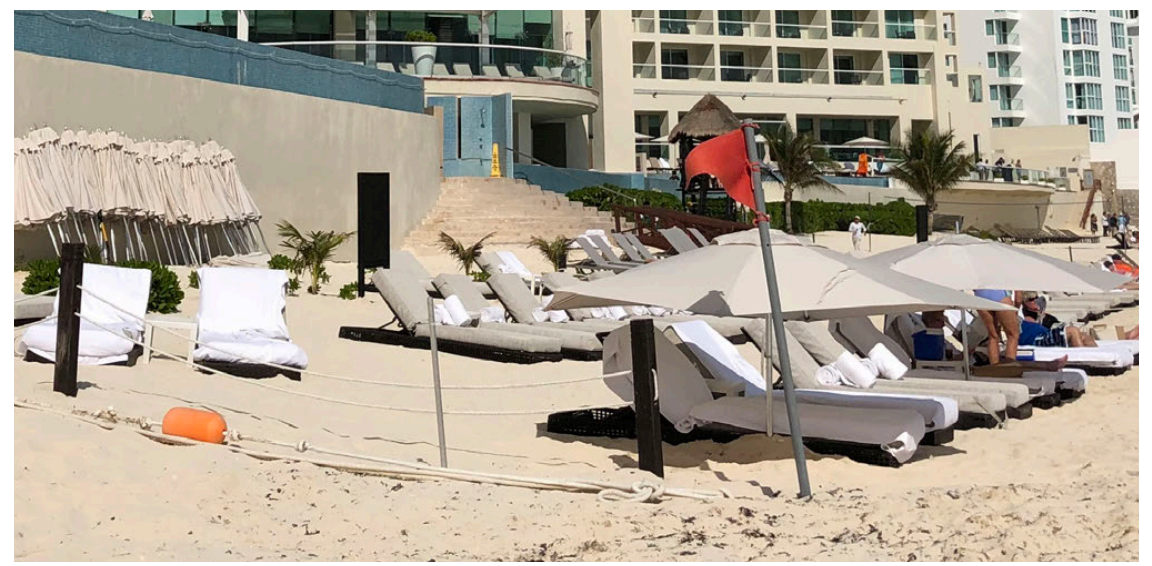

Travelling along the public beach, the majority of all-inclusive resorts also achieve separation from adjacent properties through physical boundary conditions. These boundaries range from wide swaths of vegetation to solid walls with mounted surveillance equipment (see Figure 53 and 54). Extending onto the beach, property lines may be informally marked using designed promotional material (see 'Cancun' lettering in Figure 55) or through mundane objects such as buried posts and sports equipment (Figure 56). These boundaries often create areas between resorts that are poorly maintained and littered with trash.

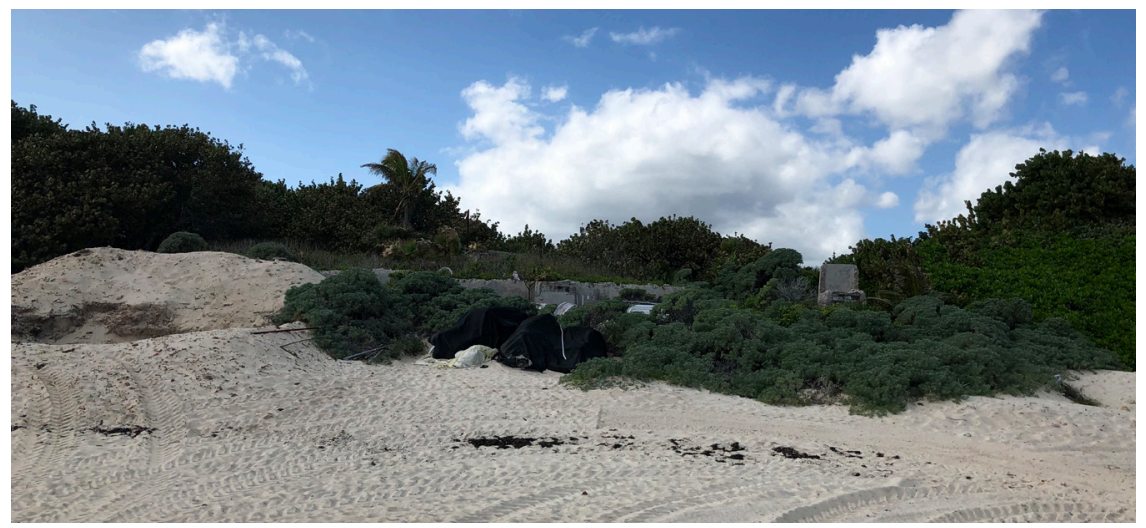


Figure 54: Resort wall and surveillance equipment.

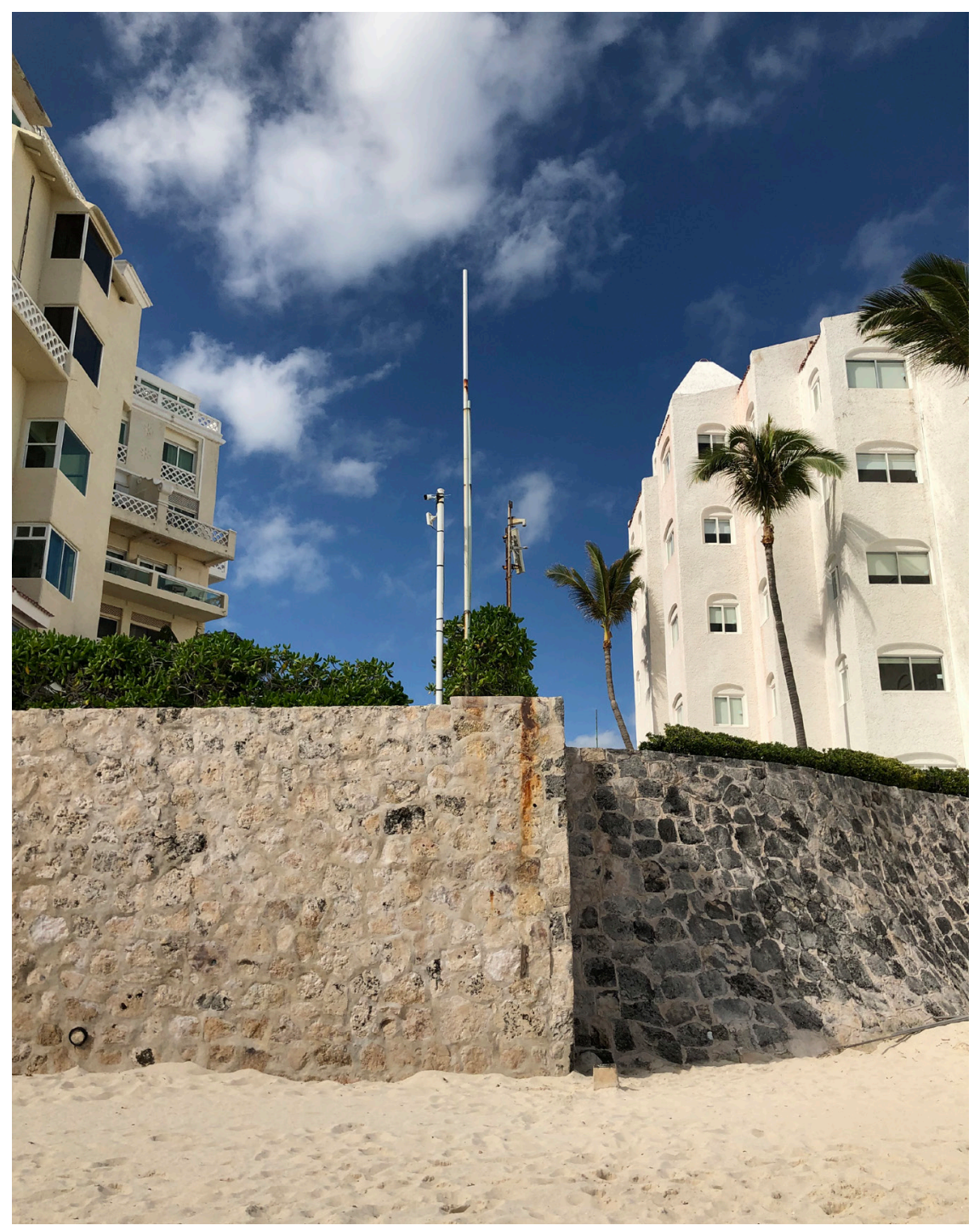

Figure 55: Branded 'Cancun' lettering.

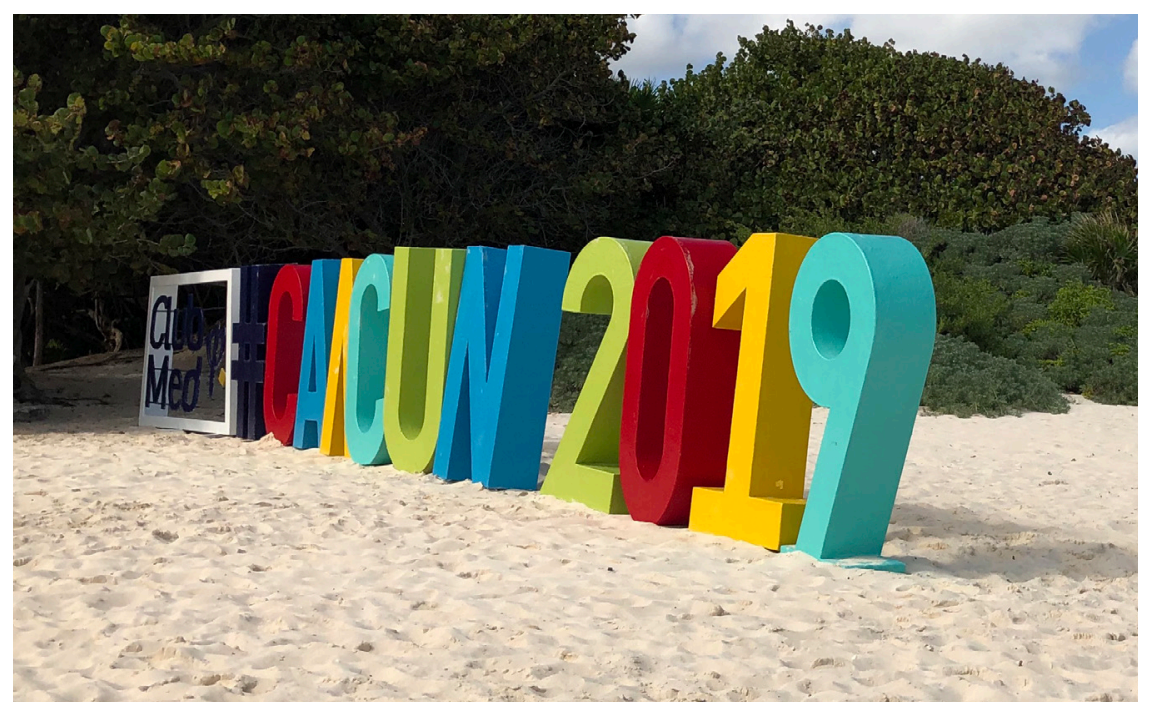




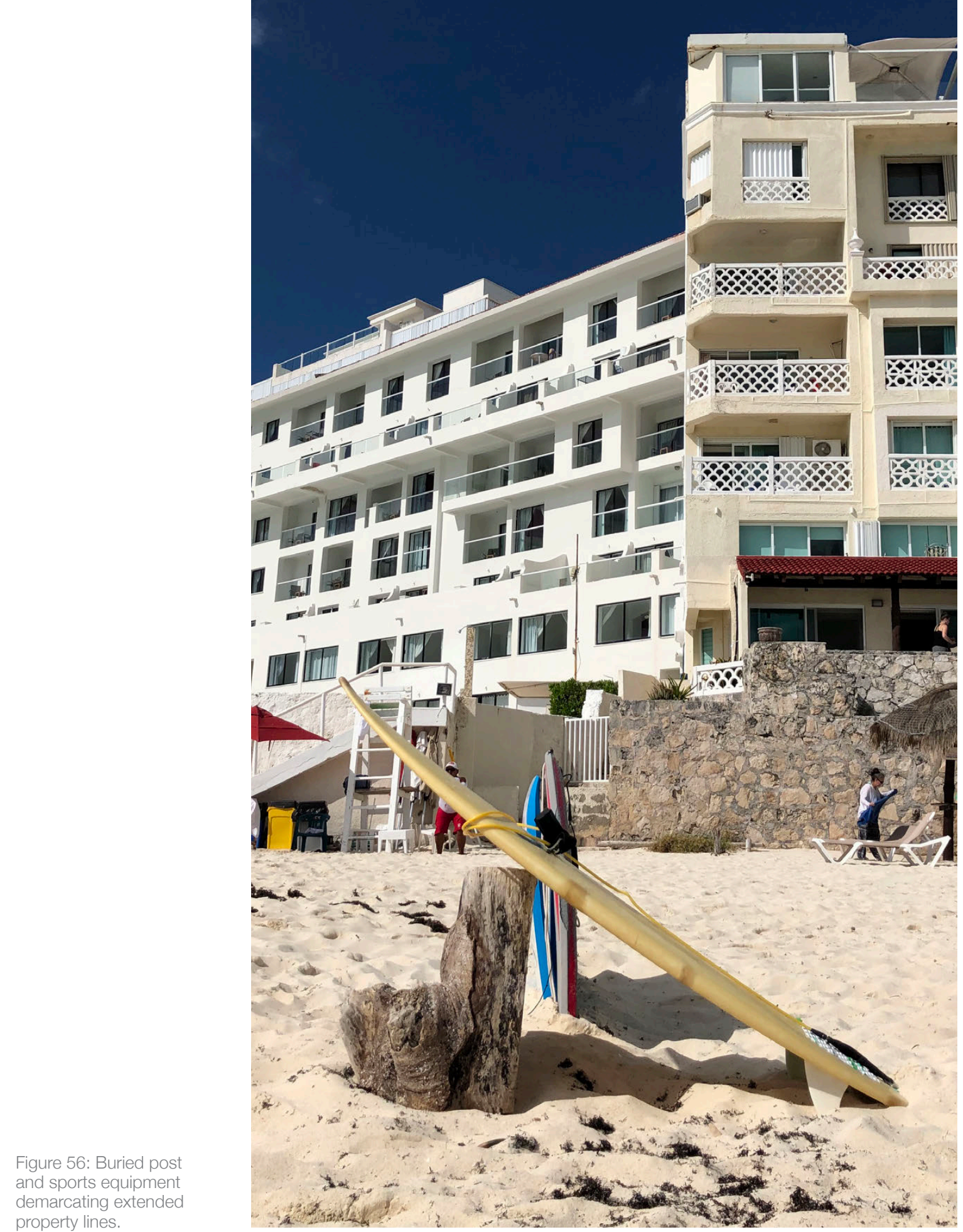


Expanding on the previous map, Figure 57 layers a temporal scale, representing how I inhabited the resort over a twelve hour period. Data was recorded using a GoPro camera to automatically capture a photo every 30 seconds. Each Imm point thus represents a 30 second time interval, with the diameter of each bounding circle also scaled to $\mathrm{Imm}=$ 30 seconds. This drawing illustrates that I spent the majority of my day stationary, moving between zones catering to a single program. I never experienced the site as a whole, instead understanding it as a sprawling sequence of sub-destinations.

Within these sub-destinations, one's attention is directed towards scenic elements that feel characteristically exotic, such as white sand beaches, pools and lagoons. Where a major natural feature or amenity is not in the view's foreground, thatched accessory structures act as thematic follies. Reflecting the systematic gaze ${ }^{99}$ imbued into resort design, these nodes generate the quintessential images of mass Caribbean tourism. Carefully omitting people, workers and signs of everyday architecture, this diagram illustrates the layering of expected views around carefully designed systems of boundaries and barriers. Critically, these views rarely fixate on edge conditions or resort limits, emphasizing impressions of expansiveness over confinement. Viewscapes also rarely intersect with the linear parcels extending off of guest suites, allowing guests to fully retreat into the private spheres of the resort when desired.

Finally, selected points illustrated in Figure 57 are enlarged in Figures 58 to 60 . Imaging key locations such as beaches, dining rooms and a typical guest suite, these three matrices compile GoPro photographs shot at five minute intervals on January $\mathrm{II}^{\text {th }}, 2019$. 


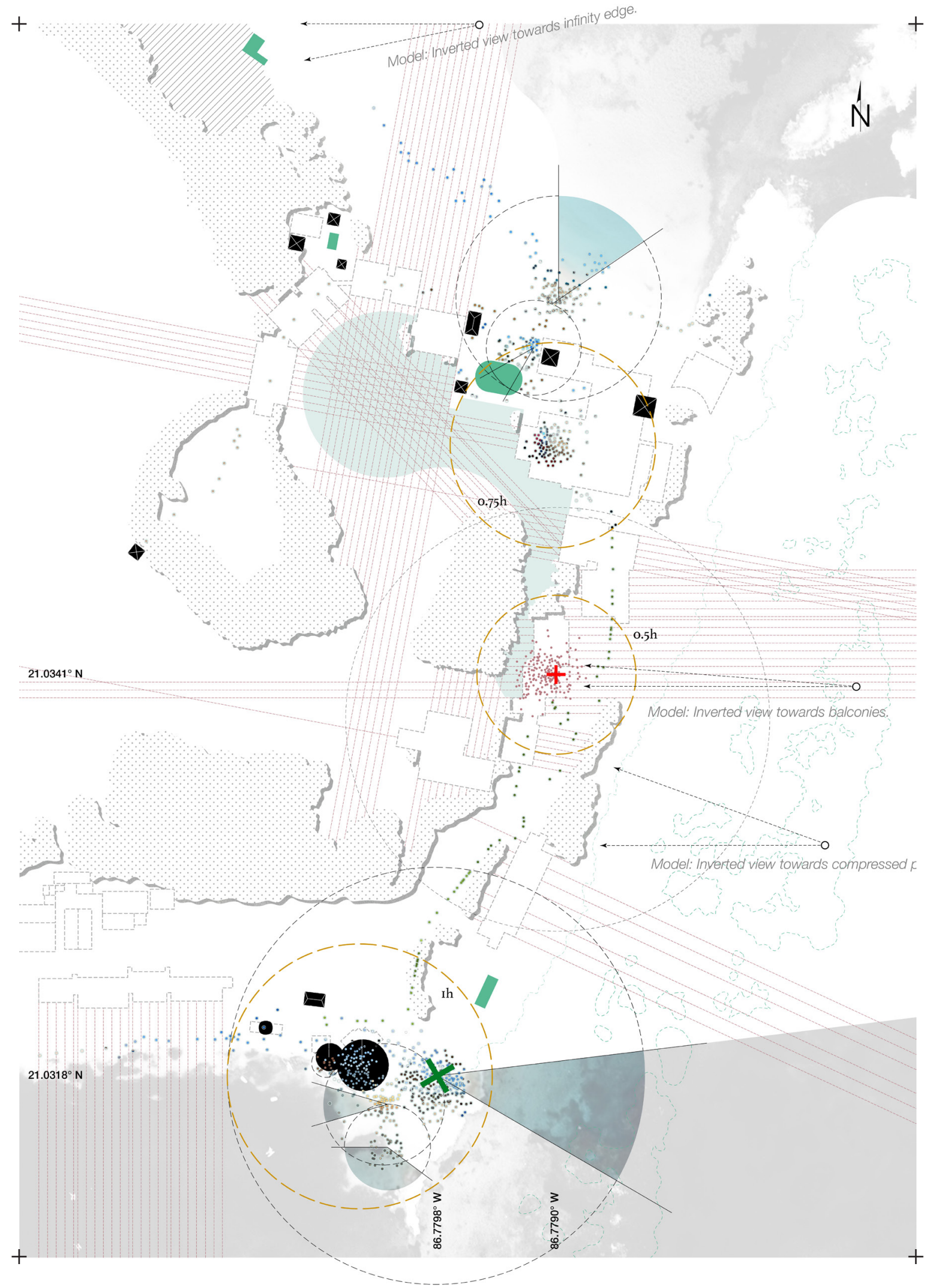

Figure 57: Site map showing inhabitation.

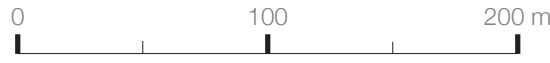




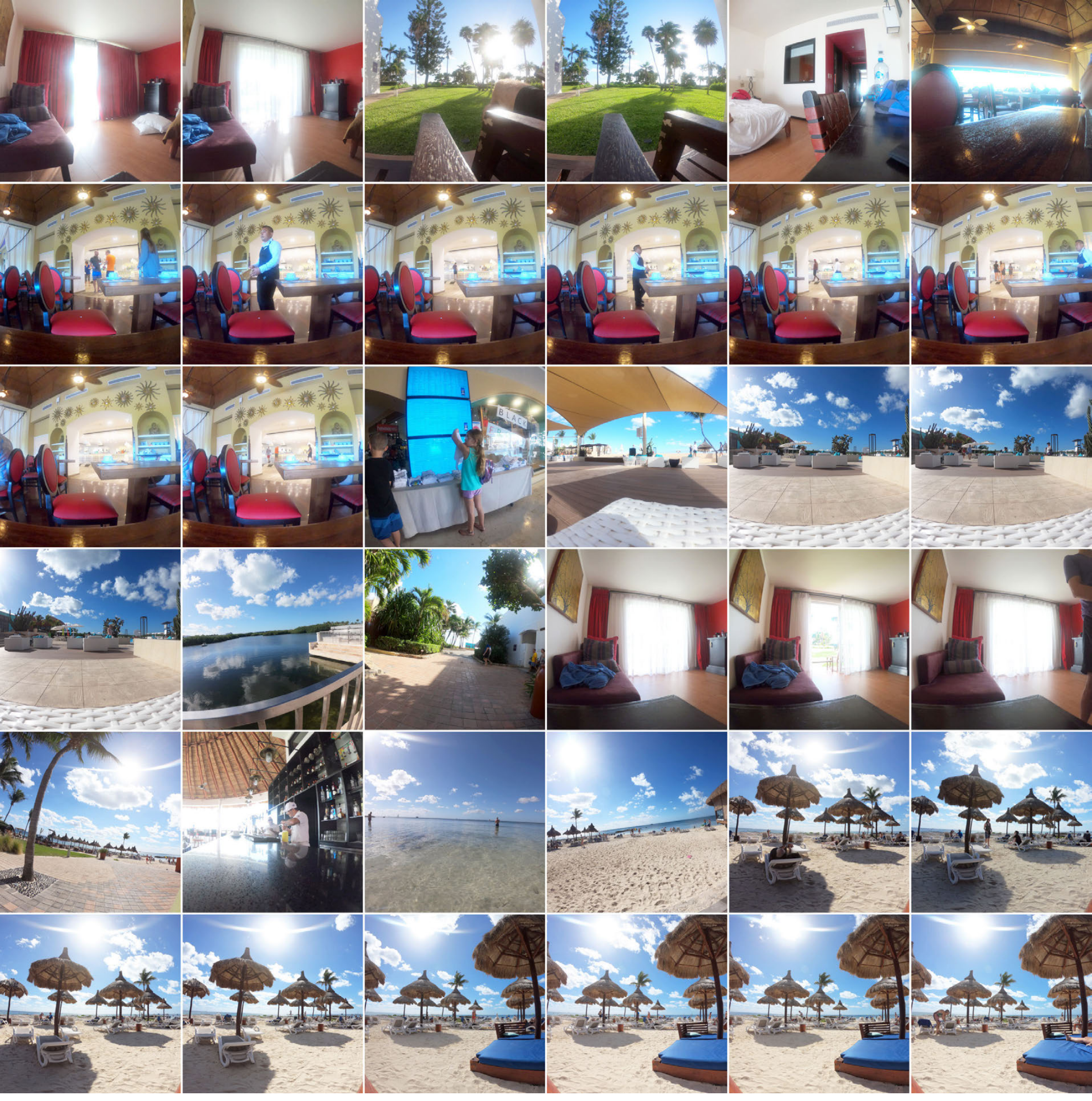



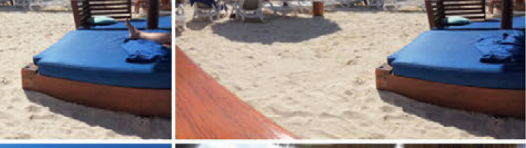

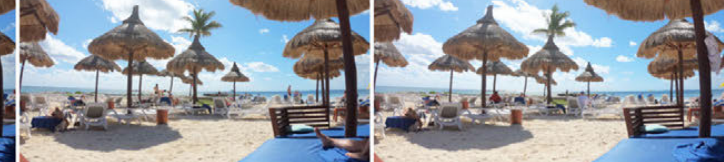
S.1.4
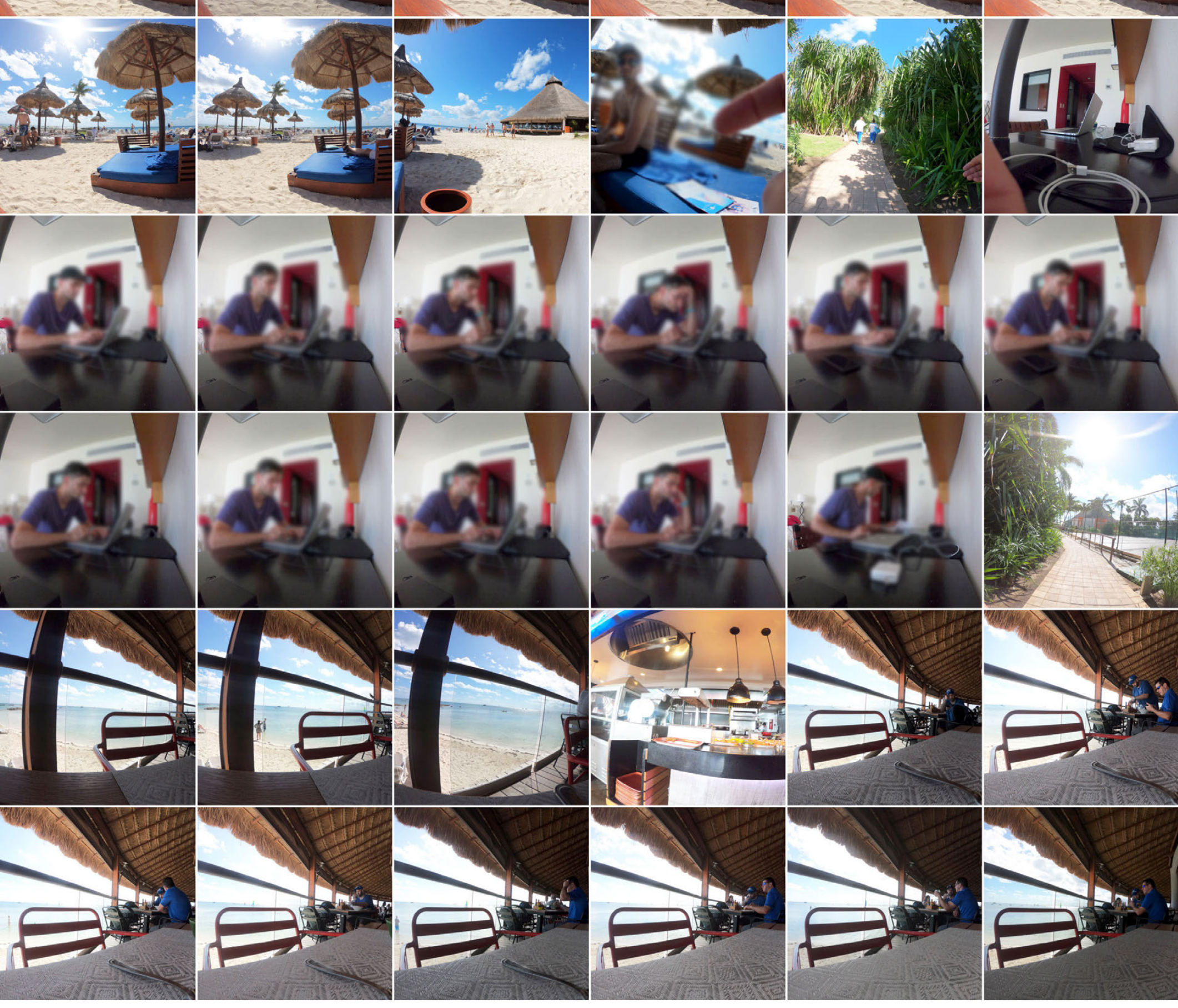

Figure 59: 01.11.2019 
100 Zukin, Sharon.

"Disney World: The Power of Façade/The Façade of

Power." In Landscapes

of Power: From Detroit

to Disney World, 240.

Berkeley, CA: University of

California Press, 1991.

101 Baudrillard

Simulacra, 75

102 Sheller,

Infrastructures, 1386.

103 Sheller, Demobilizing, 18.

104 Ibid., 18.
The previous site analysis rendered Club Med Cancun as a series of public nodes and private parcels, paralleling subdivision strategies commonly implemented in North American suburbs. Cumulatively, these drawings suggest connections between a tourist's perception of psychological escape and their physical enclosure on all-inclusive properties. For all-inclusive resorts to commercially deliver on their commitment to restoration and relaxation, they must in turn be situated away from local communities ${ }^{100}$ and provide secure separations between resort occupants. These parameters functionally depend on an array of implicit and explicit boundaries, entailing all-inclusive resorts to operate as a distinctly interior realm.

While counter-intuitive, the experience of interiority has the potential to amplify a tourist's sensation of blissful freedom. In the crafting of all-inclusive experiences, mental and temporal abandonment takes precedence over unrestricted movement. Tourists are transparently aware of their circular trajectory between 'home' and 'away', voluntarily admitting themselves into the confines of resorts for a defined period of leisure. Their circulation is centralized in airports and dispersed across a multiplicity of destinations, ${ }^{\text {Ior }}$ entering and exiting based on the terms of their booking arrangement.

This controlled traffic in and out of resort boundaries has the larger effect of disembedding properties from their geographical territories, ${ }^{102}$ and repositioning them as placeless nodes within global systems of transportation, media, data and finance. When travelling, all-inclusive tourists transcend multiple scales, all while sitting stationary on airplanes, busses and beach loungers. Achieving extremes of speed and movement, tourists are actively mobilized in their global contexts while remaining enclosed on all-inclusive properties. Their mobility is in turn contrasted by the demobilization of local people, who may only enter resorts to provide entertainment and perform service duties. ${ }^{103} \mathrm{~A}$ tourist's apparent freedom "is thus produced by the techniques of binding people, places and meanings in place," (I8) ${ }^{104}$ only to be remobilized in the distribution of reductive travel narratives. These complex relationships are tangibly expressed through the configuration of resort boundaries, indicating how data-driven observations about suburbia may be manifested at a more personal scale. 
A series of three sectional models were subsequently produced, associating elements of escape with enclosure on all-inclusive properties. Based on spatial conditions observed while travelling in Cancun, each model is correlated to a specific trope of suburbia: either (I) the porch, (2) the pool or (3) the garden path. The models suggest where each trope may be identified on all-inclusive properties, analyzing how the trope mediates between suburban and touristic ideals. Complementing this analysis are a series of small design gestures, serving as a provocation toward new ways of inhabiting existing touristic sites.

The models are fabricated at a scale of I:50, articulating thresholds previously represented in the I:30 ooo terrain models. While the combination of hardwood and resin still achieves an alluring finish, this second model series features a more granular tactility than what was previously produced at the regional scale. Indulgent materials are applied as thin veneers over plywood, and small surface imperfections are scattered throughout the scenes (i.e. bubbles in the cured resin). Through the construction and subtle alteration of existing conditions, these models intend to reveal understated qualities of surface, continuity and adjacency. Ultimately, it is hoped that viewers may imagine themselves in the scenes, reading their own views, breezes and tension into the settings. 


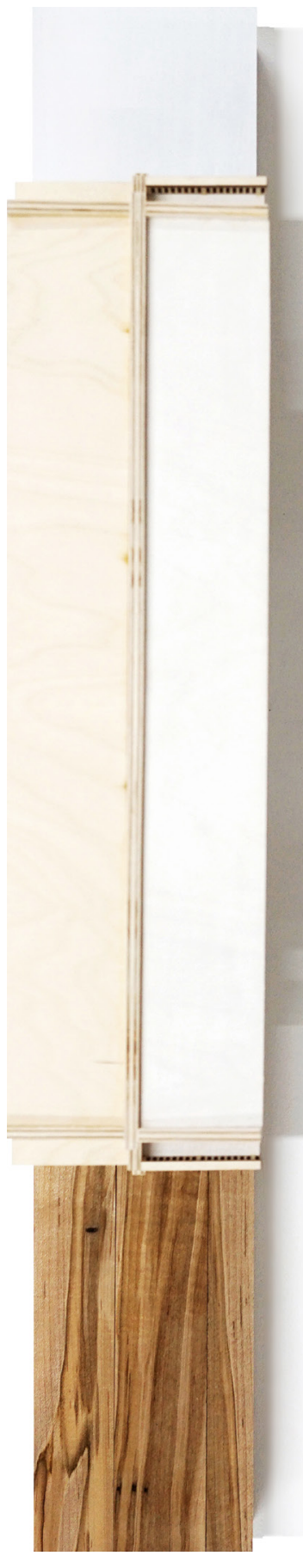

The Porch

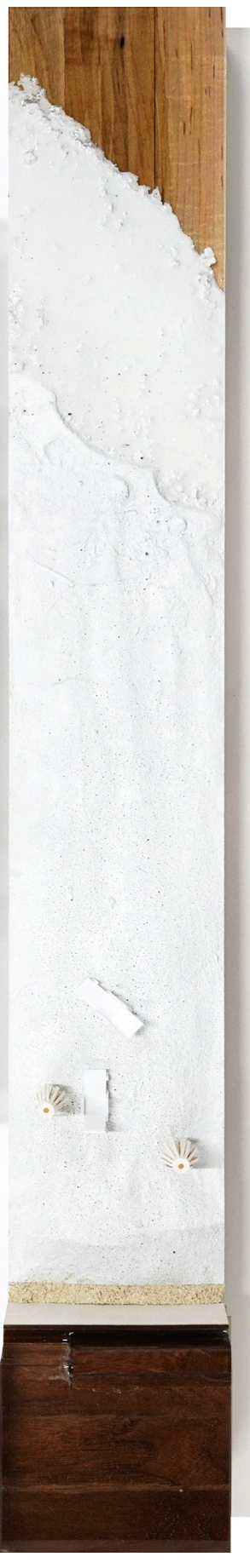

The Pool
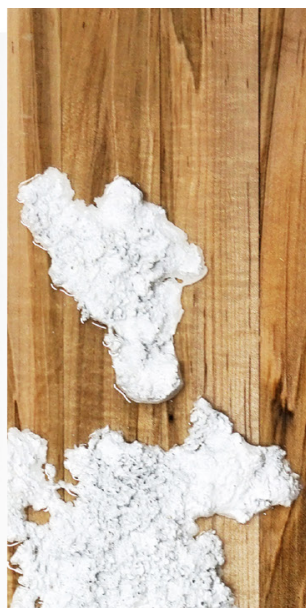

sinis
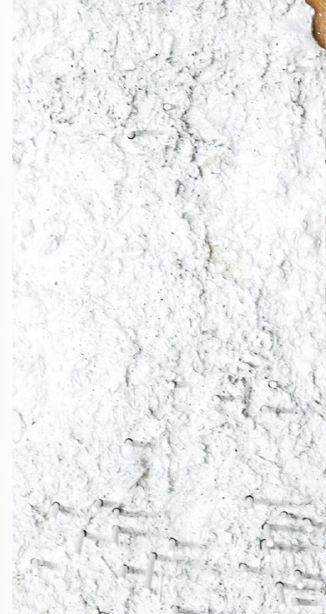

4. $x^{2}$ and
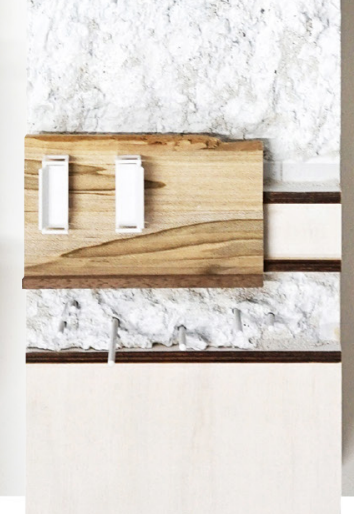

The Garden Path

Figure 61: 1:50 surburban trope models. 
A signifier of domesticity, porches suggest a primary entrance at the front of many suburban homes. Establishing a threshold between public and private residential space, the use of one's porch often influences the tone of interaction among neighbours. Additionally, a porch's construction and materiality often give the clearest indication of a home's targeted style or regionality.

Porches are also featured in the design of all-inclusive resort rooms. Despite incredible outdoor amenities, the vast majority of all-inclusive resort rooms also provide guests with semi-private outdoor space. This space usually comes in the form of balconies or terraces, connected to guest suites through sliding glass doors. These glass doors offer a false front to individual units, as suites are most commonly accessed via central public corridors. While in Cancun, it was observed that these outdoor spaces were consistently underused. As a result, balconies and terraces failed to animate the facades of residential blocks.

Regardless of their limited programmatic benefit, balconies and terraces are ubiquitous throughout resorts, illustrating a repetition of unit types. These units are commonly built using basic construction techniques such as poured concrete, skimmed with thin finishes such as textured concrete, colourful paint or terracotta tile. Like the construction of porches, these building techniques superficially offer a sense of place, easily and cheaply replicated throughout entire resort properties.

A typical porch condition is modelled off of the unit I booked in Cancun. One side of the block abuts the rear lagoon, while the other side faces a lawn and access road. Concrete walls separate identical adjacent suites. In the model, one side of suites is finished with surfacing materials, while the opposite side leaves the units' concrete construction exposed. In the latter scenario, the sliding glass doors are also removed, effectively deleting the amenity of private outdoor space and limiting the suites' sensory connection to the tropical outdoor environment. In this modified block, guests must exit their room to engage with the charismatic site. 


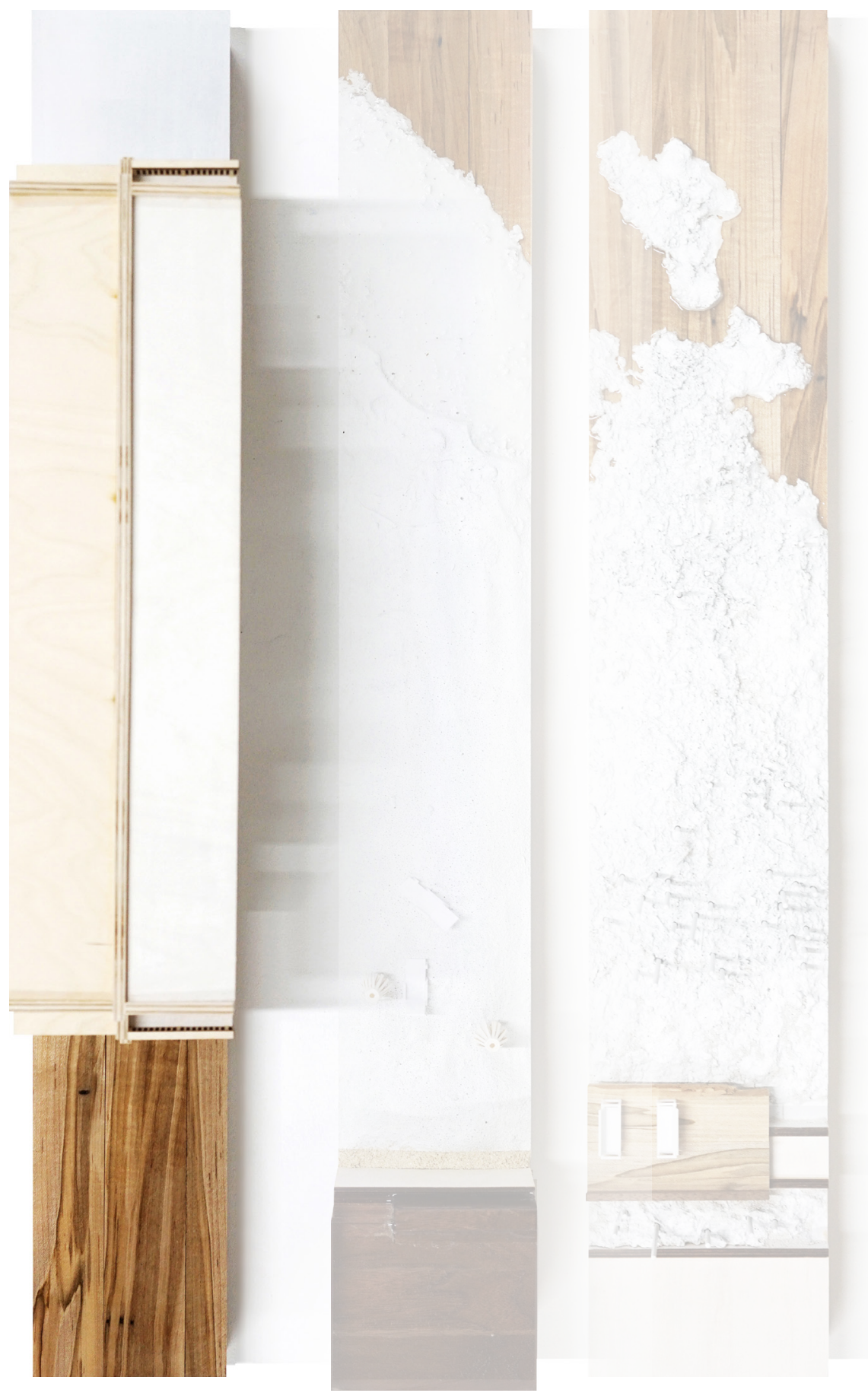

The Porch

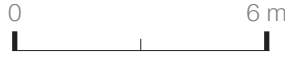




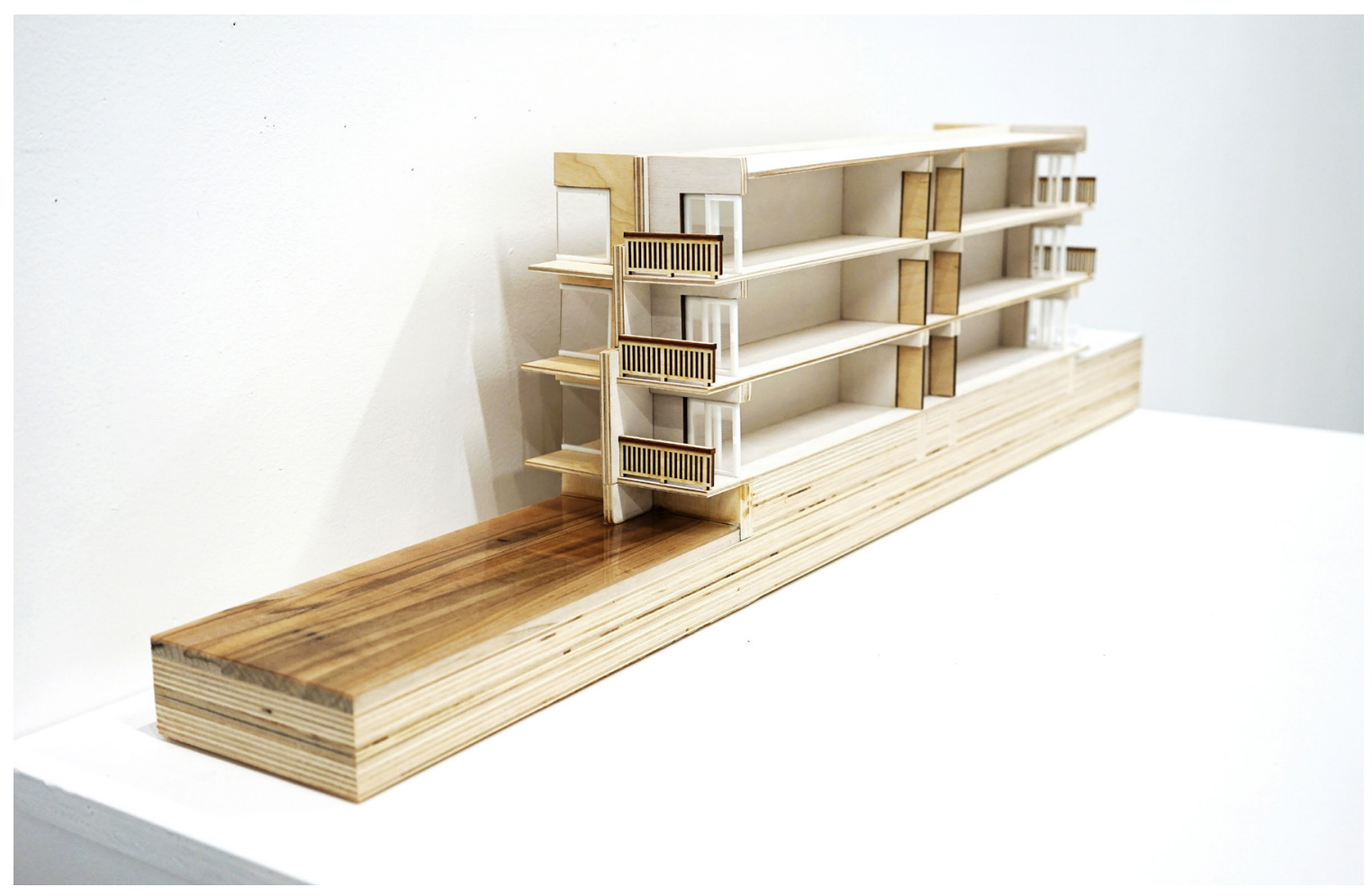

Figure 62 \& 63: 'The

Porch' model details.

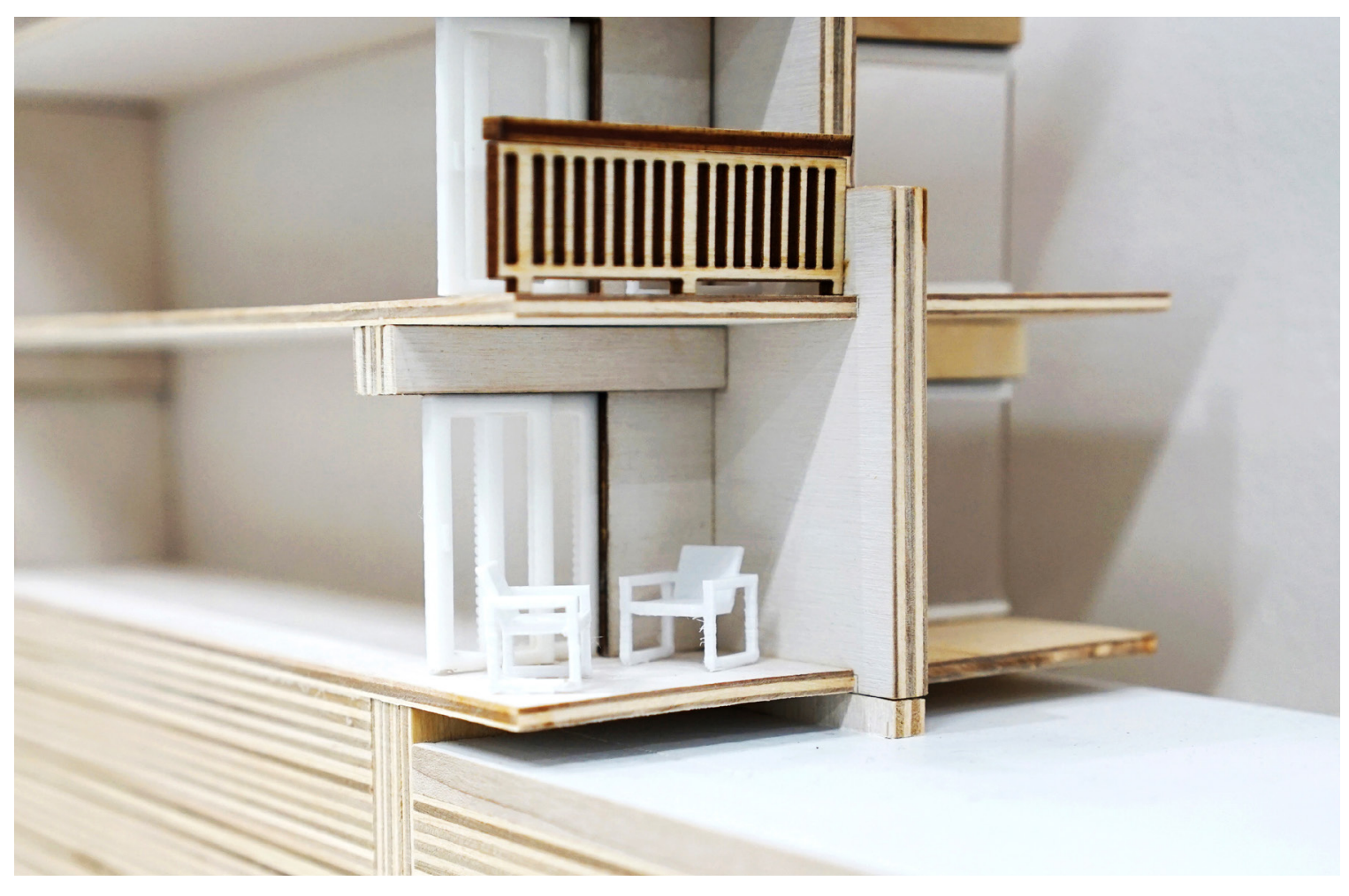



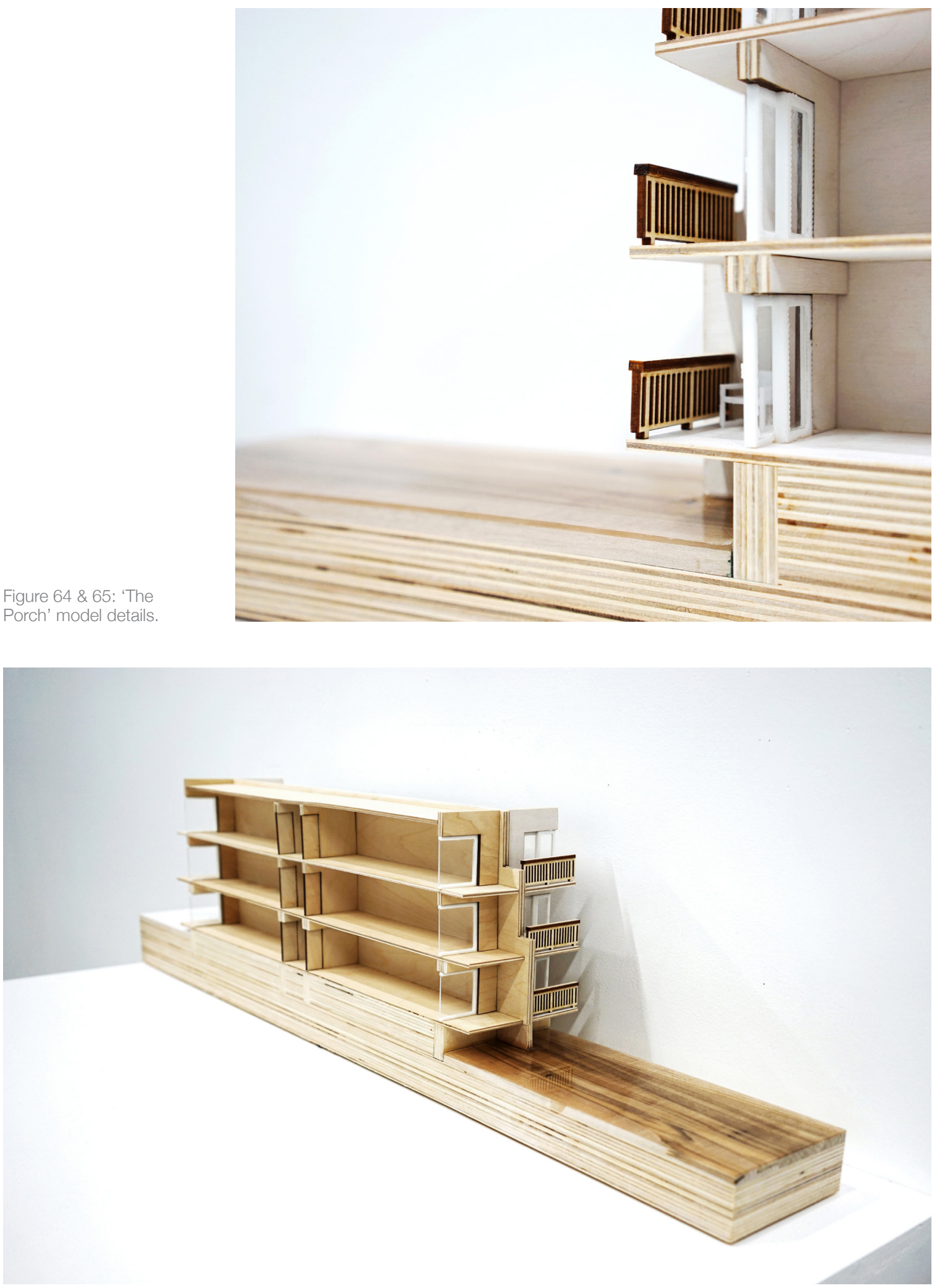
The swimming pool is a signifier of socio-economic status, representing both the aspiration and banality of suburbia. Requiring large amounts of space and maintenance, swimming pools devote major portions of private property to seasonal leisure. Whether in-ground or above-ground, pools stand out as a significant home amenity, suggesting that fun and leisure can be achieved in one's own back yard.

Swimming pools are also a key all-inclusive amenity, serving as a focal point to many resort properties. Possessing great marketing value, swimming pools are typically imaged in a way that showcase their scale, sprawling configuration and views. Due to compact resort sites in Cancun, infinity pools are especially common. Their wet infinity edge is precisely detailed, crafting two distinct sides to the pool. The resort side is elevated, holding deep water. Views are cast over the horizon, skimming over the abutting public beach. Exposed to the breezes and saline scents of the ocean, infinity pools offer the perception of infinite space to guests.

Conversely, those viewing the infinity pool from the public beach face a wall. Being lower than the elevation of the resort guest, one's sense of space is compressed against an often poorly maintained concrete screen. With no means to see or access this resort amenity from the beach, the infinity pool operates as an ingenious exclusionary tool - offering a heighted sense of space to guests, while presenting an unwelcoming surface to the public.

This scene is modelled as a site section based off of conditions observed while walking down the Cancun beach. Cutting through pool water, eroding sand and shallow sea water, the model positions the pool's infinity edge in relation to wider site tiers. Intervening on this scene, a large window is placed within the infinity pool's outer wall. This window disrupts the infinity pool's continuous ledge, creating a sharp border that is uncomfortable to lean on or against. The window also inverts the viewscapes previously established in the scene, shifting the resort guests from the viewers to the viewed. 


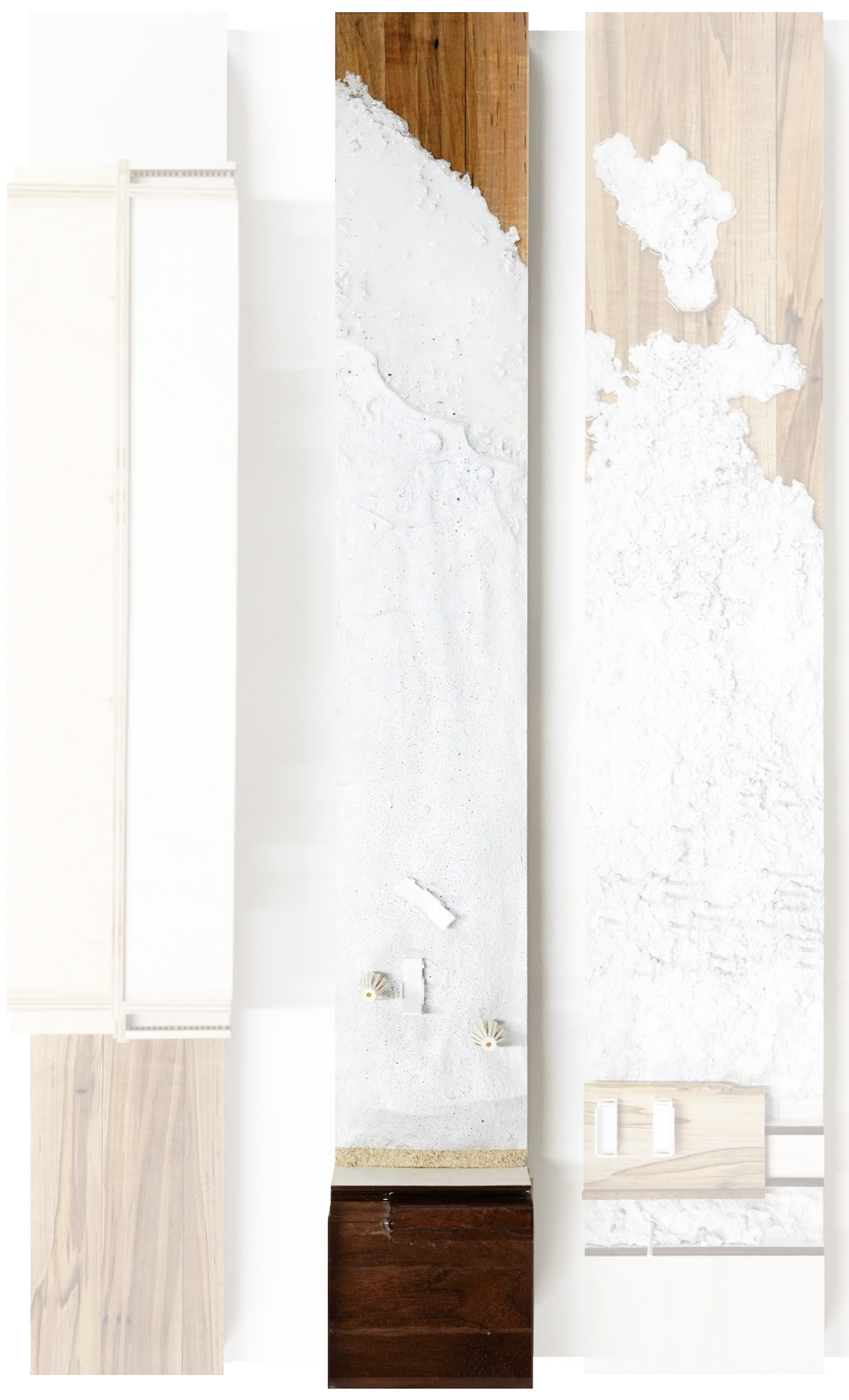

The Pool

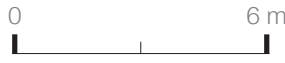


Assurance

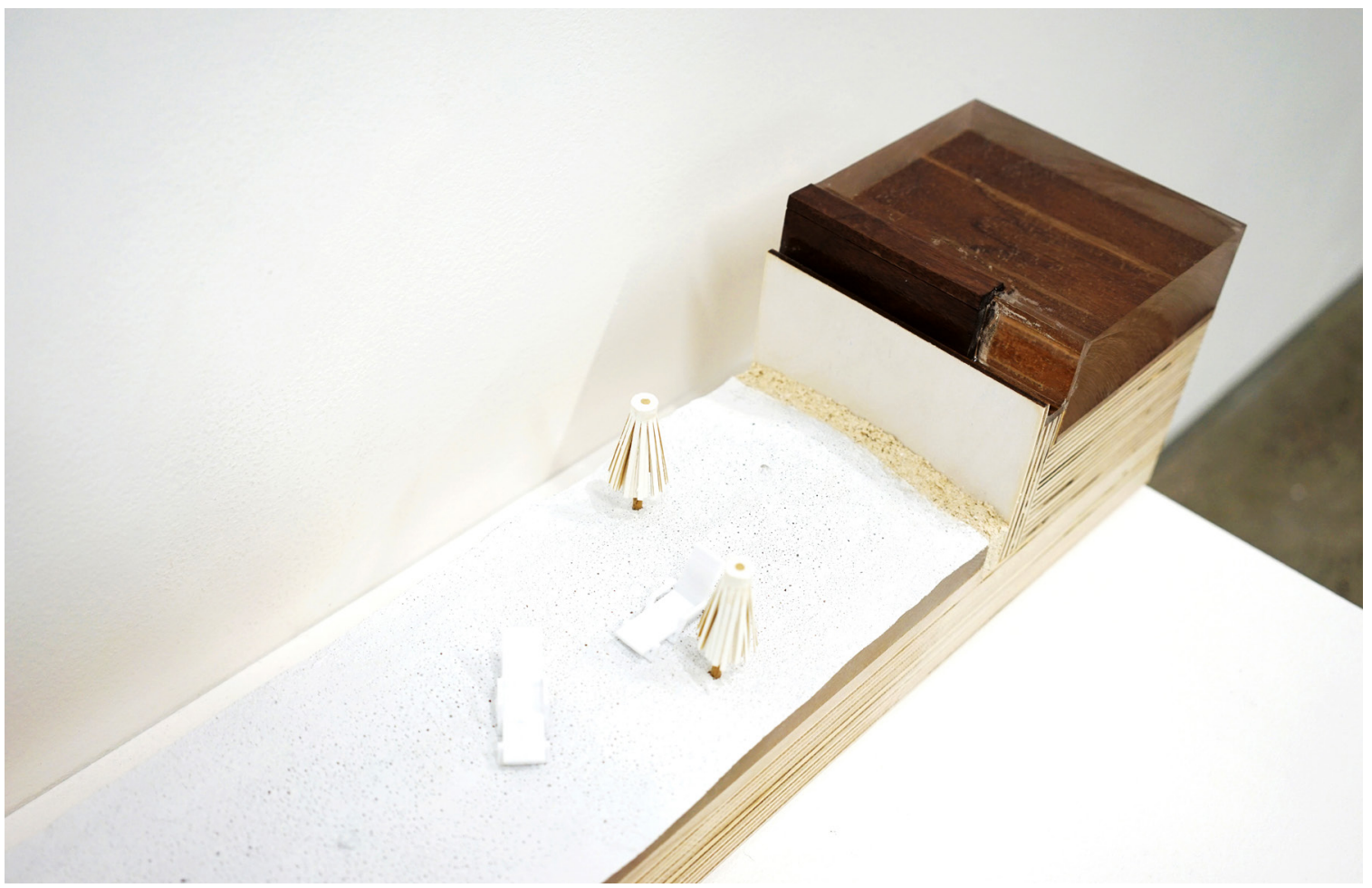

Figure 66 \& 67: 'The Pool' model details.

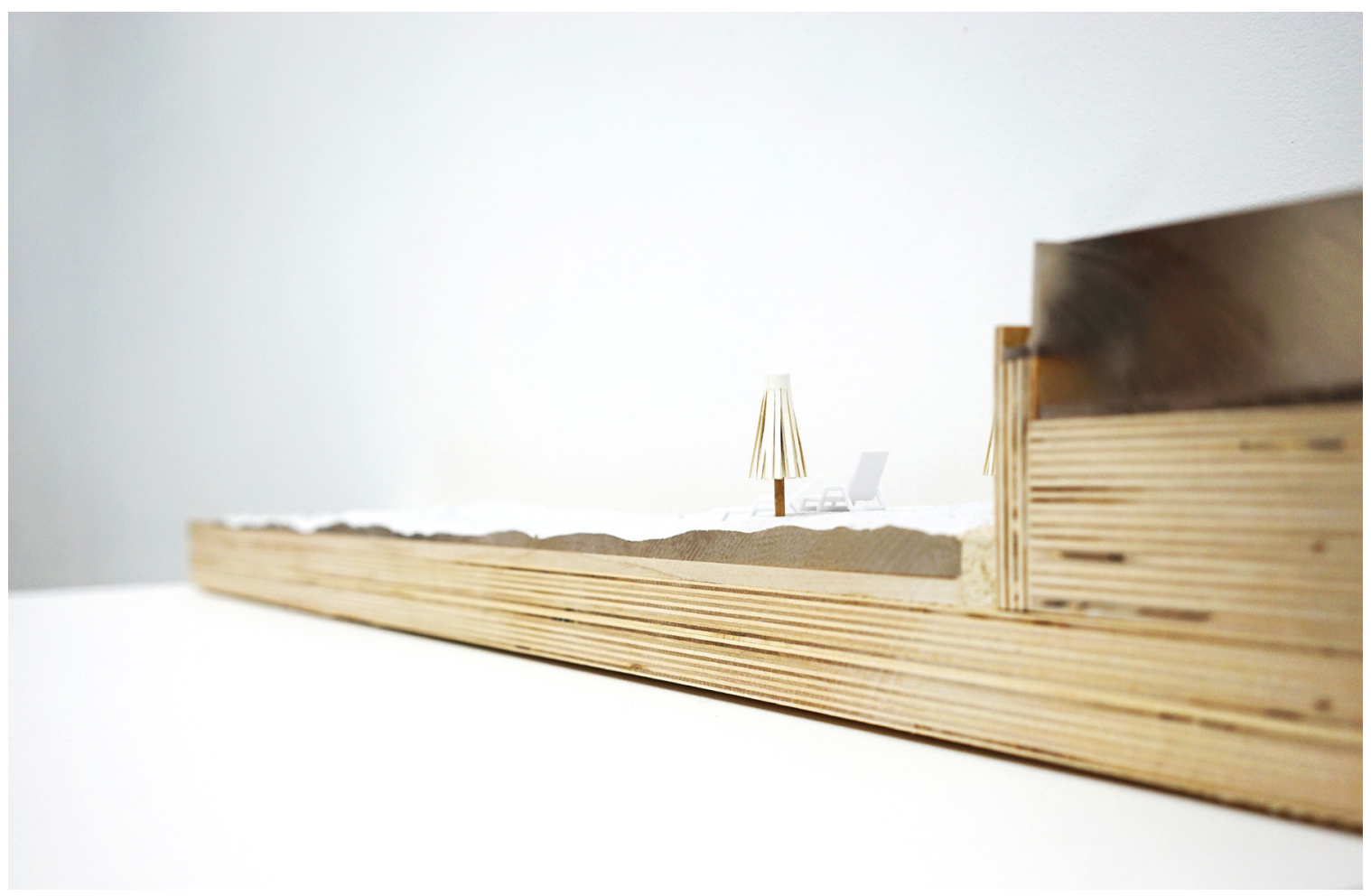



Garden paths wind through private yards, between suburban properties and across neighbourhood parks. These scenic routes are often romanticized for their pastoral qualities, meandering indirectly between destinations. Separated from traffic by parkland, yards or medians, garden paths notably demonstrate an abrupt shift from the grids of urban spaces.

Garden paths frequently connect disparate zones in all-inclusive resorts. Featuring loose, curvilinear configurations, they generally contrast the layout of other compactly designed areas. While resort nodes usually only contain sporadic planting, garden paths exhibit lush, layered vegetation. Closely illustrating a resort's curated approach to nature, plant densities and varieties are carefully selected to amplify a guest's experience of verdant tropical vegetation.

While garden paths are necessary to connect resort zones, their separation from core amenities makes them a less controlled environment. Garden paths are also where guests are most likely to encounter local workers such as housekeepers, gardeners and van drivers. Managing pedestrian circulation thus becomes a key mandate for resort planners. Path widths are compressed and few rest points are provided, ensuring guests remain en route for the shortest time possible. Furthermore, no resort programming is oriented towards pedestrian walkways, limiting the potential for informal interaction outside of key resort nodes. While garden paths are lush and immersive, they are not designed as places to linger.

The garden path is modelled as a cross section through one of Club Med's primary pedestrian pathways. This particular pathway connects the resort's northern and southern amenities, running adjacent to a vehicular access route, dense vegetation and a portion of exposed coastal reef. While the majority of the pathway is narrow and enclosed by vegetation, this scene features wider pathway dimensions and clusters of seating. This seating is intended for guests as well as resort workers, extending the duration and impact of their intersection. 

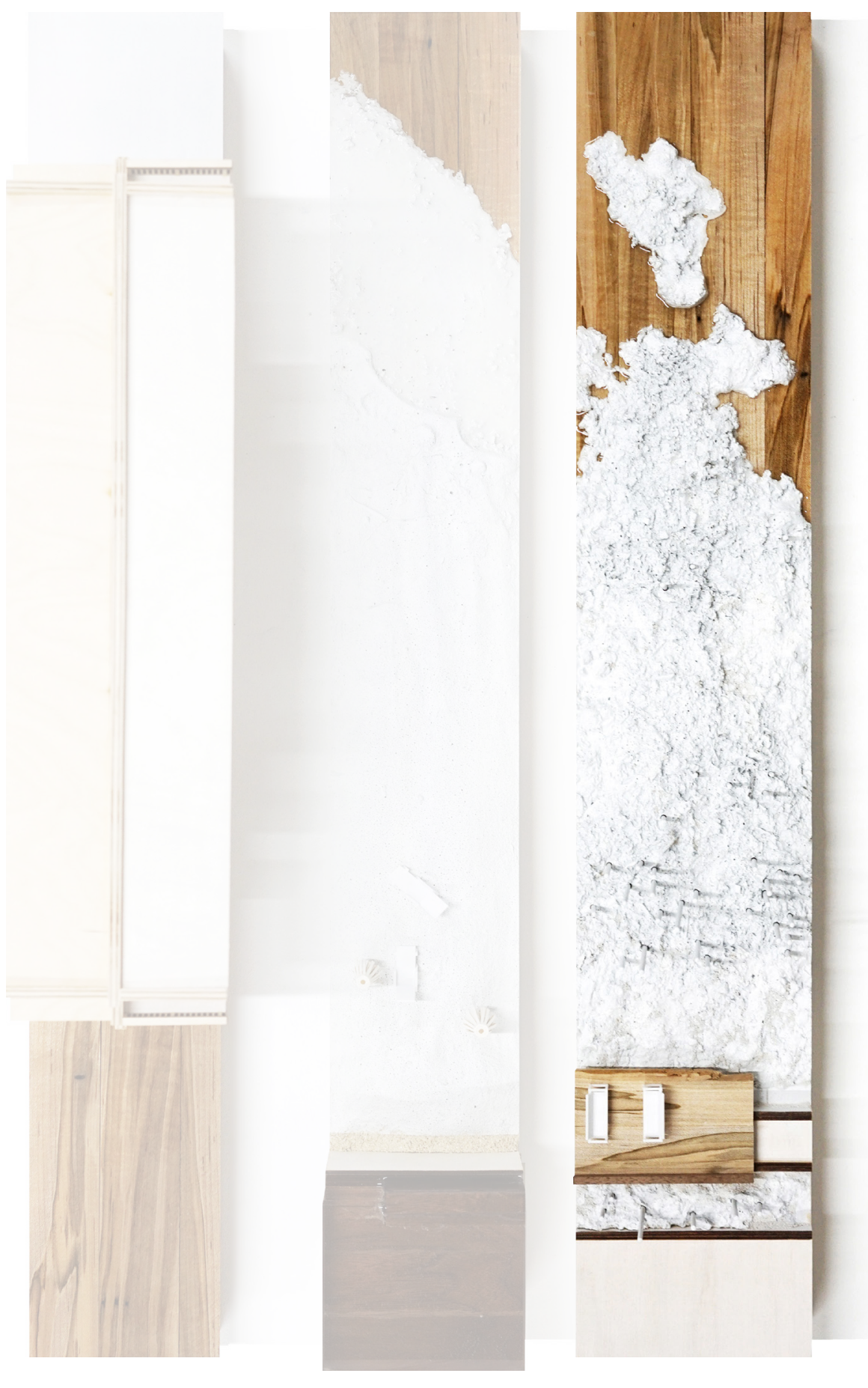

The Garden Path

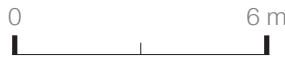




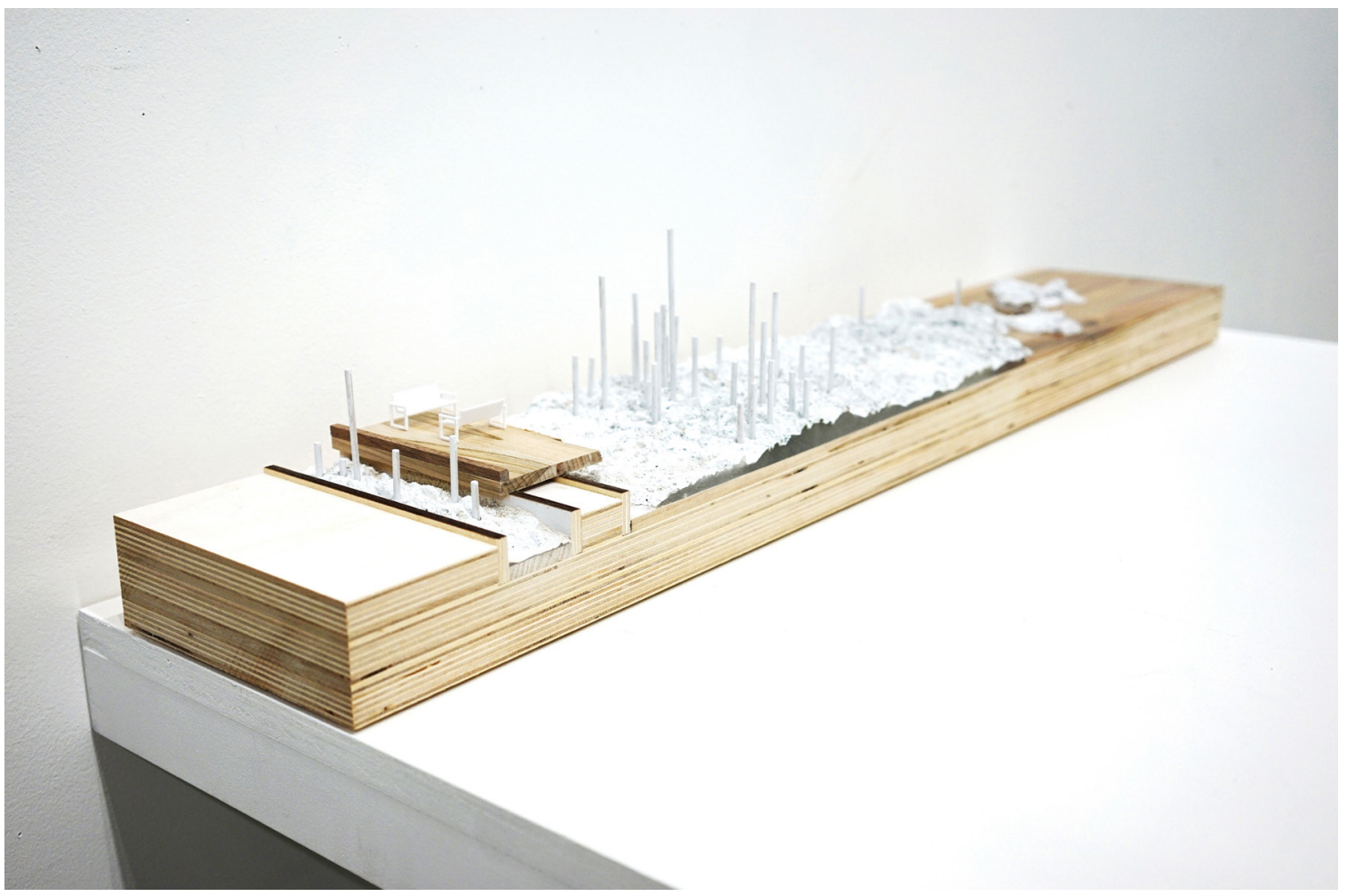

Figure 70 \& 71: 'The

Path' model details.

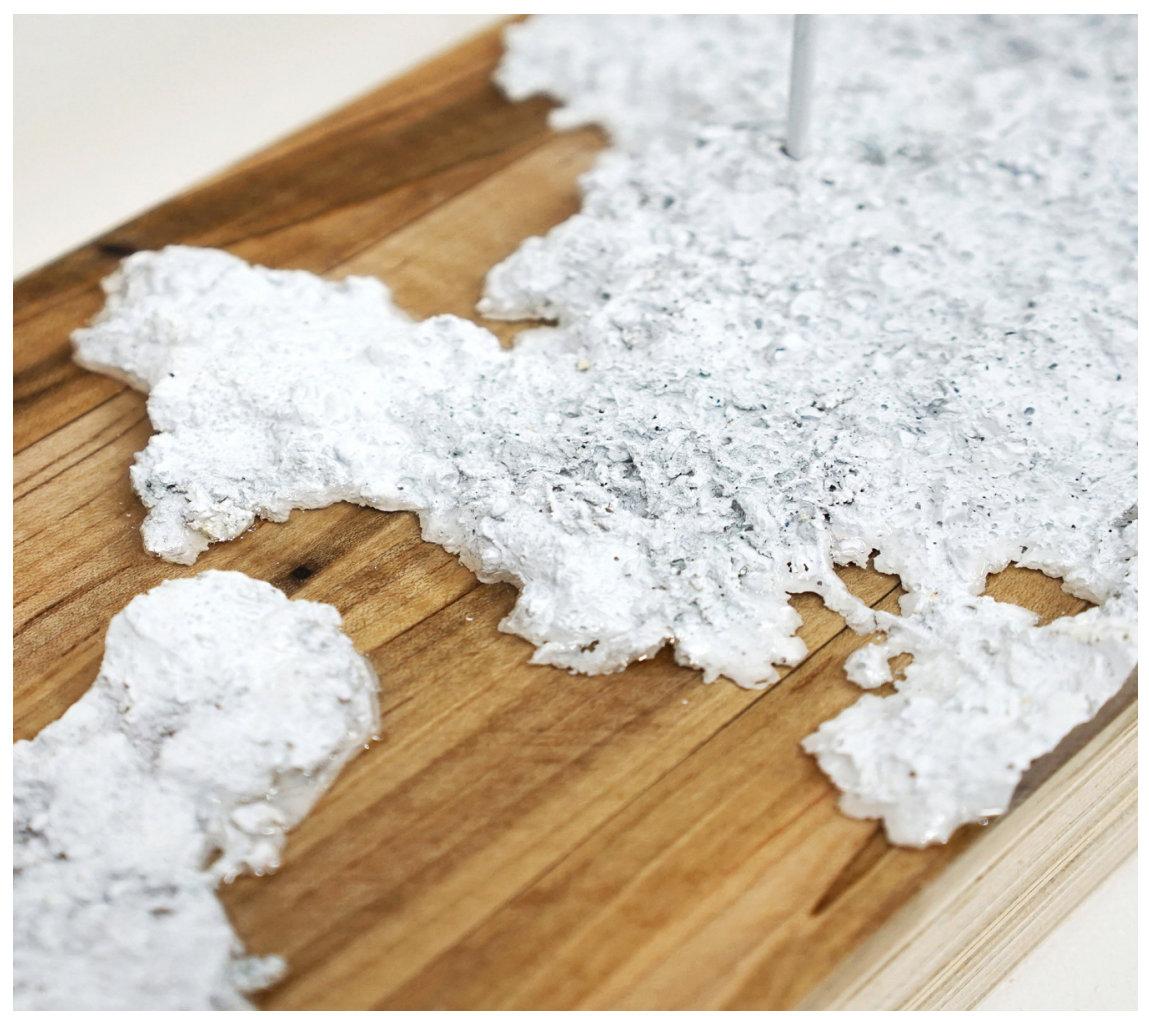




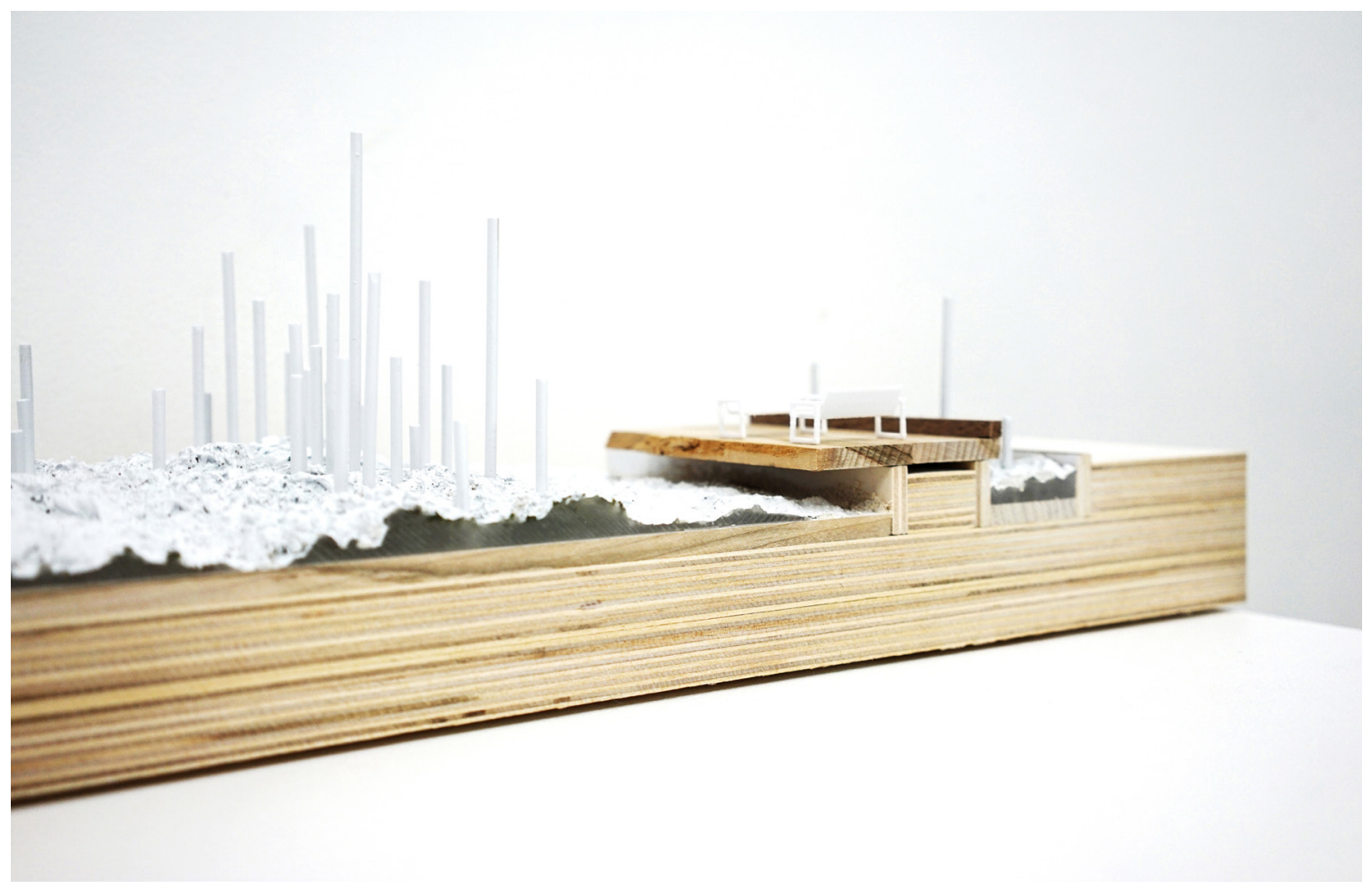

Figure 72 \& 73: 'The

Path' model details.

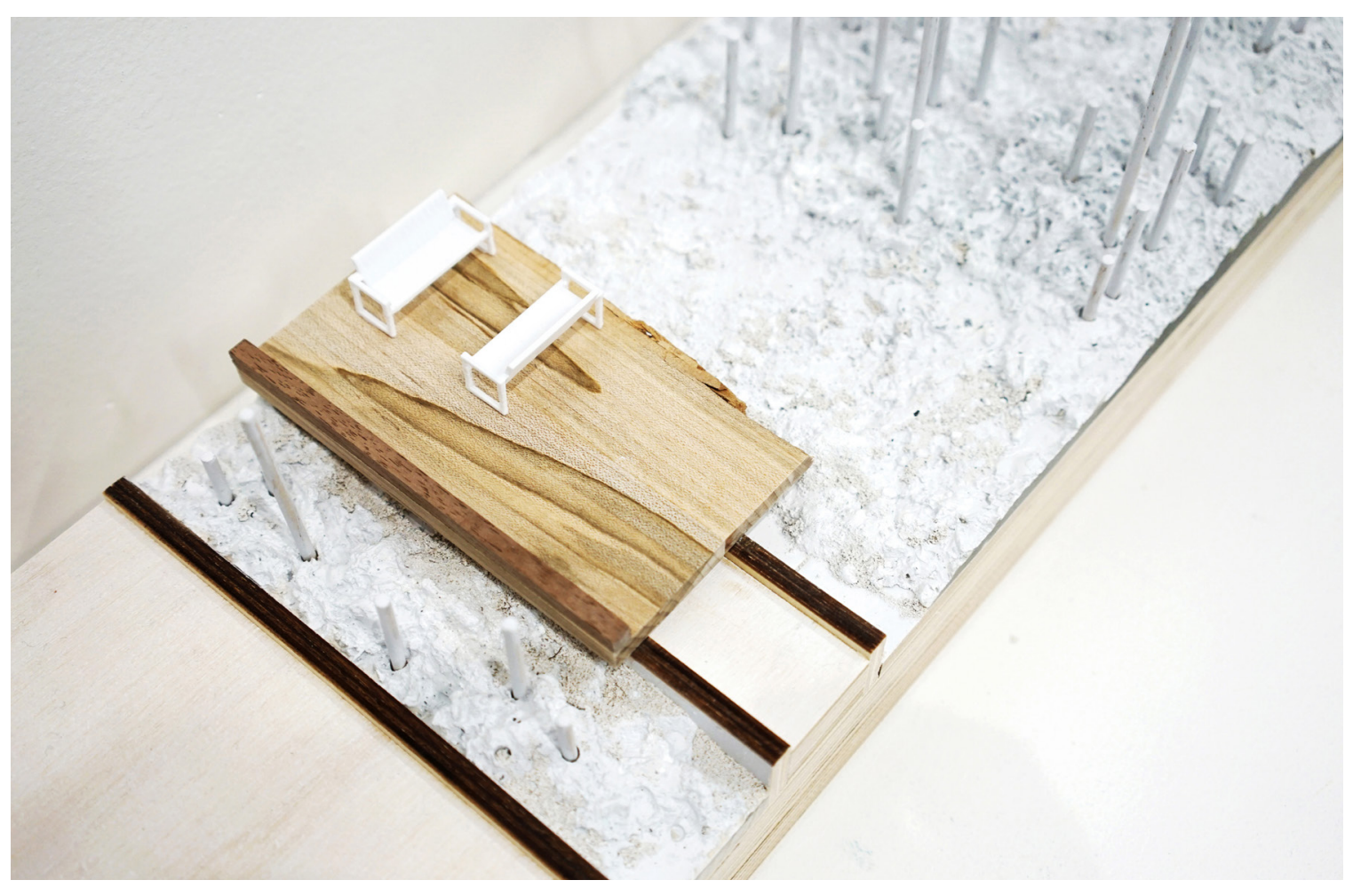


In sites as thoroughly composed as all-inclusive resorts, every detail is carefully considered to meet anticipated levels of privacy and material consistency. As a result, all-inclusive spaces employ a range of layered strategies to make tourists feel safe, comfortable and settled. These strategies include tangible devices such as walls or tiers, yet may also encompass the design of spaces that are intentionally made dull or uncomfortable, thereby limiting their potential for meaningful inhabitation. At the same time, all-inclusive operators continue to market resorts as places that are 'family-friendly' or 'romantic', while dually instilling a vague sense of unease around adjacent cities and 'others'. Tying elements of all-inclusive construction to familiar suburban tropes encourages architectural designers and consumers to reflect on how spatial expectations are commonly manifested across domestic and enclavic environments.

By physically modelling a series of three resort segments, a wide array of thresholds may be identified that subtly guide the occupation of mass touristic space. Despite contributing to the choreography of allinclusive sites, these edge conditions define zones where the façade of tropical paradise begins to fracture and peel. The choice to model these zones allows key thresholds to be actively viewed from all sides, while furthermore, the intentional omission of scale figures invites inquiry into how these segments are ultimately populated post-intervention. Note that Figure 74 further elaborates on these models, layering site photographs and promotional material over the resin surfaces.

Finally, through clearly describing exclusionary design devices, site tension is acknowledged, while simultaneously identifying opportunities to linger in spatial ambiguity. The small design gestures described in the previous sub-sections thus seek to generate varied and inconsistent interactions between visitors and 'others'. While these gestures suggest ways of modifying existing space from the perspective of an architectural designer, crucially, these same spaces may also be negotiated by allinclusive tourists themselves -

Leave your room. Look on the other side of the wall. Walk slowly through circulation spaces. Introduce yourself to the bartender, the housekeeper, the gardener. 


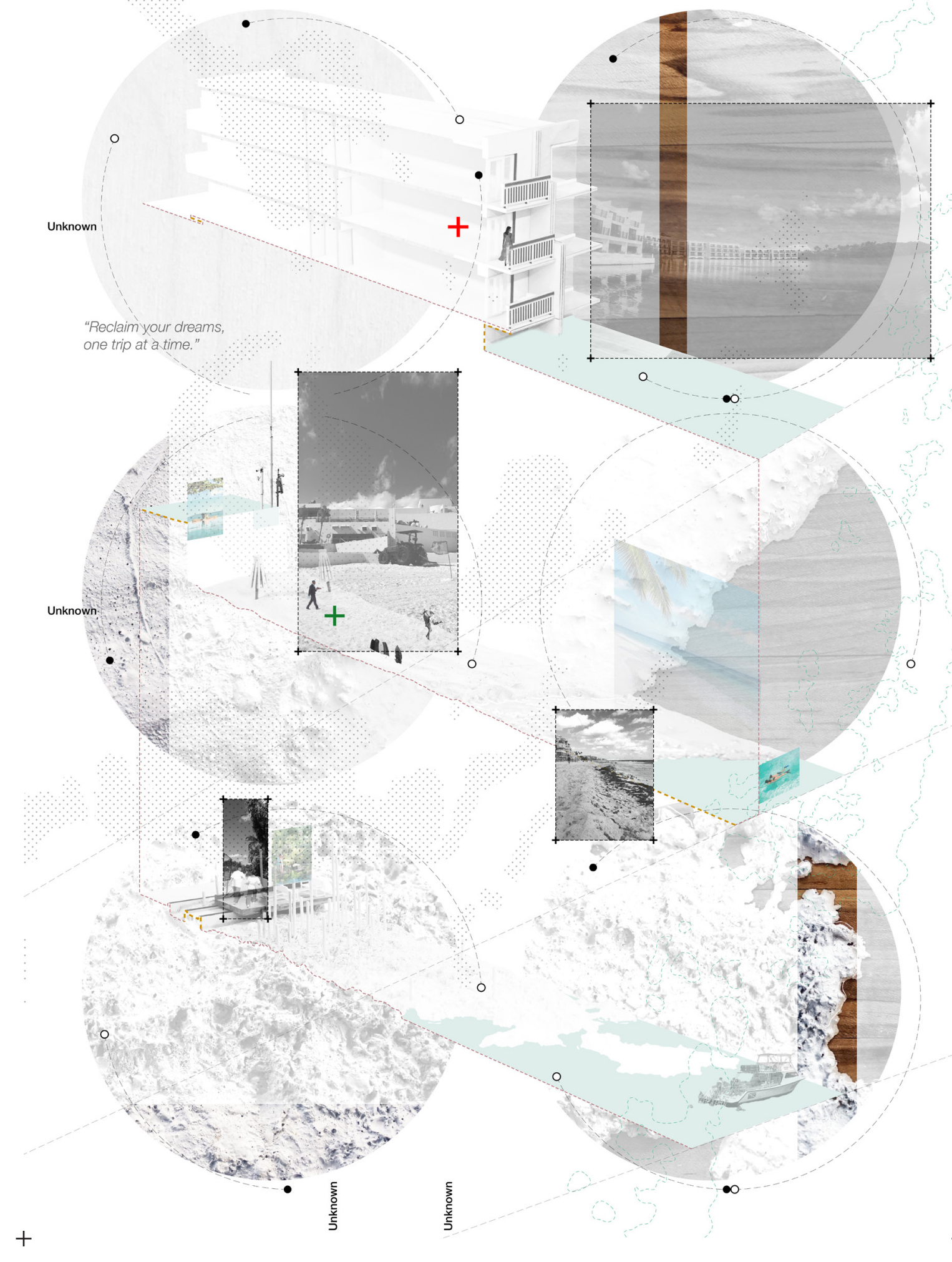

Figure 74: Trope collage over textured surface mapping. 
'home' vs. 'away'

'host' vs. 'guest'

'fantasy' vs. 'reality'

Tourism is an industry that thrives on binary terms. Narratives of difference and otherness ${ }^{105}$ propel tourists to seek encounters that are considered outside the realm of everyday experience. ${ }^{106}$ Despite the potential for travel to promote genuine intercultural exchange, often the practice relies on establishing bland, reductive dualisms. ${ }^{107}$

Through investigating the relationships between budget airlines and all-inclusive resorts, I have sought to develop a counter narrative that focusses on the fluidity and continuity of touristic spaces, while acknowledging the presence of critical boundaries. At the outset of this thesis, I suggested that tropical paradise, as constructed through allinclusive resorts, may be interpreted as a global extension of suburbia. This position was subsequently mapped as a speculative concentric realm, influencing how tourists perceive their surrounding spaces at continental, regional, site-specific and personal scales. Reflecting on these investigations, I would like to conclude with a wider discussion on mass tourism as a cultural and economic force, generating immense spatial transformation around the world.

As a "hyper-globalizing" (494) ${ }^{108}$ industry, mass tourism's own speed and accessibility often blur out a multitude of problems. Behind manicured sites and stunning vistas are issues of labour exploitation,

105 Salazar, Toward, 1.

106 Urry, The Tourist, 3.

107 Bianchi, The Critical, 486.

108 Ibid., 494.

109 Simpson, Mapping 15.

110 Salazar, Toward, 18 11 McRae, Rethinking, 241.

112 Edensor, Performing, 74. fragile habitat destruction and unfavourable neoliberal policy. ${ }^{109}$ Mass

tourism in particular is also associated with the commodification of drastically abridged cultures. ${ }^{\text {II }}$ These challenges are further compounded by tourism pathways themselves, which collectively make travel as unambiguous, risk-free and comfortable ${ }^{\mathrm{III}}$ as possible.

While it is easy to problematize all-inclusive resorts from a distance, it is more challenging to recognize one's individual role in perpetuating key issues. For many tourists, there is a certain pleasure associated with opting out of responsibility when on vacation. ${ }^{\text {II2 }}$ This is understandable, as all-inclusive tourism relies on the delivery of restoration, relaxation 
and release from everyday stressors. Recognizing insecurity and unpredictability is innately distressing, particularly when travelling. When within the friendly confines of all-inclusive resorts, tourists must elect to notice uncomfortable relationships and adjacencies, as they are largely hidden.

Sites of mass tourism are evidently designed for passive engagement, ${ }^{113}$ implementing discreet methods of control to program negative qualities out of key scenes. ${ }^{\mathrm{II}}$ This is problematic, as tourists may traffic through designed space with little awareness of manipulation and constraint. Without a clear understanding of how people are spatially, culturally and commercially bound, it becomes increasingly difficult to question and confront established travel habits. ${ }^{115}$ Through blindly repeating expected touristic practices, difference may indefinitely remain "contained, sedate and secure for consumption" (24I). ${ }^{.16}$

Ultimately, it is tourists who reproduce tourism. ${ }^{117}$ Average tourists thus have the agency to transform existing space through shifting their patterns of consumption and occupation. ${ }^{118}$ Through clearly juxtaposing the fantasy of all-inclusive tourism with the familiarity of suburban development, I have sought to establish a clear datum through which tourists may evaluate some of their travel expectations. By coming to

113 Eco, Umberto.

"Travels in Hyperreality." In Travels in Hyper Reality: Essays, 48. San Diego, CA: Harcourt Brace Jovanovich Publishers, 1986.

114 Zukin, Disney, 222.

115 Ritzer, McDisneyization, 106.

116 McRae, Rethinking, 241.

117 Ateljevic, Irena "Circuits of Tourism: Stepping Beyond the "production/consumption" Dichotomy." Tourism Geographies 2, no. 4 (2000): 377

118 Edensor, Performing, 64.

119 Salazar, Toward, 1.

120 Klingmann, Brandscapes, 2 terms with domestic assumptions carried forward after departure, I hope that tourists may feel confident pursuing a deeper engagement with their settings when abroad.

A second function of this thesis was to challenge dominant perceptions of all-inclusive resorts, interrupting the stale images frequently associated with 'package' tourism. The realms of tropical paradise and suburbia are both frequently stereotyped in contemporary media, yet are experienced with complexity and nuance. While this work was limited in its use of promotional material as primary references, highly marketable mediums such as travel catalogues and brochures generate significant commercial allure. The notion of tropical paradise thus holds great cultural and capital power, visibly achieved through manipulating how real spaces are imagined. ${ }^{.19}$ Consequently, in order for architects to engage most critically with the structural issues surrounding all-inclusive tourism, they must actively debate the robust imaginaries driving current consumer culture. In doing so, architecture may act as a platform for new experiences and thoughtful discourse. ${ }^{120}$ 
On this note, my intention was not to fixate on solutions, but rather tease out possibilities in mass tourism. Several questions subsequently arose while developing this project, particularly relating to tourism's major themes of authenticity and nostalgia. ${ }^{\mathrm{I21}}$ While open to argument, I personally believe that there is no tourism which is not in some way staged or contrived. Are well-trodden backpacking routes really more authentic than all-inclusive resorts? When nobody meets their neighbours, does Airbnb actually immerse tourists in a community? If all-inclusive resorts are most closely a reflection of domestic development, can their separation from local communities allow adjacent cultures to exist on their own terms?

Not all tourists are intrepid. Not all tourists are young and mobile. Not every parent feels confident wrangling multiple small children in an urban setting. With this in mind, all-inclusive resorts hold potential for hosting extended, consistent interactions. By virtue of the model's own insularity, most tourists are held on a single site for the entire duration of their vacation. Many tourists also return to the same resort year after year. While visiting Club Med Cancun, I routinely witnessed guests who established long-term relationships with individuals they saw on a daily basis while vacationing. The architecture and infrastructure of mass tourism thus holds the capacity to support evolving interactions on a grand scale. Instead of strictly regarding all-inclusive resorts as an insular product of 'package' tourism, much more profound local engagement could be achieved if all-inclusive resorts are regarded as a pattern of urban development with wider programmatic potential.

Over the course of this thesis I have been critical of 'package' tourism; however, I have also sought to open a balanced discussion on how all-inclusive resorts may be spatially reinterpreted and negotiated, particularly in light of their integration within the budget airline industry. The tendency to exclude all-inclusive resorts from contemporary architectural discourse does little to advance the imaginative possibilities of mass tourism. Travel — in its many forms - holds the potential to degrade rigid boundaries and fixed global

1 McRae, Rethinking, 237.

122 Ibid., 245.

123 Ateljevic, Circuits, identities, ${ }^{122}$ constructing spaces that are "actively produced, represented and contested" (378). ${ }^{123}$ While all-inclusive tourists undoubtedly encounter regulation, their individual experiences are also open to variability and surprise. 


\section{On Displaced Comfort}

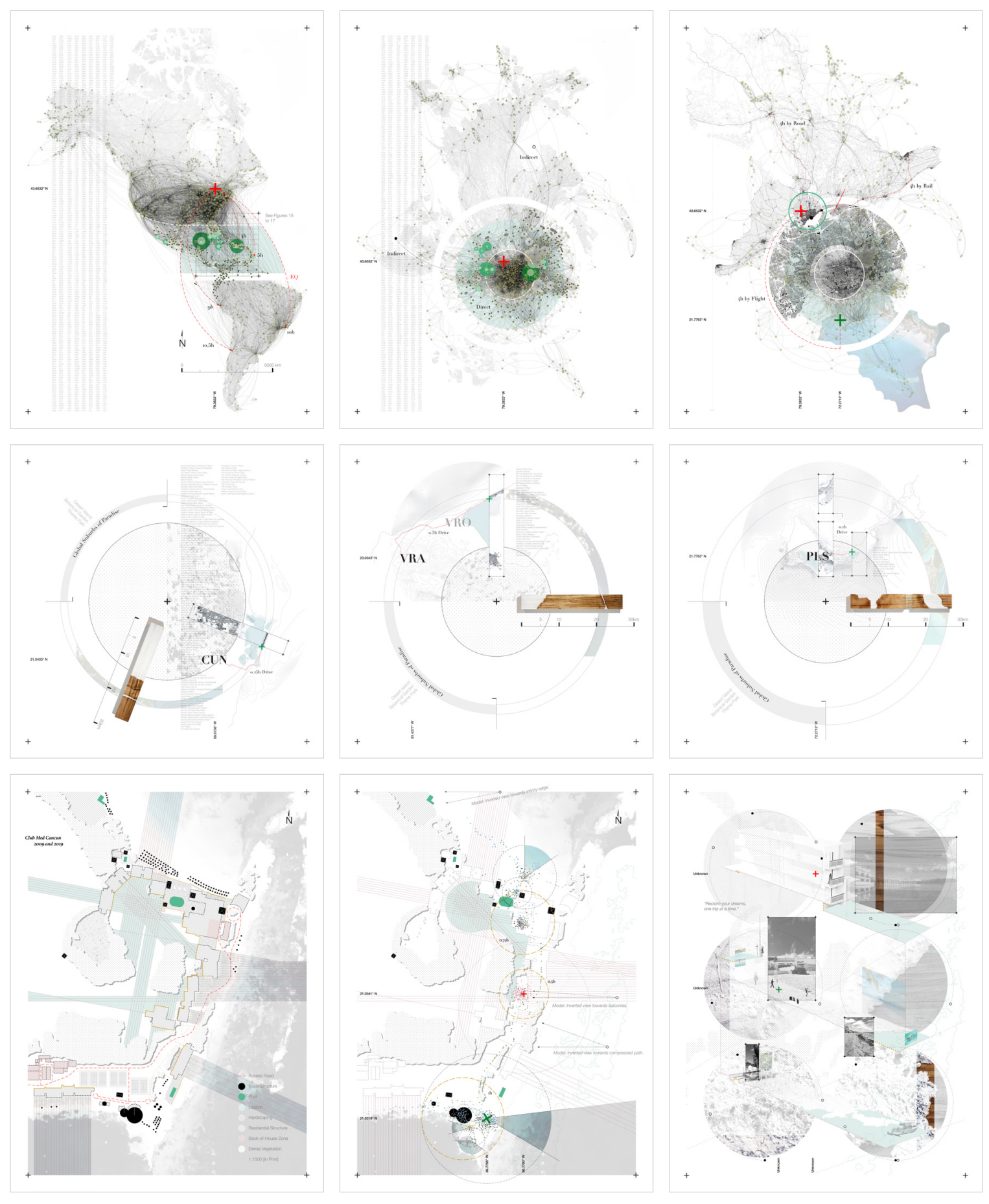

Figure 75: Final matrix of nine key thesis panels. 
During the thesis defence, several interesting discussions arose on the nature of paradise-suburbia at different scales, and how their associated relationships may be represented using architectural drawing conventions. To conclude, I feel one question in particular deserves a more extended reflection:

\section{How can this work inform a future mode of practice?}

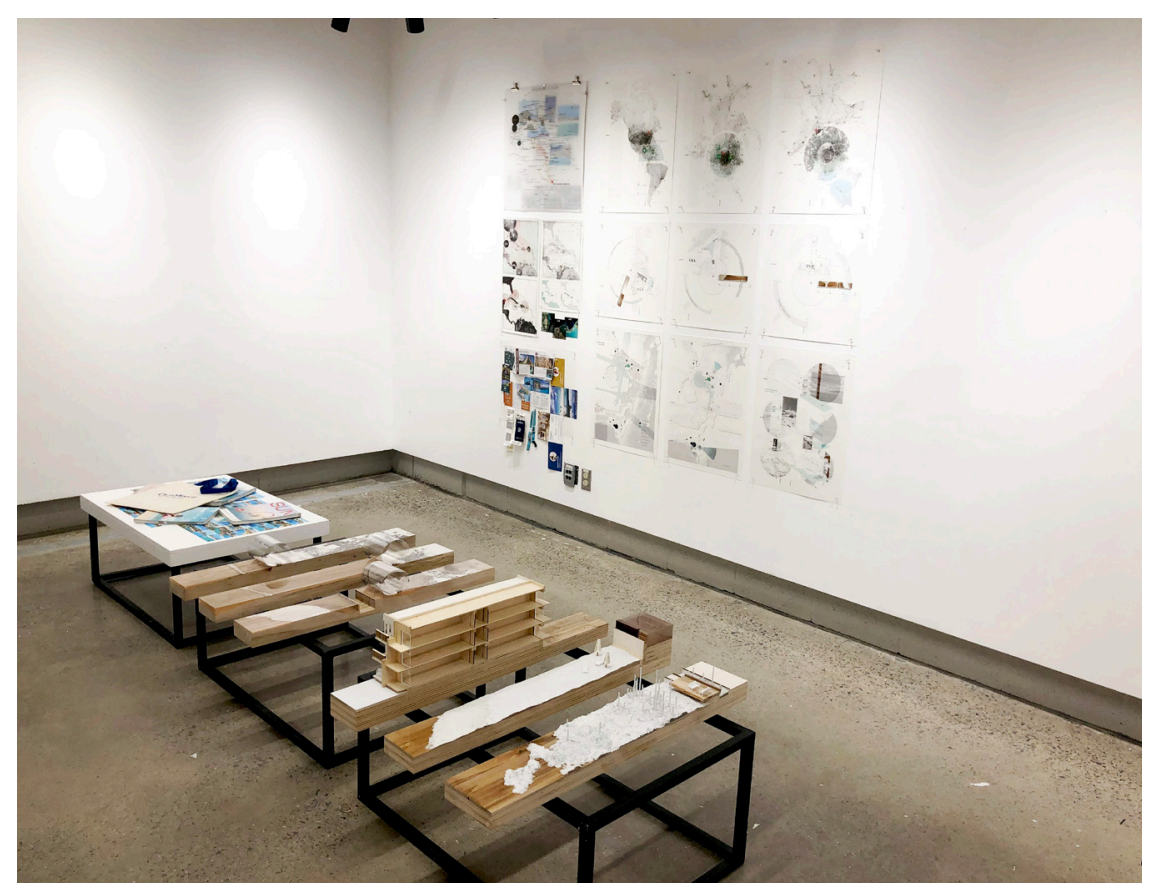


While the scope of this thesis was limited to the study of all-inclusive resorts in the greater Caribbean region, the project followed a research methodology that could be generalizable to a wide array of architectural investigations. Moving forward, this analysis of all-inclusive resorts could be considered a single case study in the development of workflows that study the expression of global networks in even the most mundane architectural details.

The thesis followed a cyclical approach whereby individual datasets were mapped, analyzed, and manipulated to better represent the spatial perception of specific places and experiences. These manipulated maps were then used to inform subsequent drawings and/or models. This process was repeated at each change of scale and with the introduction of each new series of physical models. With every cycle, my engagement with the fields of suburbia and tropical paradise evolved from drawing broad generalizations to crafting momentary intersections. Architectural drawing, mapping, and modelling conventions thus became critical tools to represent geographically disparate realms interconnected by tangible and intangible infrastructures. In the case of paradise-suburbia, the graphic neutrality of 'the architectural eye' additionally freed the project from relying on visual crutches that immediately suggest a beach holiday or suburban home, at the expense of more nuanced encounters with each domain.

Thus, some of the most fruitful aspects of this thesis were the surprising relationships that emerged during the repetitive processes of speculative mapping and modelling. At the outset of the academic year, I did not anticipate traits of suburbia to be reflected in both the imagination and construction of tropical paradise; however, I hope this thesis opens new design potential for the architecture of mass tourism. 


\section{Print}

Archer, John. Architecture and Suburbia: From English Villa to American Dream House, I690-2000. Minneapolis, MN: University of Minnesota Press, 2008.

Ateljevic, Irena. "Circuits of Tourism: Stepping Beyond the "production/ consumption" Dichotomy." Tourism Geographies 2, no. 4 (2000): 369-88. doi:I0.I080/I46I66800750035495.

Baudrillard, Jean. Simulacra and Simulation. Ann Arbor, MI: University of Michigan Press, I98I.

Bianchi, Raoul. "The Critical Turn in Tourism Studies." Tourism Geographies II, no. 4 (2009): 484-504. doi:I0.4324/9780080470986.

Chawla, Gaurav, and Marcelina Wanjiru Ndungu. "The Ethics of an Allinclusive Plan: An Investigation of Social Sustainability in the Case of All-inclusive Resorts, Jamaica." Research in Hospitality Management 4, no. I-2 (2OI4): 2I-28. doi:IO.IO8O/22243534.2OI4.II8283IO.

Coles, Tim. "What makes a resort complex?" In Tourism in the Caribbean: Trends, Development, Prospects, 235-256. London, UK: Routledge, 2004.

Corner, James. "The Agency of Mapping: Speculation, Critique and Intervention." In Mappings, 213-252. London, UK: Reaktion Books, 1999.

Deleuze, Gilles. "Desert Islands." In Desert Islands and Other Texts: 19531974, 9 - I4. Los Angeles, CA: Semiotext(e), 2004.

Deloughrey, Elizabeth. "Island Ecologies and Caribbean Literatures." Tijdschrift Voor Economische En Sociale Geografie 95, no. 3 (2004): 298-310.

Deloughrey, Elizabeth. "“The Litany of Islands, The Rosary of Archipelagos": Caribbean and Pacific Archipelagraphy." A Review of International English Literature 32, no. I (200I): 2I-5I.

Duval, David Timothy. "Trends and Circumstances in Caribbean Tourism." In Tourism in the Caribbean: Trends, Development, Prospects, I-22. London, UK: Routledge, 2004.

Eco, Umberto. "Travels in Hyperreality." In Travels in Hyper Reality: Essays, I-58. San Diego, CA: Harcourt Brace Jovanovich Publishers, 1986.

Edensor, T. "Performing Tourism, Staging Tourism: (Re)producing Tourist Space and Practice." Tourist Studies I, no. I (200I): 59-8I. doi:Io.II77/I46879760IOoIOoIO4.

Forsyth, Ann. "Defining Suburbia." Journal of Planning Literature 27, no. 3 (2012): 270-8I. doi:IO.II77/08854I22I2448IOI.

Foucault, Michel. "Of Other Spaces: Utopias and Heterotopias." Architecture/Mouvement/Continuité, October 1984.

Grove, Richard. Green Imperialism: Colonial Expansion, Tropical Island Edens and the Origins of Environmentalism, I60o-I860. Cambridge, UK: Cambridge University Press, 1995. 
Jordan, June. "Report from the Bahamas (1989)." In A Stranger in the Village: Two Centuries of African-American Travel Writing, 319-329. Boston, MA: Beacon Press, 1998.

Kincaid, Jamaica. A Small Place. New York, NY: Penguin Group, 1988.

Klingmann, Anna. Brandscapes: Architecture in the Experience Economy. Cambridge, MA: MIT Press, 2007.

Koolhaas, Rem. Delirious New York: A Retroative Manifesto for Manhattan. New York, NY: Monacelli Press, I994.

Lambert, Leopold. "Archipelagos and Indigenous Imaginaries." In The Funambulist: Politics of Space and Bodies 9 (Jan. \& Feb. 2017).

Le Corbusier. Aircraft: The New Vision. London, UK: Trefoil Publications, 1987.

Le Corbusier. Towards a New Architecture. New York, NY: Dover Publications, 1986.

McRae, L. "Rethinking Tourism: Edward Said and a Politics of Meeting and Movement." Tourist Studies 3, no. 3 (2003): 235-5I. doi:I0.II77/I468797603049658.

More, Thomas. Utopia. New Haven, CT: Yale Nota Bene, 200I.

Nixon, Rob. Slow Violence and the Environmentalism of the Poor. Cambridge, MA: Harvard University Press, 20II.

Ndebele, Njabulo. "Game Lodges and Leisure Colonialists." 1999.

Picon, Antoine. "Urban Infrastructure, Imagination and Politics: From the Networked Metropolis to the Smart City." International Journal of Urban and Regional Research 42, no. 2 (2018): 263-75. doi:IO.IIII/I4682427.12527.

Salazar, Noel, and Nelson Graburn. "Toward an Anthropology of Tourism Imaginaries." In Tourism Imaginaries: Anthropological Approaches, I-28. New York, NY: Berghahn Books, 2016.

Scafi, Alessandro. "Mapping Eden: Cartographies of the Earthly Paradise.” In Mappings, 50-70. London, UK: Reaktion Books, I999.

Sheller, Mimi. "Demobilizing and Remobilizing Caribbean Paradise." In Tourism Mobilities: Places to Play, Places in Play, I3-2I. London, UK: Routledge, 2004.

Sheller, Mimi. "Infrastructures of the Imagined Island: Software, Mobilities, and the Architecture of Caribbean Paradise." Environment and Planning A 4I, no. 6 (2009): I386-403. doi:I0.IO68/a4I248.

Sheller, Mimi. "Natural Hedonism." In Tourism in the Caribbean: Trends, Development, Prospects, 23-38. London, UK: Routledge, 2004.

Simpson, Tim. "Mapping Tourist Utopias." In Tourist Utopias: Offshore Islands, Enclave Spaces, and Mobile Imaginaries, 13-4I. Amsterdam, Netherlands: Amsterdam University Press, 2017.

Stratford, Elaine, Godfrey Baldacchino, Elizabeth McMahon, Carol Farbotko, and Andrew Harwood. "Envisioning the Archipelago." Island Studies Journal 6, no. 2 (20II): II3-30.

Strauss, Claudia. "The Imaginary." Anthropological Theory 6, no. 3 (2006): 
322-44. doi:Io.II77/I46349960606689I.

Ritzer, George, and Allan Liska. “'McDisneyization' and 'Post-Tourism': Complementary Perspectives on Contemporary Tourism." In Touring Cultures: Transformations of Travel and Theory, 96-IO9. London, UK: Routledge, 1997.

Turner, Simon, and Carolyn Troiano. "The Attraction of All-Inclusive Resorts." Cornell Hotel and Restaurant Administration Quarterly 28, no. 3 (November 1987): 25-27. doi:IO.II77/ooIO880487028003II.

Urry, John. The Tourist Gaze: Leisure and Travel in Contemporary Societies. London, UK: Sage Publications, 1990.

Venturi, Robert, Denise Scott Brown, and Steven Izenour. Learning from Las Vegas: The Forgotten Symbolism of Architectural Form. Cambridge, MA: MIT Press, I99I.

Zukin, Sharon. "Disney World: The Power of Façade/The Façade of Power." In Landscapes of Power: From Detroit to Disney World, 217-250. Berkeley, CA: University of California Press, I99I.

\section{Web}

Boghosian, Alison. "Retro Ad of the Week: Club Med, I984." M//G. Accessed November 20I8. https://mascola.com/insights/retro-ad-weekclub-med-1984/.

Lambert, Leopold. "\# FOUCAULT /// Episode 7: Questioning the Heterotopology." The Funambulist. Accessed November 25, 2018. https://thefunambulist.net/architectural-projects/foucault-episode-7questioning-the-heterotopology.

Ostrow, Joanne. "For a Club Med In Cancun." The Washington Post. May 22, 1983. Accessed February 28, 2019. https://www.washingtonpost.com/ archive/lifestyle/travel/1983/05/22/for-a-club-med-in-cancun/357e3bob4588-46I9-a79o-8d79bf55949e/?utm_term=.f22Ic9e2443f

Thompson, Derek. "How Airline Ticket Prices Fell 50\% in 30 Years (and Why Nobody Noticed)." The Atlantic. February 28, 2013. Accessed July 30, 20I8. https://www.theatlantic.com/business/archive/2013/02/ how-airline-ticket-prices-fell-50-in-30-years-and-why-nobodynoticed/273506/

“'Sun' E-Brochure." Air Canada Vacations. 2018 / 2019. Accessed November 2018. https://view.publitas.com/air-canada-vacations/ aircanadavacations_sun20I8/.

"Coastal Deposition." S-Cool. Accessed November 20I8. https:// www.s-cool.co.uk/a-level/geography/coastal-processes/revise-it/coastaldeposition.

"Country Reports." World Travel \& Tourism Council. March 20I8. Accessed October 20I8. https://www.wttc.org/economic-impact/ country-analysis/country-reports/.

"First Time at Club Med." Club Med. Accessed February 2019. https://www.clubmed.ca/l/first-time-at-club-med.

"Sandals Resorts: Fly Free \& Save?." Mouse Print. August 4, 2008. Accessed November 20I8. https://www.mouseprint.org/2008/08/04/ sandals-resorts-fly-free-save/ 
Fig. or: Multiple images. From left to right, top to bottom:

Sun e-brochure cover. Digital image. Air Canada Vacations. 2018/20I9. Accessed September 20I8. https://view.publitas.com/air-canadavacations/aircanadavacations_sun20I8/page/I.

Ultimate Escapes e-brochure cover. Digital image. Air Canada Vacations. 2018/2019. Accessed September 20I8. https://view.publitas.com/aircanada-vacations/ultimate-escapes/page/I.

Sun E Fun e-brochure cover. Digital image. Air Transat. 2018/2019. Accessed September 20I8. https://staticcontent.transat.com/Ebrochures/EN/ south-2018-2019/.

Weddings e-brochure cover. Digital image. Air Transat. 2018/2019. Accessed September 20I8. https://staticcontent.transat.com/Ebrochures/ EN/weddings-2019-2020/?_ga=2.I24310922.1635300037.I54621058II4I084949I.I54621058I.

'Great memories start here.' e-brochure cover. Digital image. West Jet Vacations. 20I8/20I9. Accessed September 20I8. https://www.westjet. com/en-ca/interactivebrochureredirect/index.

Wings e-brochure cover. Digital image. Sunwing. 2018/2019. Accessed September 2018. https://www.sunwing.ca/eblast/brochures/en/WingsFall-2018/index.html?page $=$ I.

Fig. 05: Beaches ${ }^{\odot}$ Resort in Providenciales, Turks and Caicos. Digital image. Air Canada Vacations "Sun" E-Brochure. 20I8/20I9. Accessed September 20I8. https://view.publitas.com/air-canada-vacations/ aircanadavacations_sun20I8/page/II2-II3.

Fig. o6: Sandals ${ }^{\oplus}$ Resort in Grenada. Digital image. Air Canada Vacations "Sun" E-Brochure. 2018/2019. Accessed September 20I8. https://view. publitas.com/air-canada-vacations/aircanadavacations_sun2OI8/ page/86-87.

Fig. 07-09, and 13-I4: Various promotional photographs. Air Canada Vacations "Sun" E-Brochure. 2018/2019. Accessed September 2018. https://view.publitas.com/air-canada-vacations/aircanadavacations_ sun20I8/page/I.

Fig. IO-I4: Multiple images. Clockwise from left:

Ogilby, John. Map of Barbados. I67I. New York Public Library, New York. https://digitalcollections.nypl.org/items/5IOd47eI-f5c9-a3d9-e040eooar8064a99

Shephard, Charles. Kingstown, St. Vincent (circa I8I5), plate I4 from the book An historical account of the island of St. Vincent, I831. As published in Grove, Richard. Green Imperialism: Colonial Expansion, Tropical Island Edens and the Origins of Environmentalism, I60o-I86o. Cambridge, UK: Cambridge University Press, 1995.

Rousseau, Henri. The Flamingoes. 1907. Private Collection. https://www. wikiart.org/en/henri-rousseau/the-flamingoes-1907

Blake, William. A Surinam Planter in His Morning Dress, plate Io from the book Narrative of a Five Year's Expedition against the Revolted Negroes of Surinam in Guina ... from the year I772 to I777 by J.G. Stedman, I793. Princeton University Art Museum, Princeton, New Jersey. https:// artmuseum.princeton.edu/collections/objects/3252 
Instituto Moreira Salles, designed by Brule Marx, 1970. As published in Stepan, Nancy. Picturing Tropical Nature. Ithaca, NY: Reaktion Books, 200I.

View of Las Vegas from the Desert. Plate 50, as published in Venturi, Robert, Denise Scott Brown, and Steven Izenour. Learning from Las Vegas: The Forgotten Symbolism of Architectural Form. Cambridge, MA: MIT Press, I99I.

Aerial View of Disneyland, 1960. https://www.yesterland.com/aerialı96o. html

Las Vegas Signs. As published in Venturi, Robert, Denise Scott Brown, and Steven Izenour. Learning from Las Vegas: The Forgotten Symbolism of Architectural Form. Cambridge, MA: MIT Press, I99I.

Aerial View of Las Vegas. Plate I8, as published in Venturi, Robert, Denise Scott Brown, and Steven Izenour. Learning from Las Vegas: The Forgotten Symbolism of Architectural Form. Cambridge, MA: MIT Press, I99I.

Flight over Holland Coast. Plate 7, as published in Le Corbusier. Aircraft: The New Vision. London, UK: Trefoil Publications, 1987.

Fig. 23: U.S. Geological Survey. LC80I804520I8I94LGNoo. 20I8-07-30 TI4:21:55Z .Landsat 8 Satellite Imagery, Earth Observing System Data and Information System. Accessed October 2018. https://earthdata. nasa.gov/.

Fig. 24: U.S. Geological Survey. LC80I504420I7026LGNoI. 2017-02-I8 To9:07:24Z. Landsat 8 Satellite Imagery, Earth Observing System Data and Information System. Accessed October 2018. https:/learthdata. nasa.gov/.

Fig. 25: U.S. Geological Survey. LC80090452016286LGNoI. 2017-03-I9 T23:I4:I7Z. Landsat 8 Satellite Imagery, Earth Observing System Data and Information System. Accessed October 2018. https://earthdata. nasa.gov/.

Fig. 49: Cancun Yucatan. Digital image. Club Med. Accessed March 2019. https://www.clubmed.ca/r/Cancun-Yucatan/y?_ab2=b\& 
Data

“I:Iom Cultural Vectors," “I:Iom Physical Vectors," "I:Iom Raster Data." Natural Earth, North American Cartographic Information Society. Accessed October 2018. https://www.naturalearthdata.com/.

"Airport, Airline and Route Data." OpenFlights. June 2014. Accessed October 2018. https://openflights.org/data.html.

"CCMP Wind Vector Analysis Product." Remote Sensing Systems. 20I5. Accessed October 20I8. http://www.remss.com/measurements/ $\mathrm{ccmp} /$.

"City of Toronto Building Outlines." Map and Data Library, University of Toronto Libraries. July 2I, 20I4. Accessed November 2018. https://mdl.library.utoronto.ca/collections/geospatial-data/city-torontobuilding-outlines.

"Global Multi-Resolution Topography Data Synthesis." GMRT, US National Science Foundation. February 20I8. Accessed October 2018. https://www.gmrt.org/.

"Greg's Cable Map." June 25, 2016. Accessed October 20I8. https:// www.cablemap.info/.

"Road Network Files." Government of Canada. 2015. Accessed November 20I8. https://open.canada.ca/data/en/dataset/8eo894098b6e-40a9-a837-5Ifcb2736b2c.

"USGS Geology of the Caribbean." Orr \& Associates. Accessed October 20I8. https://www.orrbodies.com/resource/usgs-geologycaribbean/. 